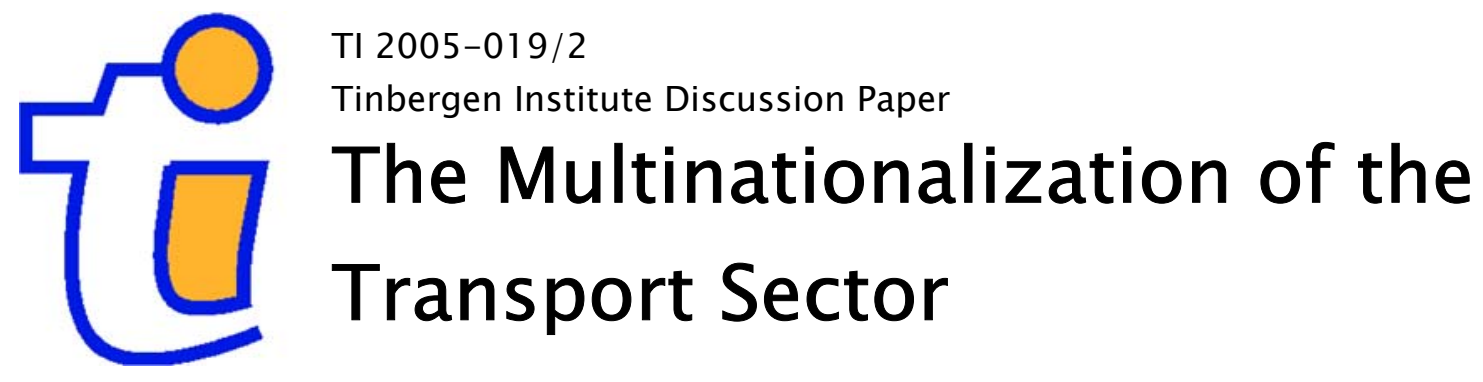

Mario Larch

University of Innsbruck, Austria. 
Tinbergen Institute

The Tinbergen Institute is the institute for economic research of the Erasmus Universiteit Rotterdam, Universiteit van Amsterdam, and Vrije Universiteit Amsterdam.

Tinbergen Institute Amsterdam

Roetersstraat 31

1018 WB Amsterdam

The Netherlands

Tel.: $\quad+31(0) 205513500$

Fax: $\quad+31(0) 205513555$

Tinbergen Institute Rotterdam

Burg. Oudlaan 50

3062 PA Amsterdam

The Netherlands

Tel.: $\quad+31(0) 104088900$

Fax: $\quad+31(0) 104089031$

Please send questions and/or remarks of nonscientific nature to driessen@tinbergen.nl.

Most TI discussion papers can be downloaded at http://www.tinbergen.nl. 


\title{
The Multinationalization of the Transport Sector
}

\author{
Mario Larch*
}

December 1, 2004

\begin{abstract}
According to the World Investment Report 2004, the structure of FDI has shifted towards services. Further, the composition of services FDI is also changing from trade and finance to such industries as electricity, water, telecommunications, storage and transportation. In the latter sector the value of FDI stock rose 16-fold between 1990 and 2002. Incorporating a transport sector dominated by multinationals and economies of scale in a model of the new trade theory leads to different predictions regarding the volume of trade and income as compared to a model with iceberg transport costs. It also opens up a further possibility for specialization.
\end{abstract}

JEL classification: F12; F23

Keywords: Multinationals; Transport sector; Iceberg transport costs; Economies of Scale

*Department of Economics and Statistics, University of Innsbruck, Universitätsstraße 15, A-6020 Innsbruck, Austria. Phone: +43-512-507-7377; Fax: +43-512-507-2980; E-mail: Mario.Larch@uibk.ac.at 


\section{Introduction ${ }^{1}$}

In the top 50 non-financial TNCs from developing economies ranked by foreign assets, three TNCs operate in the transport and storage sector ${ }^{2}$ and even 5 out of the 25 top non-financial TNCs from Central and Eastern Europe are in the transportation industry ${ }^{3}$. The Canadian National Railway Company made it in the top 100 non-financial TNCs in the year 2002 (ranked by foreign assets), and one of the newcomers engaging in transport and storage in the year 2000 is the Deutsche Post (see the World Investment Reports, UNCTAD, 2002, 2004).

Comparing inward (outward) FDI stocks from 1990 and 2002, we find a sharp increase of the transport, storage and communications sector as share of all services from around $3 \%(5 \%)$ to $11 \%(10,5 \%)$, and from around $1 \%(2 \%)$ to $6.5 \%(7 \%)$ as share of total inward (outward) FDI stocks. The largest increase took place in the developed countries (around $8 \%$ increase in the share), whereas it was modest in the developing countries (around 2\% increase in the share). In the Central and Eastern European countries the transport sector is especially important, where it accounts for $24 \%(18,5 \%)$ of the inward (outward) FDI stocks in services and $13 \%$ of total inward and outward FDI stocks. Over this period the value of inward (outward) FDI stock rose 16-fold (13-fold). These facts suggests that multinational activities in the transport sector play a crucial role and become more and more important. ${ }^{4}$

Transport costs are important in models of the new trade theory. On the one hand, there are economies of scale, leading to concentration of production at a single location, and on the other hand there are transport costs, encouraging firms to locate near their customers. However, the introduction of transport costs into models of international trade was long avoided, because factor price equalization only emerges for countries with similar relative factor endowment and size and the balance-of-payments condition becomes non-linear, making it hard to solve general equilibrium models with increasing returns to scale $(I R S)$ analytically.

Early attempts to introduce transport costs in trade models are for example Samuelson $(1952,1954)$. He formalizes the idea that a fraction of the good shipped melts away in transport and therefore only part of the goods (the "unmelted" one) reaches the destination. Mundell (1957) relaxes the assumption that only the good shipped hast to melt and the exporter necessarily has to take care of the transport services.

\footnotetext{
${ }^{1}$ I am grateful to Hartmut Egger, Peter Egger, Jörn Kleinert, Michael Pfaffermayr and participants at the $6^{\text {th }}$ Göttinger Workshop, the $6^{\text {th }}$ Annual Conference of the European Trade Study Group in Nottingham and the research seminar in Innsbruck for helpful comments. Financial support from the Austrian Fonds zur Foerderung der wissenschaftlichen Forschung (FWF, grant no. P17028-G05) is gratefully acknowledged. For comments and for the provision with data I want to thank Joe Francois.

${ }^{2}$ Namely Neptun Orient Lines (Singapur), Orient Overseas International (Hong-Kong), and Singapur Airlines (Singapur).

${ }^{3}$ These are Novoship Co. (Russian Federation), Primorsk Shipping Corporation (Russion Federation), Far Eastern Shipping Co. (Russian Federation), Malév Hungarian Airlines (Hungary) and Croatia Airlines (Croatia).

${ }^{4}$ The driving force behind the increase in FDI stock have been cross-border M\&As. Especially the M\&A activities in the capital-intensive telecoms, as for example the deal that took place in 2000 when Vodafone acquired Mannesmann AG, account for the increasing importance of the transport, storage and telecommunications sector. For more details see the World Investment Report 2004, which focuses on FDI in the services sector.
} 
Rather he allows that some other good melts too, which even can be provided from the importer. Later contributions model the transport sector more explicitly. Falvey for example showed that factor intensity differences between goods production and transport services determine who produces the transport service using a HeckscherOhlin-framework with three goods, where one is the transport service. Bottazzi and Ottaviano (1996) provide a good overview of different attempts to introduce transport costs in international trade ${ }^{5}$ and present a general model which embeds various of these earlier contributions as special cases.

All these models rely on the assumption of perfect competition in both the goods market and the transport sector. To keep matters as simple as possible, most models with imperfect competition in the goods market incorporate iceberg transport costs (see, for example, Helpman and Krugman, 1985). However, there are a few models that introduce imperfect competition in the transport sector.

Casas and Choi (1990) introduce a transport sector with variable returns to scale into a model of one small country with two traded goods, both produced under constant returns to scale. Their main result is that immiserizing growth can arise in the presence of decreasing returns to scale in the transport sector if increased efficiency in transportation exerts a trade-expanding effect and, in the presence of increasing returns to scale, if increased efficiency in transportation has a trade-contracting effect.

Francois and Wooton (2001) maintain the assumption of perfect competition in the goods market, but highlight the importance of imperfect competition in the shipping industry. They conclude that trade liberalization in the absence of any form of deregulation of the shipping sector will not result in the increased benefits that would otherwise be expected.

Mansori (2003) introduces iceberg transport costs in a new economic geography model, which are subject to increasing returns to scale, assuming that in each period a fixed cost must be incurred before the transport of goods between two regions can take place. He then shows that increasing returns to scale reinforce the tendency towards a dispersed equilibrium but that trade liberalization may cause a country to move from the dispersed equilibrium to an equilibrium where firms are more concentrated in one region. To the best of our knowledge this is the first attempt to introduce imperfect competition in both the goods market and the transport sector.

Similar to Mansori (2003), we assume imperfect competition in the goods market as well as in the transport sector. But our framework introduces a separate transport sector dominated by horizontal multinationals (MNEs), i.e. firms running plants in both countries and not engaging in trade, in order to account for the tendency of multinationalization. This implies that we assume fixed costs to be important in the transport sector, which is well in line with the various statements in the literature ${ }^{6}$

\footnotetext{
${ }^{5}$ Like the ones from Mundell (1957), Herberg (1970), Falvey (1976), Cassing (1978), Casas (1981, 1983), Casas and Choi (1985), Inoue (1985) and Rousslang (1991).

${ }^{6}$ Neary (2001) and van Schijndel and Dinwoodie (2000) for example argue that the transport industry seems to be characterized by very high ratios of fixed to variable costs. Similar arguments can be found in various reports from the OECD, as in Railways: Structure, Regulation and Competition Policy, 1998, DAFFE/CLP(98)1, http://www.oecd.org/; Cost Savings Stemming from Non-Compliance with International Environmental Regulations in the Maritime Sector, 2002, DSTI/DOT/MTC(2002)8/FINAL, http://www.oecd.org/; Regulatory Issues in International Martime Transport, 2001, http://www.oecd.org/.
} 
and empirical findings ${ }^{7}$. Furthermore we explicitly account for the fact that a larger network of firms providing transport services leads to lower prices for the customer (see Janelle and Beuthe, 1997).

Introducing horizontal MNEs in the transport sector no longer relies on iceberg transport costs, which forms a simplifying assumption, but does not come without costs.

First, one of the implicit assumptions of iceberg transport costs is that the transport service is produced with the same factor intensities as the good shipped. This seems at odds with empirical facts. In Table 1 we show the division between factor incomes of unskilled labor, skilled labor and capital, neglecting natural resources and land since we do not incorporate these factors into our model. ${ }^{8}$ Looking at these facts, it is obvious that for example the rice \& grains sector, the crops sector as well as the meat sector are much more unskilled labor intensive and use fewer skilled labor than the transport sector. The foods sector and the natural resources sector are much more capital intensive, whereas auto \& machinery as well as the other manufacturing, i.e. the high-tech industry sectors, are more skilled labor intensive than the transport services sector.

\section{- Table 1 -}

The second shortcut of iceberg costs stems from the fact that in a model with more than one good, transport services are different for every good as they are always a part of the good shipped. Normally, one would think of transport services to be more or less independent of the goods shipped. Let's take trucks for example. With the same truck one can ship such different goods as diamonds, cars and wood. Further, the early attempts treated the transport service as an additional good, neglecting the difference between the demand for transport services and that for traded goods. In order to account for this difference it is necessary to introduce a transport sector, where customers are forced to demand the service when they want to transport goods, but "consumption" of transport services as such does not lead to utility gains.

Third, iceberg costs implicitly assume that the transport service and the good shipped are produced by the same firm. This assumption has strong implications if we have firms producing under economies of scale stemming from fixed costs. In this case, iceberg transport costs imply joint production of the transport service and the good shipped. This means that higher transport costs may reduce exports, but as long as the additional transport service compensates for it, this does not harm domestic goods producers. Furthermore, iceberg transport costs implicitly assume that the market structure and conduct for both, the transport sector and the goods sector, are the same. The transport service is provided by the exporter, i.e., if a consumer wants to import a good, she has no choice from whom she wants to buy

\footnotetext{
${ }^{7}$ Hummels (1999) finds that the transportation technology for a particular vessel is almost affine in distance. However, fixed costs vary with the size of the vessels.

${ }^{8}$ The GTAP database version 6 provides data about sources of factor income divided into unskilled labor, skilled labor, capital, land and natural resources for 86 regions and 57 sectors corresponding to the global economy in 2001. For a detailed description of the database see http://www.gtap.agecon.purdue.edu/. We aggregate over these 86 regions and build 13 sectors, where the transport sector is the most disaggregated one.
} 
the transport service, rather she has to buy the good and the transport service as a 'bundle' from the exporter. Therefore, iceberg transport costs are not able to handle the importance of a transport network for customers.

In order to study the effects of relaxing several of the strong assumptions of iceberg type transport costs, we introduce a transport sector dominated by horizontal MNEs in a model with two countries and two sectors, one homogeneous and one differentiated goods sector. This approach differs from existing ones in several directions: (i) There is imperfect competition in the goods market and in the transport sector. (ii) Transport services are the same for both goods. (iii) Production of the good shipped and the transport service is disentangled, i.e. there is no joint production of goods and transport services. (iv) The factor intensities in the transport sector and in the goods sector can differ.

The model is outlined in Section II. Section III studies the effects of introducing a multinationalized transport sector for the the volume of trade. The effects on income will be discussed in Section IV, whereas Section V focuses on the possible specialization patterns of countries, which face the addition possibility to export transport sector headquarter services. The last section concludes.

\section{The Transport Sector Model}

\section{(i) Households and the Transport Sector}

There are two economies, referred to as countries 1 and 2 and indexed as $\{i, j\}=$ $\{1,2\}$. Both countries produce two goods, $Z$ and $X$. $Z$ is a homogeneous good produced at constant returns to scale $(C R S)$ by a competitive industry. $X$-goods are differentiated in the usual Dixit and Stiglitz (1977) fashion. In the $X$ goods sector national firms (NEs) sell on the local market and export to the other country, where the number of national firms of country $i$ is denoted by $n_{i} . X_{i j}$ denote the exports of country $i$-based NEs to country $j$. $Z_{i i}$ refers to the quantity of homogeneous goods produced and consumed in $i$, and $Z_{j i}$ indicates the import quantity from $j$ of the homogeneous good consumed in $i . X_{i c}$ denotes the consumption of $X$ in country $i$, being a CES aggregate of the individual varieties. Consumer preferences are assumed to be a nest of the homogeneous $Z$-good and the differentiated $X$-good. The symmetry of varieties within a group of goods allows to formulate utility of country $i\left(U_{i}\right)$ as follows:

$$
\begin{aligned}
U_{i} & =X_{i c}^{\alpha}\left(Z_{i i}+Z_{j i}\right)^{1-\alpha} \\
X_{i c} & \equiv\left[n_{i}\left(X_{i i}\right)^{\frac{\sigma-1}{\sigma}}+n_{j}\left(X_{j i}\right)^{\frac{\sigma-1}{\sigma}}\right]^{\frac{\sigma}{\sigma-1}},
\end{aligned}
$$

where $\alpha$ denotes the Cobb-Douglas expenditure share for differentiated products ${ }^{9}$, and $\sigma>1$ is the elasticity of substitution between varieties.

\footnotetext{
${ }^{9}$ According to the United Nation's World Trade Database, the share of manufacturing trade in the 1990 s amounts to $70 \%-80 \%$ of total trade. Therefore, we assume an expenditure share for manufactures of $\alpha=0.8$.
} 
Consumers are forced to demand transport services in a fixed proportion to every unit imported. We denote the necessary amount of transport services for the import of one unit of good $X(Z)$ as $\tau_{x}\left(\tau_{z}\right)$. We choose this formulation because it allows a direct comparison with the results of the "standard" model with iceberg transport costs (see for the "standard" model Helpman and Krugman, 1985). The $\tau$ in our model can directly be translated as the share of goods that melt away in transport in the "standard" new trade theory models with iceberg transport costs. Let then $s_{t i}$ denote the price aggregator of the transport services, where we assume that the various transport services are combined to the whole "transport bundle" according to a CES-technology. The CES-technology seems reasonable since one firm alone would not be able to serve all markets. The larger the network of firms providing transport services, the better the customer will be served (see Janelle and Beuthe, 1997).

The technical rate of substitution in the transport sector $\left(\sigma_{t}\right)$ is a measure for the degree of network reliance in the transport sector. The lower this substitution parameter, the higher is the dependency on a rich network structure in order to ensure low overall trading costs. Think of firms trading overseas which use different types of transport modes (e.g. ships, plains, trucks, trains) and services (e.g. transshipment opportunities, services of forwarding agents and insurance companies) that can not easily be provided by another firm for the same costs because of technical reasons (as it is the case for different modes) or because of special knowledge (think of special country knowledge of a forwarding agent or special expertise in insuring specific types of risks of an insurance company).

In accordance with the stylized facts mentioned in the introduction, namely the ongoing multinationalization and the importance of fixed costs, transport firms are assumed to be horizontal MNEs. Let $m_{t i}\left(m_{t j}\right)$ denote the numbers of MNEs in the transport sector with headquarters in $i(j)$, and $p_{t i}$ is the price of the transport service. The price index of the transport service bundle in country $i\left(s_{t i}\right)$ is then given by:

$s_{t i}=\left(m_{t i}+m_{t j}\right)^{\frac{1}{1-\sigma_{t}}} p_{t i}$,

The consumer maximization problem can be solved in two steps. In the first step, each variety $X_{i j}$ needs to be chosen so as to minimize the cost of attaining $X_{i c}$, whatever the consumption of $X_{i c}$ is. In the second step, consumers allocate income between the $Z$-good and the composite $X$-good. Let $p_{j i}$ be the price of an $X$ variety in country $i$ produced from a firm in country $j$. The price for the homogeneous good, $q_{i}$, is indexed once, since all (indigenous and foreign) homogeneous goods consumed at a single location $i$ must face the same price $q_{i}$. Further, $s_{i}$ denotes the price aggregator, defined as the minimum cost of buying one unit of $X_{i c}$ at prices $p_{j i}$ of an individual variety:

$s_{i}=\min _{X_{j i}} \sum_{i, j} p_{j i} X_{j i} \quad$ s.t. $\quad X_{i c}=1$.

The first-stage budgeting problem leads to:

$$
X_{j i}=\left(p_{j i}\right)^{-\sigma} s_{i}^{\sigma-1} \alpha E_{i} \quad \forall \quad i, j \in\{1,2\} \quad,
$$


where $E_{i}$ denotes total expenditures of consumers in country $i$. Identical price elasticities of demand and identical marginal costs (technologies) within a country ensure that the domestic price of a locally produced good is equal to the mill price for exports. Hence, prices of all goods produced in one country $(i)$ are equal in equilibrium, so that we can omit the first subscript. Inserting these equilibrium conditions the price aggregator $s_{i}$ of differentiated goods consumed in country $i$ can be written as

$s_{i}=\left[n_{i} p_{i}^{1-\sigma}+n_{j}\left(p_{j}+s_{t j} \tau_{x}\right)^{1-\sigma}\right]^{\frac{1}{1-\sigma}}$.

The second-stage budgeting yields the division of expenditures between the two sectors:

$$
\begin{aligned}
X_{i c} & =\frac{\alpha E_{i}}{s_{i}}, \\
Z_{i i}+Z_{j i} & =\frac{1-\alpha}{q_{i}} E_{i},
\end{aligned}
$$

and we take $q_{1}$ as the numéraire.

The demand function for the transport services needed is given by:

$t_{i}=p_{t i}^{-\sigma_{t}} s_{t i}^{\sigma_{t}}\left(X_{i j} n_{i} \tau_{x}+Z_{i j} \tau_{z}\right)$

where $t_{i}$ denotes the service of transport from $i$ to $j$ provided by one transport firm. This assumption implies that the exporter takes care of the transport services. This is in line with the implicit assumption of iceberg transport costs. However, if we assume that the importing country has to bear the transport costs, the qualitative results in this paper would not change. The reason is that we assumed high fixed costs in the transport sector and that variable costs of production in the transport sector are small compared to these fixed costs. Hence, the location decision of MNEs does not change. ${ }^{10}$

Note that the introduction of horizontal MNEs in the transport sectors has the advantage that the problem of one-way transport service is mitigated. Horizontal MNEs provide their services in both countries, avoiding the problem of empty runs.

The expression in brackets on the right-hand side $\left(X_{i j} n_{i} \tau_{x}+Z_{i j} \tau_{z}\right)$ of equation (8) gives the total demand for transport services from $i$ to $j$. Since the specific trade services are combined to the whole service bundle according to a CES-technology, the total demand for transport service has to equal the composite of transport services given by the quantity index $\left(m_{t i}+m_{t j}\right)^{\frac{\sigma_{t}}{\sigma_{t}-1}} t_{i}$.

\footnotetext{
${ }^{10}$ In order to save space, figures for various scenarios are not reported in the paper but are available upon request from the author. More specifically, we produced figures showing the location of headquarters for alternative assumptions about the factor intensities in the $X$-sector, graphs for different assumptions about who takes care of transport services, as well as plots for countries that differ in size and/or relative factor endowments.
} 


\section{(ii) Factor Markets, Production and Income}

Let $w_{K i}, w_{L i}$ and $w_{S i}$ denote the factor rewards for capital, unskilled labor and skilled labor, respectively. Assuming that $Z$-production only uses unskilled labor $(L)$, variable unit costs (i.e., marginal costs) $c_{Z i}$ satisfy

$c_{Z i} \geq w_{L i} \quad \perp \quad Z_{i i} \geq 0$

where $\perp$ indicates that at least one of the adjacent conditions has to hold with equality.

For imported $Z$-goods we therefore have:

$c_{z i}+s_{t j} \tau_{z} \geq q_{j} \quad \perp \quad Z_{i j} \geq 0$.

There is monopolistic competition in the $X$-sector, where each firm produces under a Leontief technology, using capital as well as unskilled and skilled labor. The unit input coefficients of capital, unskilled and skilled labor are denoted by $a_{K x}, a_{L x}$ and $a_{S x}$, respectively. If nothing else is mentioned, we set $a_{K x}=0.3, a_{L x}=0.6$ and $a_{S x}=0.1$. For the production of the transport service we initially assume the same coefficients as in the $X$-sector in order to ensure the maximum comparability with the iceberg transport cost assumption, i.e. $a_{K t}=0.3, a_{L t}=0.6$ and $a_{S t}=0.1$. Additionally, national firms in the $X$ sector and MNEs in the transport sector require capital to set-up plants ( $a_{K n}$ and $a_{K m t}$, respectively), and they employ skilled labor to produce firm-specific assets and blue-prints $\left(a_{S n}\right.$ and $a_{S m t}$, respectively). ${ }^{11}$

Factor market clearing implies:

$$
\begin{array}{rlll}
L_{i} & \geq Z_{i i}+Z_{i j}+a_{L x} n_{i}\left(X_{i i}+X_{i j}\right)+a_{L t}\left(m_{t i}+m_{t j}\right) t_{i} & \perp w_{L i} \geq 0,(11 \\
K_{i} & \geq a_{K x} n_{i}\left(X_{i i}+X_{i j}\right)+a_{K t}\left(m_{t i}+m_{t j}\right) t_{i}+a_{K n} n_{i}+a_{K m t} m_{t i} & \perp w_{K i} \geq 0,(12 \\
S_{i} & \geq a_{S x} n_{i}\left(X_{i i}+X_{i j}\right)+a_{S t}\left(m_{t i}+m_{t j}\right) t_{i}+a_{S n} n_{i}+a_{S m t} m_{t i} & \perp & w_{S i} \geq 0 .(13)
\end{array}
$$

Variable unit costs of $X$-production in $i$ are $c_{X i}=a_{K x} w_{K i}+a_{L x} w_{L i}+a_{S x} w_{S i}$. Fixed markup pricing in the $X$-sector yields:

$$
p_{i} \leq c_{X i} \frac{\sigma}{\sigma-1} \quad \perp \quad X_{i i} \geq 0 .
$$

Transport service production implies variable unit costs of $c_{t i}=a_{K t} w_{K i}+a_{L t} w_{L i}+$ $a_{S t} w_{S i}$, and quite similar as in the $X$-sector, fixed markup pricing leads to:

$$
p_{t i} \leq c_{t i} \frac{\sigma_{t}}{\sigma_{t}-1} \quad \perp \quad t_{i} \geq 0 .
$$

We assume free entry and exit of firms in both, the $X$-sector and the transport sector, implying that operating profits are used to cover fixed costs. The corresponding

\footnotetext{
${ }^{11} \mathrm{We}$ set $a_{K n}=a_{K m t}=a_{S n}=a_{S m t}=1$.
} 
zero-profit conditions determine the numbers of firms. For the $X$-sector this gives:

$a_{K n} w_{K i}+a_{S n} w_{S i} \geq \frac{p_{i}\left(X_{i i}+X_{i j}\right)}{\sigma} \quad \perp \quad n_{i} \geq 0$

where the left-hand side represents the fixed costs and the right-hand side denotes the mark-up profits.

Similar, the number of firms in the transport sector is given by:

$a_{K m t} w_{K i}+a_{S m t} w_{S i} \geq \frac{p_{t i} t_{i}+p_{t j} t_{j}}{\sigma_{t}} \quad \perp \quad m_{t i} \geq 0$,

since we have assumed horizontal MNEs in the transport sector producing in both countries.

All factors are owned by the households, so that consumer income (i.e., GNP) in country $i$ is given by

$E_{i}=w_{K i} K_{i}+w_{L i} L_{i}+w_{S i} S_{i}$

The equivalence of total factor income $\left(E_{i}, E_{j}\right)$ and demand in each economy implicitly balances international payments.

\section{Effects on the Volume of Trade}

First, we want to investigate the effects of introducing a multinationalized transport sector on the volume of trade when the countries are identical. ${ }^{12}$

We focus on the volume of trade (VT), as defined in Helpman and Krugman (1985), as a percentage of GDP:

$V T=\frac{n_{i} p_{i} X_{i j}+Z_{i j} q_{j}^{n}+n_{j} p_{j} X_{j i}+Z_{j i} q_{i}^{n}}{E_{i}+E_{j}} \times 100$,

where $q_{j}^{n}\left(q_{i}^{n}\right)$ is the net-of-transport-costs price for $Z$ goods exported from $i(j)$ to $j(i)$, which is given by $q_{j}^{n}=\frac{q_{j}}{1+\tau_{z}}$ in the case of iceberg transport costs, and as $q_{j}^{n}=q_{j}-s_{t i} \tau_{z}$ in the model with the transport sector, and similar for $q_{i}^{n}$.

As expected, the volume of trade declines with rising transport costs (see Figure $1)^{13}$. Two things are worth noting. First, for low levels of trade costs the iceberg type model suggests a lower trade volume than the transport sector model, but for higher levels this prediction changes. The reason is that firms in the transport sector have to bear high fixed costs. If trade costs are low, only few firms can survive. This leads to a higher price for the transport service bundle, lowering the volume of trade. Rising trade costs lead to a higher demand for transport services, allowing more firms to enter in the transport, storage and telecommunications sector. Due to complementarities through the network, this lowers the price for the whole trans-

\footnotetext{
${ }^{12}$ Note that this assumption rules out trade in the homogeneous goods sector.

${ }^{13}$ Derivations for this section are relegated to the Appendix 1.
} 
port service bundle. Actually, there is an inverted U-shaped relationship between the number of MNEs in the transport sector and trade costs and an U-shaped relationship between the costs for the transport bundle and trade costs. On the one hand higher trade costs lead to a higher demand for transport services for a given volume of trade. On the other hand higher trade costs discourage trade, leading to fewer transportation. Second, in the iceberg transport costs model, exports shrink with higher transport costs but are never exactly zero. This is not the case if we model the transport sector explicitly (see the case with $\sigma=6$ in Figure 1).

\section{- Figure 1 -}

One important aspect concerning the volume of trade is the underlying dependence on the network structure in the transport sector. Van Schijndel and Dinwoodie (2000) argue that higher congestion should lead transport companies to switch to multimodal transport. However, they point out that a competitive multimodal service will demand more co-operation between transport companies, involving large investments depending on dense goods-flows capable of generating sufficient scale economies to cover their capital costs.

As this evidence suggests, rising congestion costs could lead to a strong dependence on different providers and induce more trade. Our model predicts a greater volume of trade with a higher network dependence, i.e., a lower value of $\sigma_{t}$, if the number of MNEs is above a critical value. The reason is that the strong demand for different transport services leads to more firms in the transport sector producing at a lower scale. On the one hand this raises the price of the service supplied by one firm $\left(p_{t i}\right)$, but on the other hand it lowers the price of the whole transport service bundle $\left(s_{t i}\right)$. This seems to be a reasonable prediction and is well in line with the findings of van Schijndel and Dinwoodie (2000). Longer trading distances induce the need for more complex transport service networks as usually more different transport services and modes have to be used in order to bring the good to its final destination ${ }^{14}$. To cover the additional fixed costs of such a network, the volume of trade has to rise.

As shown in Table 1 and discussed in the introduction, factor intensities vary quite a lot between different industries. With a transport sector, different factor intensity assumptions lead to different volumes of trade (see Figures 2 and 3). ${ }^{15}$ The volume of trade is highest if $X$-goods production needs only skilled labor. ${ }^{16}$ In this case additional transport service demand rises factor prices of capital and unskilled labor, leading to more income which partly is spent on foreign variants. Overall we can conclude that the volume of trade is typically higher when factor intensities are different in the transport sector and in the differentiated goods sector, due to possibility of a more flexible allocation of resources. Put differently, if $p_{t i}$ falls relative to $p_{i}$, which is likely when the sectors use different resources, then the volume of trade will rise.

\footnotetext{
${ }^{14}$ See also Janelle and Beuthe (1997).

${ }^{15}$ We have chosen the following values: Transport sector: $a_{L t}=0.45, a_{K t}=0.4, a_{S t}=0.15$; Agricultures: $a_{L x}=0.6, a_{K x}=0.35, a_{S x}=0.05$; Natural Resources: $a_{L x}=0.3, a_{K x}=0.6$, $a_{S x}=0.1$; High-tech industry: $a_{L x}=0.4, a_{K x}=0.25, a_{S x}=0.35$.

${ }^{16}$ The labels in the figures have to be interpreted in the following way: In the case of "Capital only" $X$-goods production only needs capital. Similar "Skilled labor only" ("Unskilled labor only") indicates that $X$-goods production only requires skilled (unskilled) labor.
} 
With iceberg transport costs the volume of trade as percentage of GDP for completely symmetric countries does not depend on income or factor intensities in production at all. Furthermore, the first derivative with respect to $\sigma$ indicates, that a higher substitutability between variants leads to a lower volume of trade, which is also true if a transport sector is present. In both models the derivative with respect to $\alpha$ is positive, which is due to the increased importance of the differentiated sector leading to more intra-industry trade. However, as was demonstrated above, the level between the transport sector model and the iceberg transport costs model differs. The assumption of iceberg transport costs leads to an underestimation (overestimation) of the volume of trade for low (high) transport costs as compared to a transport sector dominated by multinationals. ${ }^{17}$

\section{Effects on Income}

Samuelson's iceberg transport costs generate income in the country where the good to be shipped is produced. The income is distributed according to the factor intensities in the production of the shipped goods. Introducing a transport sector relaxes the assumption of where the income has to be earned and breaks up the tie of the same factor income distribution as in goods production.

Let us take the first step and change the elasticity of substitution for variants, but stick to the assumption of symmetric countries. In Figure 4 the percentage changes in GDP are calculated relative to the GDP-level when there are no transport costs. The transport sector model with increasing returns to scale suggests that for higher values of $\sigma$ income raises, whereas it falls for lower values. If $\sigma$ is equal to the technical rate of substitution in the transport sector, income does not vary with changes in the amount of transport services needed. ${ }^{18}$ The reason for this result lies in the resources needed to provide the goods. If the reliance on a tight transport network weights more than the love for varieties ${ }^{19}$, more and more factors (mainly capital) are needed to set up transport firms as trade costs rise. This leads to higher factor price of capital and, therefor, to a higher income. In the opposite case, i.e. $\sigma_{t}>\sigma$, higher transport costs imply that less $X$-goods producing firms are able to survive because resources are needed to provide the transport services. But as the transport sector is more competitive, less firms are able to finance their fixed costs, which leads to a lower demand for resources needed to set-up firms.

With the same line of reasoning Figure 5 can be understood. A higher reliance on different transport firms leads to more firms engaging in transport, storage and telecommunication as demand for this services rises. This leads to a higher income, because the capital price, mainly needed to set-up firms, rises. The opposite holds true for higher values of $\sigma_{t}$.

We also plotted the results for a model where the transport sector is characterized by

\footnotetext{
${ }^{17}$ For reasons of comparison we will present results for the case where there is perfect competition in the transport sector in the Appendix 3.

${ }^{18}$ To put it more technically, we can say that our results below are not driven from the doublenested "CES" structure.

${ }^{19} \sigma_{t}<\sigma$. Note that in Figure $4 \sigma_{t}=4$.
} 
CRS. In this case higher trade costs unambiguously lead to a lower income because there is no gain from variety so that lowering transport costs releases resources which can be reallocated and used somewhere else more efficiently. Specifically, capital and skilled labor can be used to set-up new differentiated goods producing firms, leading to higher factor prices and, hence, to a higher GDP.

- Figures 4 and 5-

Figure 6 shows the effect of different factor intensities in the transport sector and in the differentiated goods sector. As can be seen, whether GDP rises or falls strongly depends on the factor intensities in the differentiated goods industry. If the $X$-sector is very unskilled labor intensive, capital and skilled labor is mainly needed in the transport sector and to set up plants. A rise in transport costs can therefore lead to a rise in GDP by rising factor rewards of skilled labor and capital. On the other hand, if the differentiated sector is capital and/or skilled labor intensive, transport costs are relatively more unskilled labor intensive. Higher transport costs increase the factor demand for unskilled labor but lower factor demand of skilled labor and capital. This leads to lower factor rewards of the latter two, and consequently, to a lower GDP. Calculating real GDP (defined as $E_{i} s_{i}^{-\alpha} q_{i}^{1-\alpha}$ ), we find that rising transport costs always lower real GDP, irrespective of factor intensities.

In the model with iceberg transport costs income does not change as transport costs rise (see Appendix 2). The reason is that higher transport costs lead to higher domestic consumption. But this does not change the factors needed to produce the goods. Therefore, factor demands and, hence, factor rewards remain unchanged. The same holds true with a transport sector, as long as factor intensities in the transport sector and the differentiated goods sector as well as $\sigma$ and $\sigma_{t}$ are equal. In the case of different factor intensities, income does vary with transport costs as was demonstrated above.

So far we focussed on equally endowed countries. The income invariance in the iceberg transport costs model holds as long as the homogeneous good is not traded. If there is homogeneous goods trade, income in the country that exports the $Z$-good raises whereas it falls for the net-exporter of differentiated goods. This result is driven by the fact that higher trade barriers lead to less trade and, therefore, the homogeneous goods exporter partly shifts resources form $Z$-goods to $X$-goods production, thereby raising the factor price of capital and skilled labor (remember that we assumed a fixed coefficient technology) and increasing GDP. This reallocation effect is also present in the case of a separate transport sector and can for example outweigh the reallocation effects described above for changes in $\sigma$ and $\sigma_{t}$.

\section{Effects on Specialization Patterns}

In new trade theory models with two countries and two sectors, every country has two possibilities for specialization: On the one hand it can focus on producing homogeneous goods, and on the other hand a concentration in the differentiated 
sector is possible. Considering a multinationalized transport sector opens up a third possibility: to specialize in running MNEs in the transport sector. We therefore will now investigate, which country will specialize in transport services and whether predictions concerning the specialization pattern of goods production do change or not by explicitly considering a transport sector.

We have three factors of production and, therefore, present only slices through the factor cube. One slice is the capital to unskilled labor endowment box when skilled labor is divided equally between countries and another slice shows the capital to skilled labor endowment box when unskilled labor is symmetrically distributed. ${ }^{20}$

\section{- Figures 7 and 8 -}

Transport services concentrate in the relatively skilled labor and/or capital abundant country. The reason is that headquarter services and setting up plants are capital and skilled labor intensive activities. If capital or skilled labor is scarce, the country specializes in $Z$-sector production and to some extend in $X$-sector production, but does not run horizontal MNEs in the transport sector.

If we assume that the $X$-sector is the natural resources sector, than transport sector MNEs mainly concentrate in the skilled labor to capital abundant country, since the natural resources sector is very capital intensive. Still, an unskilled labor abundant country will not run MNEs in the transport sector. Taking the $X$-sector to be the skill-intensive high-tech industry, we find a concentration of transport service MNEs in the skilled labor to capital scarce country, as the skilled labor abundant country has a comparative advantage in high-tech $X$-goods production.

To sum up, different endowments and factor intensity assumptions exert important effects for the distribution of the MNEs in the transport sector between countries. According to our model, transport MNEs are mainly headquartered in the skilled labor abundant countries and unlikely in an unskilled labor abundant one. This fits nicely with the empirical facts. According to the World Investment Report (UNCTAD, 2004), across the developing countries mainly Hong Kong and Singapore headquarter MNEs in the transport sector. Sorting countries by their relative skilled labor endowment using information from the GTAP database, we find that Hong Kong and Singapore are on the top of the developing countries. Similarly, the United Kingdom, the United States, Germany, Spain, France, Italy, Singapor and Canada, countries which are on the list of the top 100 MNEs ranked by foreign assets engaging in transport, storage and telecommunications, are all in the first third according to skilled worker endowments. ${ }^{21}$ On the other hand, very unskilled labor intensive countries like Uganda, China and Tanzania do not host (large) transport MNEs according to the World Investment Report.

The distribution of sectors between countries has been widely discussed in the literature. A main theoretical finding is that in a world with transport costs and two sectors, one homogeneous goods sector and one increasing returns to scale sector, a country with higher demand has a proportionally larger share of production in

\footnotetext{
${ }^{20}$ Factor intensities are as in the base case, i.e. $a_{L x}=a_{L t}=0.6, a_{K x}=a_{K t}=0.3$, and $a_{S x}=a_{S t}=0.1 . \tau_{x}=\tau_{z}=0.5 . \sigma=\sigma_{t}=4$.

${ }^{21}$ Italy, the least skilled labor abundant country out of the mentioned according to the GTAP database, is at place 27 out of 86 . The first two are even in the top 10 .
} 
the increasing returns to scale sector. This phenomenon is called the home-marketeffect (HME). Accordingly, the larger region becomes more and more industrialized whereas smaller regions continue to produce primary products. However, Davis (1998) introduced transport costs in the homogeneous sector and proved that with equal transport costs in both sectors, the homogeneous good will not be traded and therefore production of the differentiated sector is in proportion to country size.

Does the possibility to specialize in transport services change the prediction regarding the home market effect? When comparing the outcome concerning the HME of the model with iceberg transport costs and the transport sector model, we have to make one important decision: Should we add the transport service or not? So far, in the literature, the HME was calculated as the production of the $X$-good in one country. As one part of the good shipped melts away, but has to be produced, iceberg transport costs are included in the computation of the HME. If one is interested in the specialization pattern of countries, this seems not to be the natural way. One would only include the $X$-sector output and not the transport service. In Figure 9 we compare both, the HME when transport costs are included, and the HME if the transport costs are excluded. The latter is computed as follows:

$H M E=\frac{\frac{n_{i}\left(X_{i i}+X_{i j}\right)}{n_{j}\left(X_{j j}+X_{j i}\right)}}{\frac{\phi}{1-\phi}}$,

where $\phi$ is country $i$ 's share of world factor endowments.

When we include transport costs, the HME in the case of iceberg transport costs is given by:

$H M E=\frac{\frac{n_{i}\left(X_{i i}+X_{i j}\left(1+\tau_{x}\right)\right)}{n_{j}\left(X_{j j}+X_{j i}\left(1+\tau_{x}\right)\right)}}{\frac{\phi}{1-\phi}}$.

For the transport sector model, the HME is given by:

$H M E=\frac{\frac{n_{i}\left(X_{i i}+X_{i j}\right)+X_{i j} n_{i} \tau_{x}}{n_{j}\left(X_{j j}+X_{j i}\right)+X_{j i} n_{j} \tau_{x}}}{\frac{\phi}{1-\phi}}$.

Including transport costs, we see from Figure 9 that, as predicted by Davis (1998), the HME disappears in the case of iceberg transport costs. In the case of a transport sector with IRS, however, the HME even exists if transport costs are identical for the two commodities. The disappearance of the HME in the case of equal transport costs is due to the assumption of iceberg transport costs and, therefore, a highly artificial case.

The additional possibility to specialize in MNEs in the transport sector with IRS does not change the prediction of the specialization patterns in goods trade, but rather reinforces the tendency that the large country has a comparative advantage in the differentiated goods sector. As discussed above, the country which is relatively skilled labor abundant, specializes in transport services. If the countries relative endowments with all three factors is identical but they differ in absolute size, the larger country specializes in $X$-goods production which uses skilled labor and capital 
intensively. The smaller country exports homogeneous goods and, therefore, has enough skilled labor left to run transport sector MNEs.

In the case of a transport sector with CRS we find that the HME is strongest if we exclude the transport service and reverses if we include the transport service. This reflects the importance of the transport sector in the small country. If we include transport services, the smaller country even produces more of the differentiated good and the transport service compared to its country size. This is possible because factor prices for capital and skilled labor are lower, due to our factor intensity assumption and the fact that the smaller country runs less national firms which are capital and skilled labor intensive. Hence, transport services are cheaper in the smaller country. If the exporter takes care of the transport services, this stimulates exports from the smaller to the larger country, and leads to a reversed HME. If the importer takes care of the transport services, the importance of the transport sector stems from the relatively high volume of imports due to the larger range of varieties abroad. ${ }^{22}$

For the industrialization of countries, the comparison of sectors without transport costs would be more accurate. In this case, the HME even appears in the model with iceberg transport costs. We therefore can conclude in line with Helpman and Krugman (1985) that the HME is quite pervasive.

- Figure 9 -

\section{Conclusions}

Models of the new trade theory heavily depend on the introduction of transport costs. To simplify the model, most of them introduce Samuelson's iceberg transport costs, which assume that a part of the good "melts" away during transport.

According to the World Investment Report, multinational activities in the transport sector play a crucial role and become more and more important. In order to account for the multinationalization in transport services, horizontal multinational enterprises in the transport sector are introduced, i.e. firms running plants in both countries and not engaging in trade. This framework allows for imperfect competition in the goods market as well as in the transport sector.

By explicitly modelling the transport sector it is possible to relax some of the assumptions implied by iceberg transport costs. That means (i) transport services are no longer the same for both goods, (ii) production of the good shipped and the transport service are disentangled, (iii) there is no joint production of goods, and (iv) transport services and the factor intensities in the transport sector and in the goods sector can differ.

With respect to the volume of trade, the assumption of iceberg transport costs leads to an underestimation (overestimation) of the volume of trade for low (high) transport costs. Furthermore, the volume of trade (expressed as percentage of GDP) is independent of income and factor intensity assumptions when iceberg transport

\footnotetext{
${ }^{22}$ Plotting the HME with the assumption that the importer takes care of transport services does produce a picutre very similar to Figure 9 .
} 
costs are assumed. This independency vanishes by introducing a transport sector dominated by multinationals.

Varying transport costs when countries are equal leads to no income changes in both countries when iceberg transport costs are assumed. With a multinationalized transport sector, rising transport costs may increase or decrease GDP, depending on factor intensity assumptions in the goods sector.

With a capital-intensive transport sector, the skilled labor abundant countries specialize in running transport sector multinationals. Further, the home market effect is more pronounced as compared to a model with iceberg transport costs. In the large country the increasing returns to scale sector turns out to be even larger, while the small country specializes in the homogeneous good and in running headquarters of transport firms. 


\section{References}

Bottazzi, L., and G. Ottaviano (1996): "Modelling Transport Costs in International Trade: A Comparison among Alternative Approaches," mimeo.

Casas, F. (1981): "Transport Costs in the Pure Theory of International Trade: Some Comments," Economic Journal, 91(363), 741-744.

(1983): "International Trade with Produced Transport Service," Oxford Economic Papers, 35(1), 89-109.

Casas, F., And K. Choi (1985): "Some Paradoxes of Transport Costs in International Trade," Southern Economic Journal, 51(4), 983-997.

(1990): "Transport Innovation and Welfare under Variable Returns to Scale," International Economic Journal, 4(1), 45-57.

Casssing, J. (1978): "Transport Costs in International Trade Theory: A Comparison with the Analysis of Nontraded Goods," Quarterly Journal of Economics, $92(4), 535-550$.

DAvis, D. (1998): "The Home Market, Trade, and Industrial Structure," American Economic Review, 88(5), 1264-1276.

FAlvey, R. (1976): "Tranport Costs in the Pure Theory of International Trade," Economic Journal, 86, 536-550.

Francois, J., And I. Wooton (2001): "Trade in International Transport Service: The Role of Competition," Review of International Economics, 9(2), 249-261.

Helpman, E., And P. KRugman (1985): Market Structure and Foreign Trade Increasing Returns, Imperfect Competition and the International Economy. The MIT Press, Cambridge, Massachusetts.

Herberg, H. (1970): "Economic Growth and International Trade with Transport Costs," Zeitschrift für die gesamte Staatswissenschaft, pp. 577-600.

Hummels, D. (1999): "Toward a Geography of Trade Costs," mimeo.

Inoue, T. (1985): "Theories of International Trade with Transport Costs," Economic Studies Quarterly, 36(1), 23-43.

Janelle, D., And M. Beuthe (1997): "Globalization and Research Issues in Transportation," Journal of Transport Geography, 5(3), 199-206.

Mansori, K. (2003): "The Geographic Effects of Trade Liberalization with Increasing Returns in Transportation," Journal of Regional Science, 43(2), 249-268.

Mundell, A. (1957): "Transport Costs in International Trade Theory," Canadian Journal of Economics and Political Science, 23(3), 331-348.

Neary, P. (2001): "Of Hype and Hyperbolas: Introducing the New Economic Geography," Journal of Economic Literature, 39(2), 536-561. 
OECD (1998): "Railways: Structure, Regulation and Competition Policy," DAFFE/CLP(98)1, http://www.oecd.org/.

- (2001): "Regulatory Issues in International Martime Transport," http://www.oecd.org/.

(2002): "Cost Savings Stemming from Non-Compliance with International Environmental Regulations in the Maritime Sector," DSTI/DOT/MTC(2002)8/FINAL, http://www.oecd.org/.

Rousslang, D. (1991): "Domestic Trade and Transport Costs in International Trade Theory," International Economic Journal, 5(2), 49-61.

Samuelson, P. (1952): "The Transfer Problem and Transport Costs: The Terms of Trade when Impediments are Absent," Economic Journal, 62, 278-304.

(1954): "The Transer Problem and Transport Costs II: Analysis of Effects of Trade Impediments," Economic Journal, 64, 264-289.

UNCTAD (2002): World Investment Report - Transnational Corporations and Export Competitiveness. United Nations Conference on Trade and Development, New York and Geneva.

(2004): World Investment Report - The Shift Towards Services. United Nations Conference on Trade and Development, New York and Geneva.

van SchiJndel, W.-J., And J. Dinwoodie (2000): "Congestion and Multimodal Transport: A Survey of Cargo Transport Operators in the Netherlands," Transport Policy, 7, 231-241. 


\section{Appendix 1}

\section{Volume of Trade and Transport Sector}

With iceberg transport costs the volume of trade for completely symmetric countries is given by (simplifying equation (19); due to symmetry we omit the country index.):

$$
\begin{aligned}
V T & =\frac{2 n p\left(p\left(1+\tau_{x}\right)\right)^{-\sigma}\left(n p^{1-\sigma}+n\left(\left(1+\tau_{x}\right) p\right)^{1-\sigma}\right)^{-1} \alpha E}{2 E}= \\
& =\frac{\alpha n p}{\left(p\left(1+\tau_{x}\right)\right)^{\sigma}\left(n p^{1-\sigma}+n\left(\left(1+\tau_{x}\right) p\right)^{1-\sigma}\right)}=\frac{\alpha}{\left(1+\tau_{x}\right)^{\sigma}\left(1+\left(1+\tau_{x}\right)^{1-\sigma}\right)}= \\
& =\frac{\alpha}{\left(1+\tau_{x}\right)+\left(1+\tau_{x}\right)^{\sigma}} .
\end{aligned}
$$

Therefore, the $V T$ as percentage of GDP does not depend on income or factor intensities in production at all. Furthermore, the first derivative with respect to $\sigma, \frac{\partial V T}{\partial \sigma}=\frac{-\alpha\left(1+\tau_{x}\right)^{\sigma} \ln \left(1+\tau_{x}\right)}{\left(\left(1+\tau_{x}\right)+\left(1+\tau_{x}\right)^{\sigma}\right)^{2}}<0$, indicates that a higher substitutability between variants leads to a lower volume of trade.

In the case of equal countries the expression for the volume of trade simplifies in the transport sector model to:

$$
\begin{aligned}
& V T=\frac{2 n p X_{i j}}{2 E}=\frac{2 n p\left(p+s_{t} \tau_{x}\right)^{-\sigma} s^{\sigma-1} \alpha E}{2 E}=\frac{\alpha}{\left(1+\frac{s_{t} \tau_{x}}{p}\right)+\left(1+\frac{s_{t} \tau_{x}}{p}\right)^{\sigma}} \\
& =\frac{\alpha}{\left(1+\frac{(2 m)^{\frac{1}{1-\sigma_{t}}} p_{t} \tau_{x}}{p}\right)+\left(1+\frac{(2 m)^{\frac{1}{1-\sigma_{t}}} p_{t} \tau_{x}}{p}\right)^{\sigma}} \text {. }
\end{aligned}
$$

Similar as the volume of trade in the case of iceberg transport costs, $\frac{\partial V T}{\partial \alpha}>0$ and $\frac{\partial V T}{\partial \sigma}<0$. The positive derivative with respect to $\alpha$ indicates the increased importance of the differentiated goods sector, leading to more intra-industry trade, whereas the negative derivative with respect to $\sigma$ points to lower intra-industry trade due to the higher substitutability of variants. Further, $\frac{\partial V T}{\partial \tau_{x}}<0$, indicating that higher transport costs lead to a lower volume of trade.

In the expression of the VT, the endogenous variable of the number of multinational transport firms still pops up. We could solve the model analytically by assuming $a_{K x}=a_{S x}=a_{K t}=a_{S t}=a_{K m t}=a_{S n}=0$ and $a_{L x}=a_{L t}=1$. This implies that the differentiated good as well as the transport service is only produced with unskilled labor, capital is only needed to set-up national firms and skilled labor is only required to run MNEs in the transport sector. The number of multinational firms would therefore be determined by the endowment with skilled labor, and prices would cancel out, leading to an analytical solution for the volume of trade.

The derivative with respect to $\sigma_{t}$ has an ambiguous sign, depending on the number 
of firms active, specifically:

$$
\begin{aligned}
& \frac{\partial V T}{\partial \sigma_{t}}=-\frac{\alpha}{\left[\left(1+\frac{(2 m)^{\frac{1}{1-\sigma_{t}}} p_{t} \tau_{x}}{p}\right)+\left(1+\frac{(2 m)^{\frac{1}{1-\sigma_{t}}} p_{t} \tau_{x}}{p}\right)^{\sigma}\right]^{2}}\left[\frac{(2 m)^{\frac{1}{1-\sigma_{t}}} \ln (2 m) p_{t} \tau_{x}}{\left(1-\sigma_{t}\right)^{2} p}\right. \\
& \left.+\sigma\left(1+\frac{(2 m)^{\frac{1}{1-\sigma_{t}}} p_{t} \tau_{x}}{p}\right)^{\sigma-1} \frac{(2 m)^{\frac{1}{1-\sigma_{t}}} \ln (2 m) p_{t} \tau_{x}}{\left(1-\sigma_{t}\right)^{2} p}\right] \gtrless 0 \\
& \text { if } m \lessgtr 0.5 \text {. }
\end{aligned}
$$

If the "number of firms" is less than 0.5 (where we may think of the $m_{i}$ 's as different modes of transportation, each consisting of more firms), a lower degree of network dependence (i.e., a higher $\sigma_{t}$ ) leads to a lower price for the whole transport service and to a higher volume of trade, because the small range of different modes (or, the fewer firms), becomes less severe. On the other hand, if there are a lot of different modes of transportation, this is especially favorable if the network structure is really needed and used from the customers.

The derivative with respect to the number of firms is positive, $\frac{\partial V T}{\partial m}>0$, showing that more firms lead to a more dense network, profiting customers.

So far we have assumed the same factor intensity assumptions for the transport service and the differentiated good, leading to the equality of $p$ and $p_{t}$. If $p \neq p_{t}$, we can show that a rise of $p_{t}$ relative to $p$ leads to a lower VT. Define $\widetilde{p}=\frac{p_{t}}{p}$, then:

$$
\begin{aligned}
\frac{\partial V T}{\partial \widetilde{p}} & =-\frac{\alpha}{\left[\left(1+(2 m)^{\frac{1}{1-\sigma_{t}}} \widetilde{p} \tau_{x}\right)+\left(1+(2 m)^{\frac{1}{1-\sigma_{t}}} \widetilde{p} \tau_{x}\right)^{\sigma}\right]^{2}}\left[(2 m)^{\frac{1}{1-\sigma_{t}}} \tau_{x}\right. \\
& \left.+\sigma\left(1+(2 m)^{\frac{1}{1-\sigma_{t}}} \tau_{x}\right)^{\sigma-1}(2 m)^{\frac{1}{1-\sigma_{t}}} \tau_{x}\right]<0 .
\end{aligned}
$$

Let $V T_{I C}$ be the volume of trade in the model with iceberg-transport costs and $V T_{T S}$ the volume of trade in the presence of a separate transport sector. The difference is given by:

$$
\begin{aligned}
\Delta V T & =V T_{T S}-V T_{I C} \quad \alpha \\
& =\frac{\alpha}{\left(1+(2 m)^{\frac{1}{1-\sigma_{t}}} \widetilde{p} \tau_{x}\right)+\left(1+(2 m)^{\frac{1}{1-\sigma_{t}}} \widetilde{p} \tau_{x}\right)^{\sigma_{t}}}-\frac{\alpha}{\left(1+\tau_{x}\right)+\left(1+\tau_{x}\right)^{\sigma}} \\
& =\frac{\alpha\left[\left(1+\tau_{x}\right)+\left(1+\tau_{x}\right)^{\sigma}-\left(1+(2 m)^{\frac{1}{1-\sigma_{t}}} \widetilde{p} \tau_{x}\right)-\left(1+(2 m)^{\frac{1}{1-\sigma_{t}}} \widetilde{p} \tau_{x}\right)^{\sigma_{t}}\right]}{\left[\left(1+(2 m)^{\frac{1}{1-\sigma_{t}}} \widetilde{p} \tau_{x}\right)+\left(1+(2 m)^{\frac{1}{1-\sigma_{t}}} \widetilde{p} \tau_{x}\right)^{\sigma_{t}}\right]\left[\left(1+\tau_{x}\right)+\left(1+\tau_{x}\right)^{\sigma}\right]} \\
& \propto \tau_{x}\left(1-(2 m)^{\frac{1}{1-\sigma_{t}}} \widetilde{p}\right)+\left(1+\tau_{x}\right)^{\sigma}-\left(1+(2 m)^{\frac{1}{1-\sigma_{t}}} \widetilde{p} \tau_{x}\right)^{\sigma} .
\end{aligned}
$$

This expression is equal to zero for $\tau_{x}=0$. Further, using $\widetilde{p}=\frac{p_{t}}{p}=\frac{\sigma_{t}(\sigma-1)}{\sigma\left(\sigma_{t}-1\right)}, \Delta V T=0$ if $m=\frac{1}{2}\left(\frac{\sigma\left(\sigma_{t}-1\right)}{\sigma_{t}(\sigma-1)}\right)^{1-\sigma_{t}}$. If $\tau_{x} \neq 0$, the sign of the expression therefore depends only 
on the value of $m$ : if $m \gtrless \frac{1}{2}\left(\frac{\sigma\left(\sigma_{t}-1\right)}{\sigma_{t}(\sigma-1)}\right)^{1-\sigma_{t}}, \Delta V T \gtrless 0$.

\section{Appendix 2}

\section{Samuelson's Iceberg Transport Costs and Income Invariance when Countries are Equal}

In the model with iceberg transport costs and symmetric countries, one factor reward, either capital or skilled labor, approaches zero. This can be seen by comparing the factor market equations for capital and skilled labor, given by:

$$
\begin{aligned}
K_{i} & \geq a_{K x} n_{i}\left(X_{i i}+X_{i j}\left(1+\tau_{x}\right)\right)+a_{K n} n_{i} \\
S_{i} & \geq a_{S x} n_{i}\left(X_{i i}+X_{i j}\left(1+\tau_{x}\right)\right)+a_{S n} n_{i} .
\end{aligned}
$$

$X_{i i}$ and $X_{i j}$ are determined by the equations (4). The only remaining variable is $n_{i}$. The two equations above then only differ by constants and therefore both equations will only hold with equality by coincidence. Assume skilled labor abundance. In this case, the factor reward in both countries for skilled labor approaches zero. $\left(w_{S i}=w_{S j}=0\right)$. This simplifies the zero-profit condition to (assuming $\left.n_{i}>0\right)$ :

$a_{K n} w_{K i}=\frac{p_{i}\left(X_{i i}+X_{i j}\left(1+\tau_{x}\right)\right)}{\sigma}$.

Using the factor market equation for capital (A6) and for unskilled labor, given by $L_{i} \geq a_{K x} n_{i}\left(X_{i i}+X_{i j}\left(1+\tau_{x}\right)\right)+Z_{i i}+Z_{i j}\left(1+\tau_{z}\right)$, and solving both for $n_{i}$ leads to:

$n_{i}=\frac{K_{i}}{a_{K x}\left(X_{i i}+X_{i j}\left(1+\tau_{x}\right)\right)+a_{K n}}$,

$n_{i}=\frac{L_{i}-(1-\alpha) E_{i}}{a_{L x}\left(X_{i i}+X_{i j}\left(1+\tau_{x}\right)\right)}$,

where we used $(1-\alpha) E_{i}=Z_{i i}$, which holds because the $Z$-good is not traded between equal countries.

By equating (A9) and (A10) we can write:

$$
\begin{aligned}
& \left(X_{i i}+X_{i j}\left(1+\tau_{x}\right)\right)\left[\frac{a_{K x}\left(L_{i}-(1-\alpha) E_{i}\right)}{K_{i}}-a_{L x}\right]+a_{K n}\left[\frac{L_{i}-(1-\alpha) E_{i}}{K_{i}}\right]=0 . \\
& X_{i i}+X_{i j}\left(1+\tau_{x}\right)=\frac{-a_{K n}\left[\frac{L_{i}-(1-\alpha) E_{i}}{K_{i}}\right]}{\frac{a_{K x}\left(L_{i}-(1-\alpha) E_{i}\right)}{K_{i}}-a_{L x}} .
\end{aligned}
$$

Using $E_{i}=w_{K i} K_{i}+L_{i}, p_{i}=\frac{\sigma\left(a_{K x} w_{K i}+a_{L x}\right)}{\sigma-1}$ and combining (A8) and (A12) leads to:

$a_{K n} w_{K i}=\frac{\left(a_{K x} w_{K i}+a_{L x}\right)}{\sigma-1} \frac{-a_{K n}\left[\frac{L_{i}-(1-\alpha) E_{i}}{K_{i}}\right]}{\frac{a_{K x}\left(L_{i}-(1-\alpha) E_{i}\right)}{K_{i}}-a_{L x}}$. 
After some manipulation, this equation turns out to be a quadratic one:

$$
\begin{aligned}
& w_{K i}^{2}\left(-a_{K n} a_{K x}(1-\alpha) \sigma\right)+w_{K i}\left[\frac{\alpha a_{K n} a_{K x} L_{i} \sigma}{K_{i}}-a_{L x} a_{K n}(\sigma-\alpha)\right]+ \\
& +\frac{\alpha a_{L x} a_{K n} L_{i}}{K_{i}}=0
\end{aligned}
$$

with solutions as follows:

$$
\begin{aligned}
w_{K i} & =\frac{1}{2 a_{K x} K_{i}(1-\alpha) \sigma}\left(a_{L x} K_{i}(\alpha-\sigma)+a_{K x} L_{i} \alpha \sigma\right. \\
& \left. \pm \sqrt{-4 a_{K x} a_{L x} K_{i} L_{i}(\alpha-1) \alpha \sigma+\left(a_{L x} K_{i}(\alpha-\sigma)+a_{K x} L_{i} \alpha \sigma\right)^{2}}\right) .
\end{aligned}
$$

Noting that the first expression of the right hand side is always positive, we can conclude that one solution is always negative and one is always positive, because the two terms in parenthesis and outside the square root are identical to the last expression under the square root. Since we restrict factor prices to be non-negative, we find one definite and valid solution.

Together with the income definition $\left(E_{i}=w_{K i} K_{i}+L_{i}\right)$, this shows that income does not vary with transport costs, since they do not appear in the solution for $w_{K i}$.

This result holds as long as the homogeneous goods is not traded. If there is homogeneous goods trade, income does vary when transport costs change. More specifically, the income raises for the homogeneous goods exporter whereas it falls for the netexporter of differentiated products (see also Section IV).

\section{Appendix 3}

\section{A Perfectly Competitive Transport Sector}

We have argued that the transport sector is characterized by high fixed costs and a high share of multinational firms, what justified the assumption of imperfect competition and MNEs in the transport sector. For reasons of comparison we will now analyze what happens if we would assume a perfectly competitive transport sector.

Again, we assume equal countries and that the production of the transport service uses the same resources as $X$-goods production. Now, in the transport service marginal cost pricing obtains and the therefore $p_{t}=\frac{\sigma-1}{\sigma} p$. The volume of trade reads as follows:

$$
\begin{aligned}
V T & =\frac{2 n p X_{i j}}{2 E}=\frac{2 n p\left(p+p_{t} \tau_{x}\right) \alpha E}{2 E}=\frac{\alpha}{\left(1+\frac{p_{t} \tau_{x}}{p}\right)+\left(1+\frac{p_{t} \tau_{x}}{p}\right)^{\sigma}} \\
& =\frac{\alpha}{\left(1+\frac{\sigma-1}{\sigma} \tau_{x}\right)+\left(1+\frac{\sigma-1}{\sigma} \tau_{x}\right)^{\sigma}} .
\end{aligned}
$$

Let $V T_{P C}$ be the volume of trade in the case of a perfectly competitive transport 
sector, then:

$$
\begin{aligned}
\Delta V T & =V T_{P C}-V T_{I C} \\
& =\frac{\alpha}{\left(1+\frac{\sigma-1}{\sigma} \tau_{x}\right)+\left(1+\frac{\sigma-1}{\sigma} \tau_{x}\right)^{\sigma}}-\frac{\alpha}{\left(1+\tau_{x}\right)+\left(1+\tau_{x}\right)^{\sigma}} \\
& =\frac{\alpha\left[\left(1+\tau_{x}\right)+\left(1+\tau_{x}\right)^{\sigma}-\left(1+\frac{\sigma-1}{\sigma} \tau_{x}\right)-\left(1+\frac{\sigma-1}{\sigma} \tau_{x}\right)^{\sigma}\right]}{\left[\left(1+\frac{\sigma-1}{\sigma} \tau_{x}\right)+\left(1+\frac{\sigma-1}{\sigma} \tau_{x}\right)^{\sigma}\right]\left[\left(1+\tau_{x}\right)+\left(1+\tau_{x}\right)^{\sigma}\right]} \\
& \propto \frac{\tau_{x}}{\sigma}+\left(1+\tau_{x}\right)^{\sigma}-\left(1+\frac{\sigma-1}{\sigma} \tau_{x}\right)^{\sigma}>0 .
\end{aligned}
$$

This result is driven from the fact that with iceberg transport costs the same market conduct for the transport sector and the goods sector is assumed. Relaxing this assumption leads to a lower price for the transport service and, hence, to a higher volume of trade.

We now compare the VT in the case of a transport sector dominated by multinationals with the volume of trade when there is perfect competition in the transport sector:

$$
\begin{aligned}
& \Delta V T=V T_{T S}-V T_{P C} \\
= & \frac{\alpha}{\left(1+(2 m)^{\frac{1}{1-\sigma_{t}}} \tau_{x}\right)+\left(1+(2 m)^{\frac{1}{1-\sigma_{t}}} \tau_{x}\right)^{\sigma}}-\frac{\alpha}{\left(1+\frac{(\sigma-1) \tau_{x}}{\sigma}\right)+\left(1+\frac{(\sigma-1) \tau_{x}}{\sigma}\right)^{\sigma}} \\
= & \frac{\alpha\left[\left(1+\frac{(\sigma-1) \tau_{x}}{\sigma}\right)+\left(1+\frac{(\sigma-1) \tau_{x}}{\sigma}\right)^{\sigma}-\left(1+(2 m)^{\frac{1}{1-\sigma_{t}}} \tau_{x}\right)-\left(1+(2 m)^{\frac{1}{1-\sigma_{t}}} \tau_{x}\right)^{\sigma}\right]}{\left[\left(1+(2 m)^{\frac{1}{1-\sigma_{t}}} \tau_{x}\right)+\left(1+(2 m)^{\frac{1}{1-\sigma_{t}}} \tau_{x}\right)^{\sigma}\right]\left[\left(1+\frac{(\sigma-1) \tau_{x}}{\sigma}\right)+\left(1+\frac{(\sigma-1) \tau_{x}}{\sigma}\right)^{\sigma}\right]} \\
\propto & \tau_{x}\left(\frac{\sigma-1}{\sigma}-(2 m)^{\frac{1}{1-\sigma_{t}}}\right)+\left(1+\frac{(\sigma-1) \tau_{x}}{\sigma}\right)^{\sigma}-\left(1+(2 m)^{\frac{1}{1-\sigma_{t}}} \tau_{x}\right)^{\sigma} \cdot \quad \text { (A18) }
\end{aligned}
$$

This expression is again zero for $\tau_{x}=0$. Further we find that $\Delta V T \gtrless 0$ if $m \gtrless \frac{1}{2}\left[\frac{\sigma-1}{\sigma}\right]^{1-\sigma_{t}}$. There are two countervailing effects in the transport sector model driving the result: (i) Scale effects (network dependence) in the transport sector lower the price for the whole transport service bundle, (ii) whereas the imperfect competition (the markup on prices) rises the price for the transport service. For equal countries scale effects are strong enough to compensate for markups in the intermediate range of transport costs and therefore the VT is greater in this area if we have a transport sector dominated by MNEs. Rising competition in the differentiated goods sector leads to a lower value for $m$ for which $\Delta V T=0$ $\left(\frac{\partial m}{\partial \sigma}=0.5\left(1-\sigma_{t}\right)\left(\frac{1}{\sigma^{2}}\right)\left(\frac{\sigma-1}{\sigma}\right)^{-\sigma_{t}}<0\right)$. In this case the relative price of the transport service compared to the price of the differentiated goods raises, leading to a lower volume of trade in the case of a perfectly competitive transport sector whereas the volume of trade is unaffected in the case of a transport sector dominated by multinationals. The critical value for $m$ also depends on the degree of network dependence $\left(\sigma_{t}\right)$. A lower network dependence (higher $\sigma_{t}$ ) leads to a higher critical value of $m$ $\left(\frac{\partial m}{\partial \sigma_{t}}=-0.5\left(\frac{\sigma-1}{\sigma}\right)^{1-\sigma_{t}} \ln \left[\frac{\sigma-1}{\sigma}\right]>0\right)$. The reason is that for a higher degree of network dependence a tight transport sector lowers the price more than if the reliance on a dense transport network is less pronounced. 
Even though the derivatives above are made for equal countries, the main driving forces are present in cases where countries differ in size and/or relative factor endowments. 


\begin{tabular}{|l|c|c|c|}
\hline \multicolumn{1}{|c|}{ Sector } & $\begin{array}{c}\text { Unskilled } \\
\text { Labor }\end{array}$ & $\begin{array}{c}\text { Skilled } \\
\text { Labor }\end{array}$ & Capital \\
\hline Rice \& Grains & 61.72 & 2.57 & 35.71 \\
\hline Other Crops & 67.07 & 1.82 & 31.11 \\
\hline Meat & 57.95 & 5.83 & 36.23 \\
\hline Other Food & 35.21 & 9.60 & 55.19 \\
\hline Natural Resources & 32.91 & 5.54 & 61.55 \\
\hline Textile, Apparel \& Leather & 50.98 & 10.63 & 38.39 \\
\hline Auto \& Machinery & 42.75 & 24.95 & 32.31 \\
\hline Other Manufacturing & 40.54 & 17.60 & 41.86 \\
\hline Trade & 46.61 & 15.85 & 37.53 \\
\hline Water Transport & 41.40 & 14.69 & 43.91 \\
\hline Air Transport & 50.71 & 15.04 & 34.25 \\
\hline Other Transport & 43.87 & 15.15 & 40.98 \\
\hline Other Services & 29.57 & 27.11 & 43.32 \\
\hline
\end{tabular}

Table 1: Factor intensities in selected sectors (\% of total factor income of all three factors). Source: GTAP database version 6, corresponding to the global economy in 2001. 


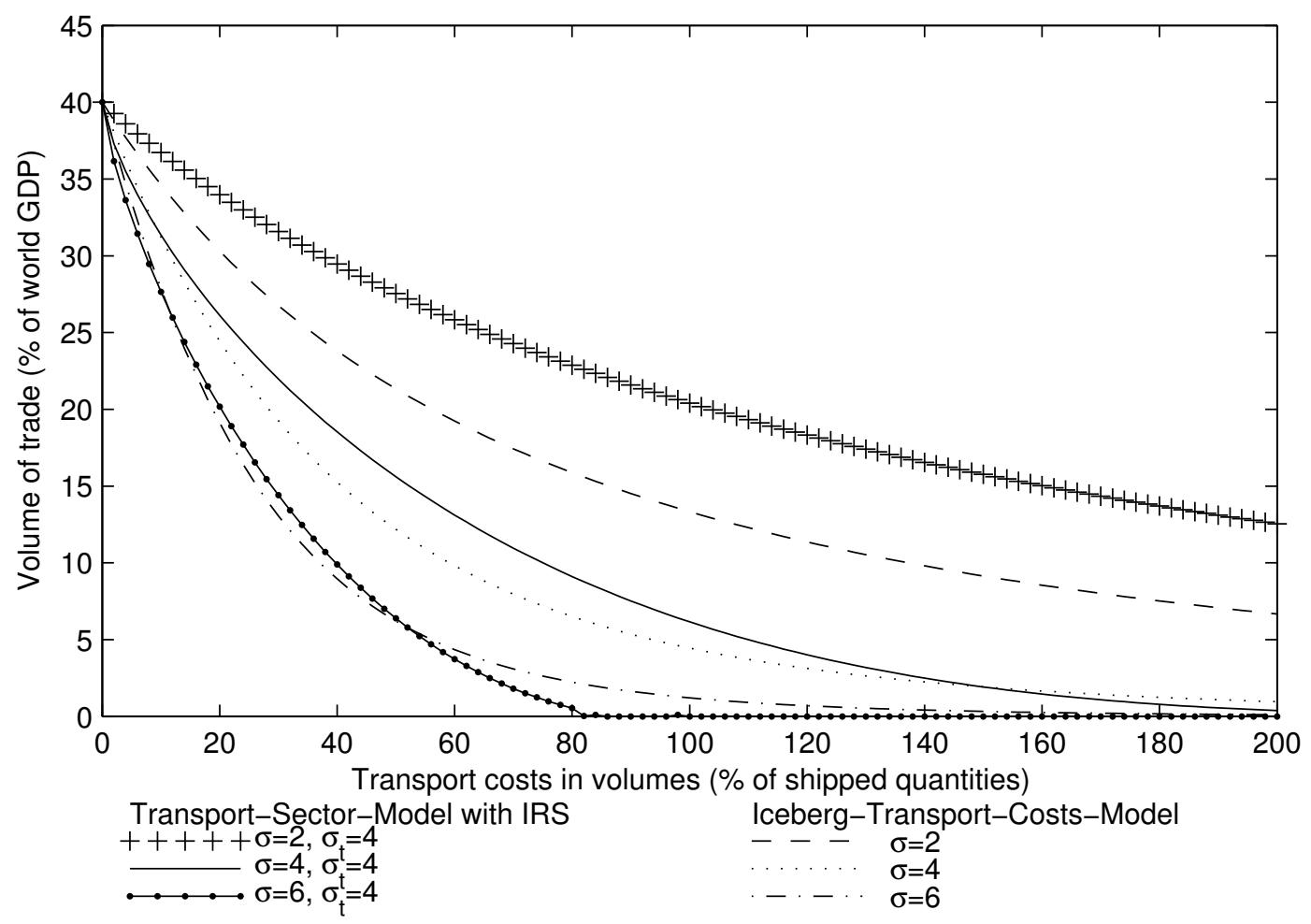

Figure 1: Volume of trade as \% of world GDP if $\sigma$ changes.

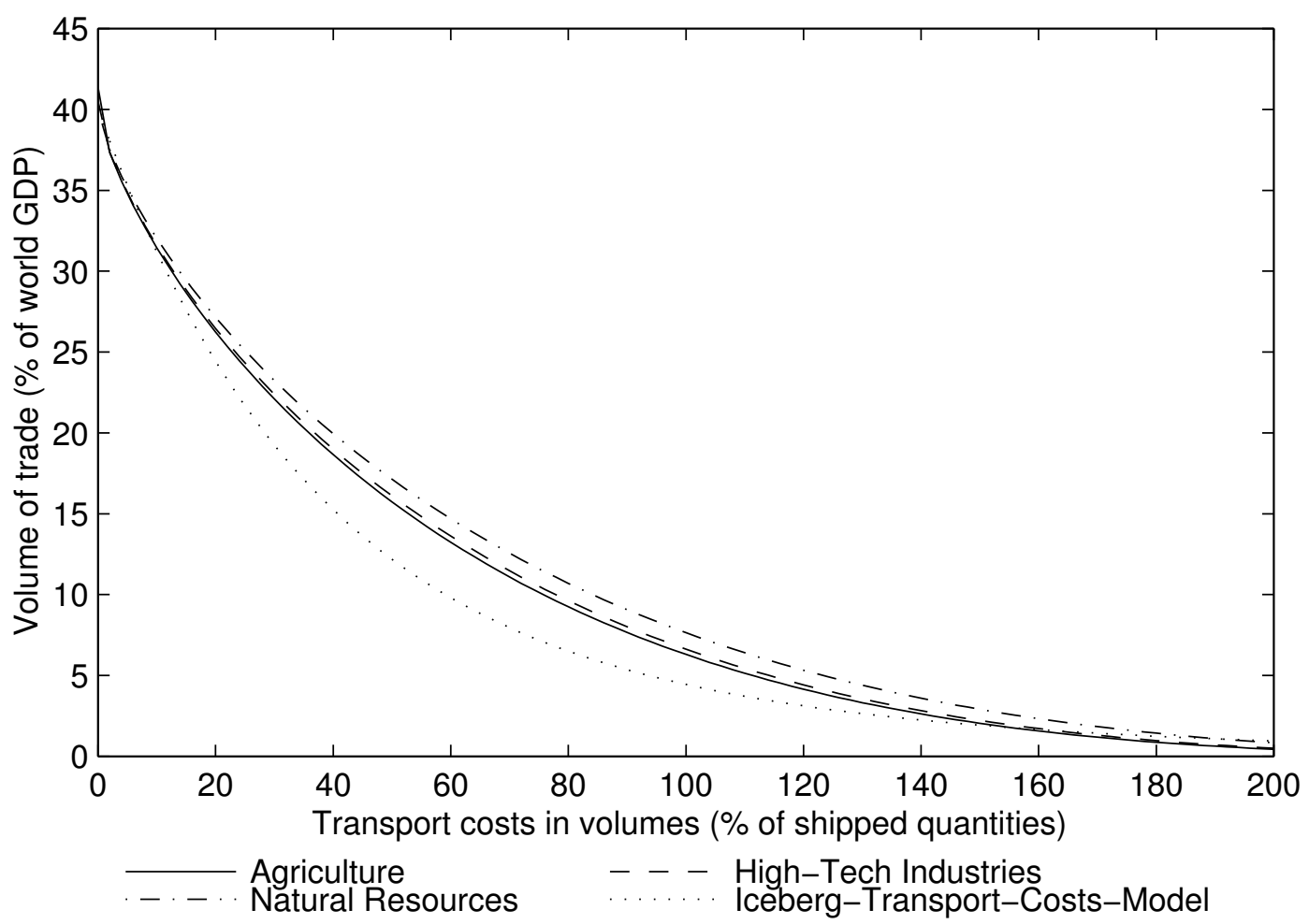

Figure 2: Volume of trade as \% of world GDP if factor intensities change. 


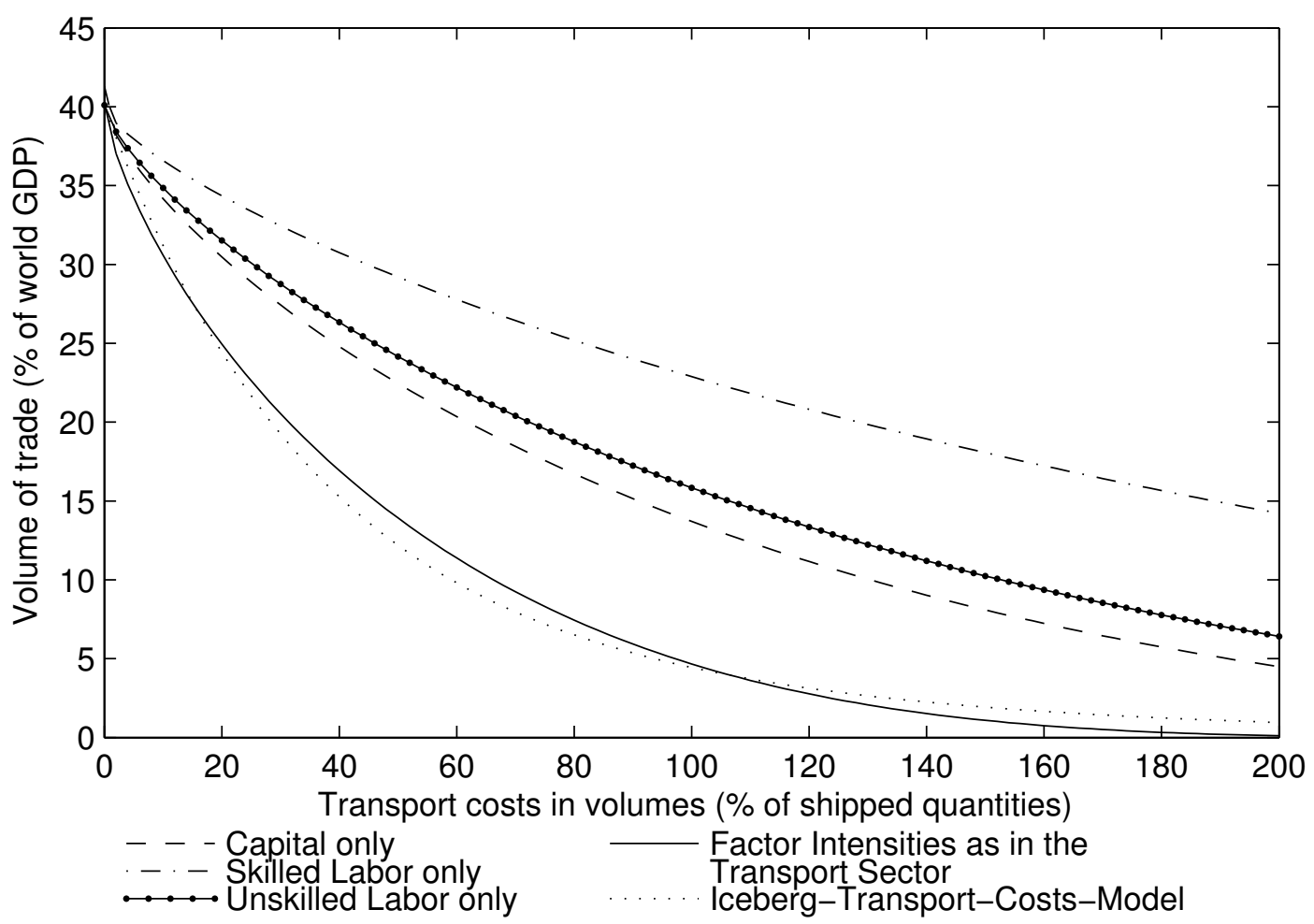

Figure 3: Volume of trade as \% of world GDP if factor intensities change.

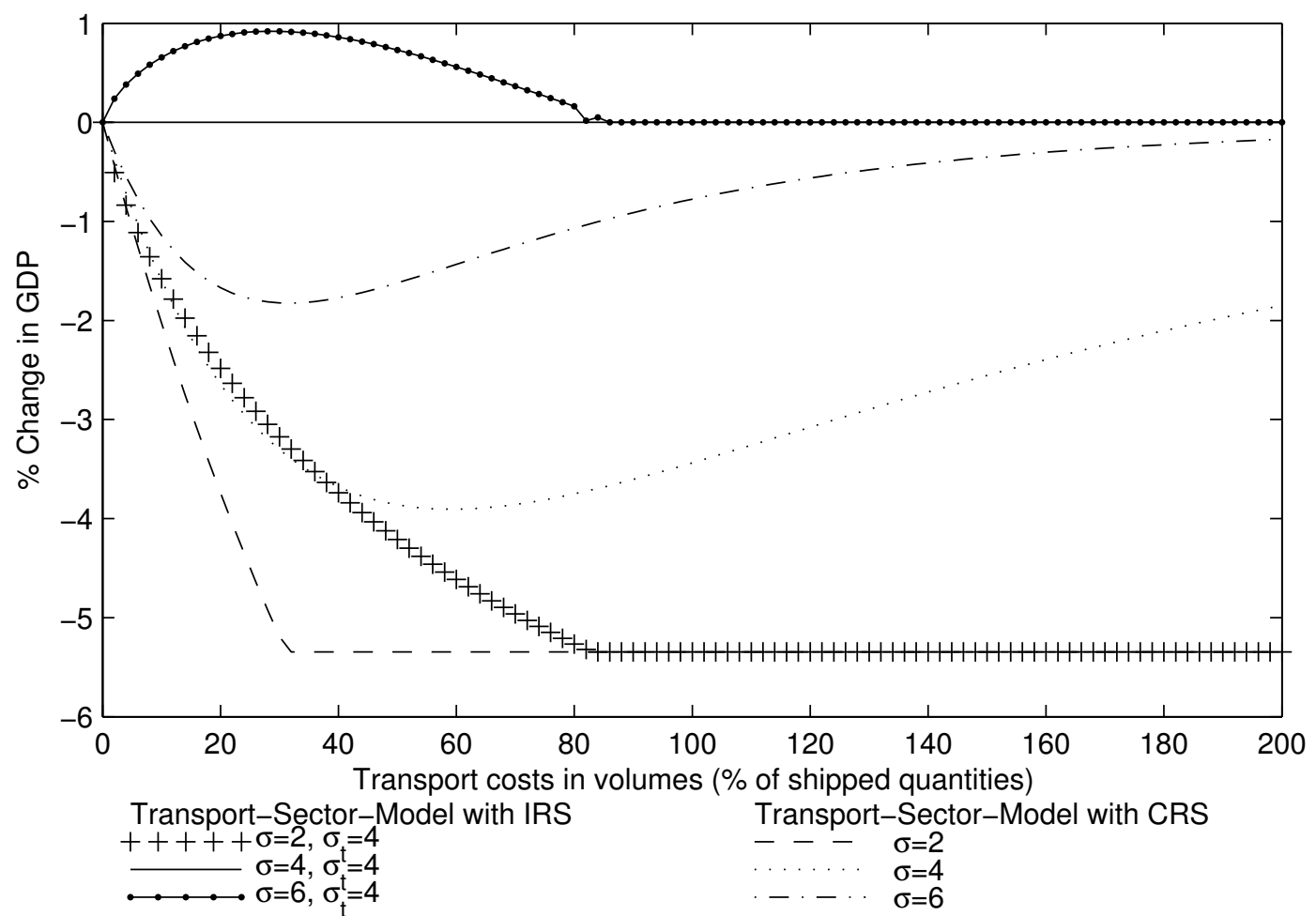

Figure 4: GDP changes in $\%$ if $\sigma$ changes. 


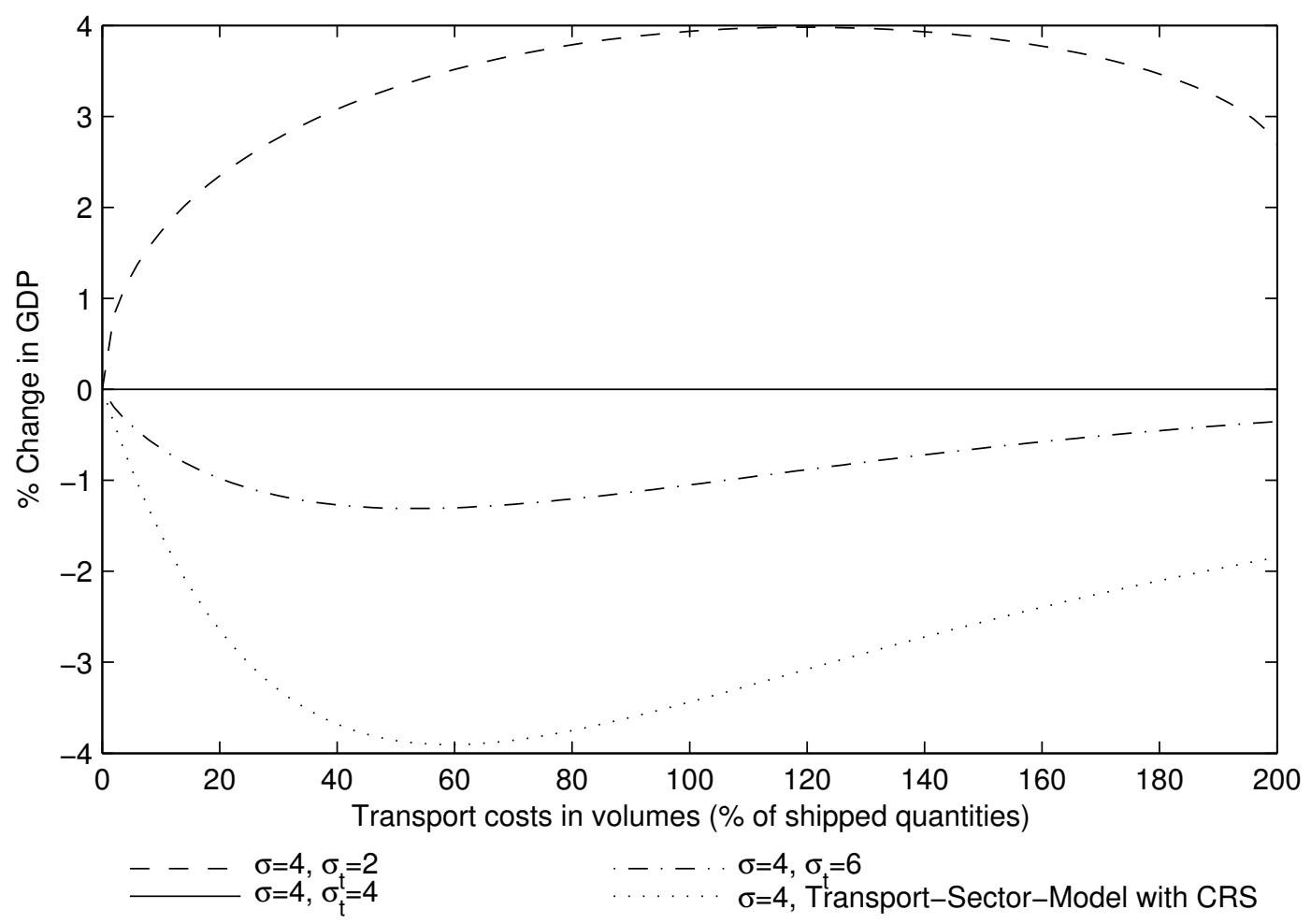

Figure 5: GDP changes in $\%$ if $\sigma_{t}$ changes.

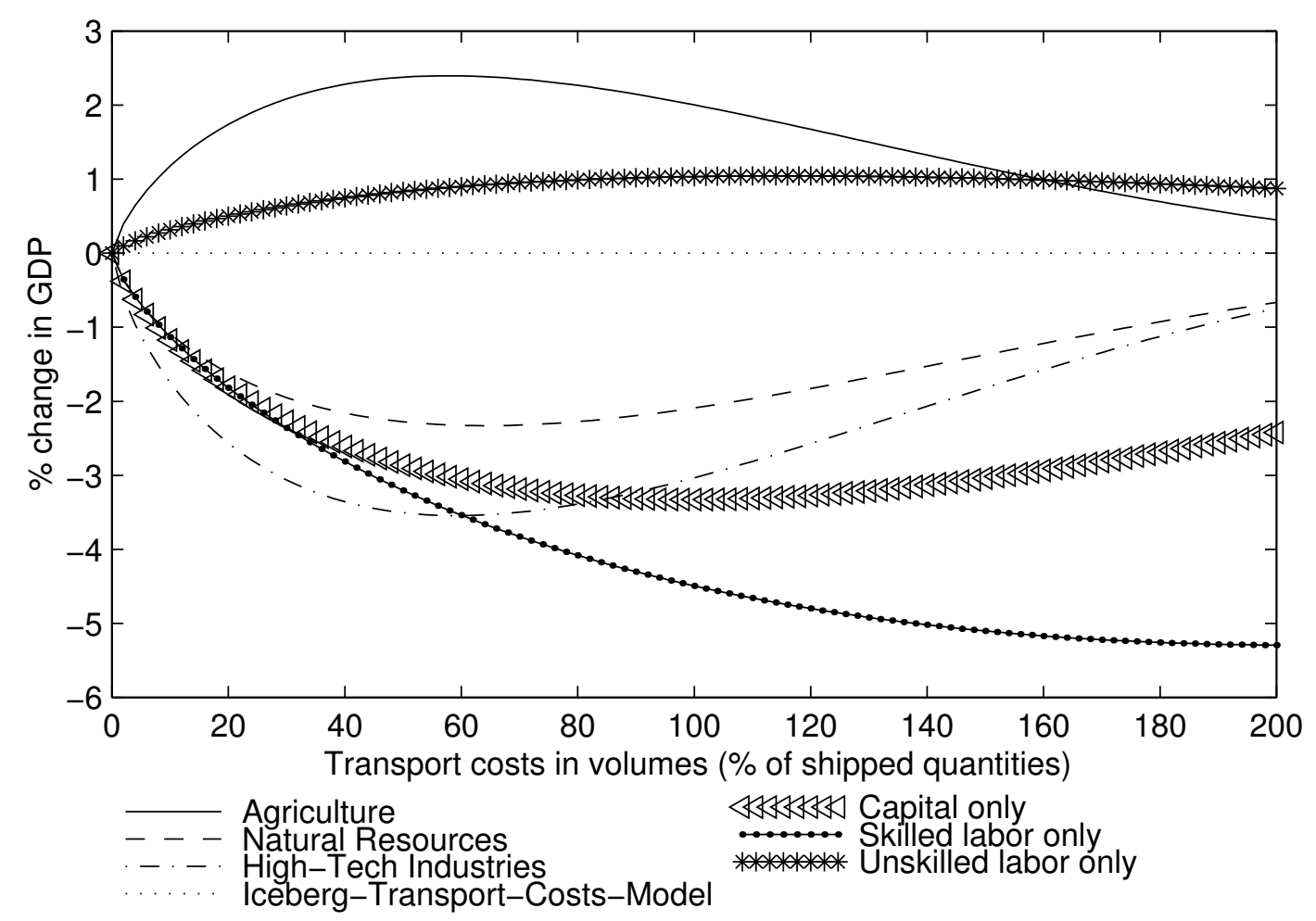

Figure 6: GDP changes in $\%$ if factor intensities change. 


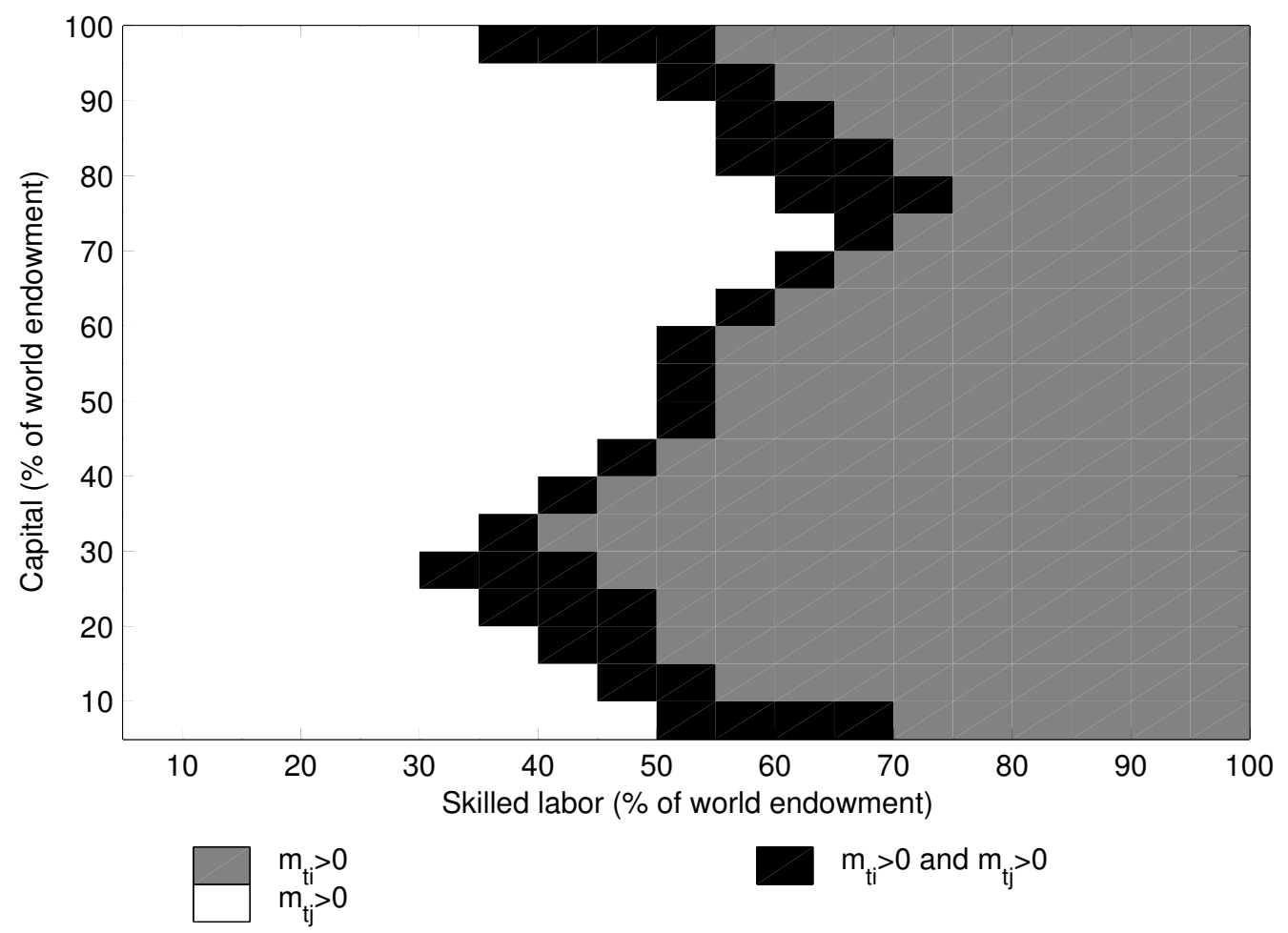

Figure 7: Existence of MNEs in the transport sector; $L_{i}=50 \%$ of world endowment.

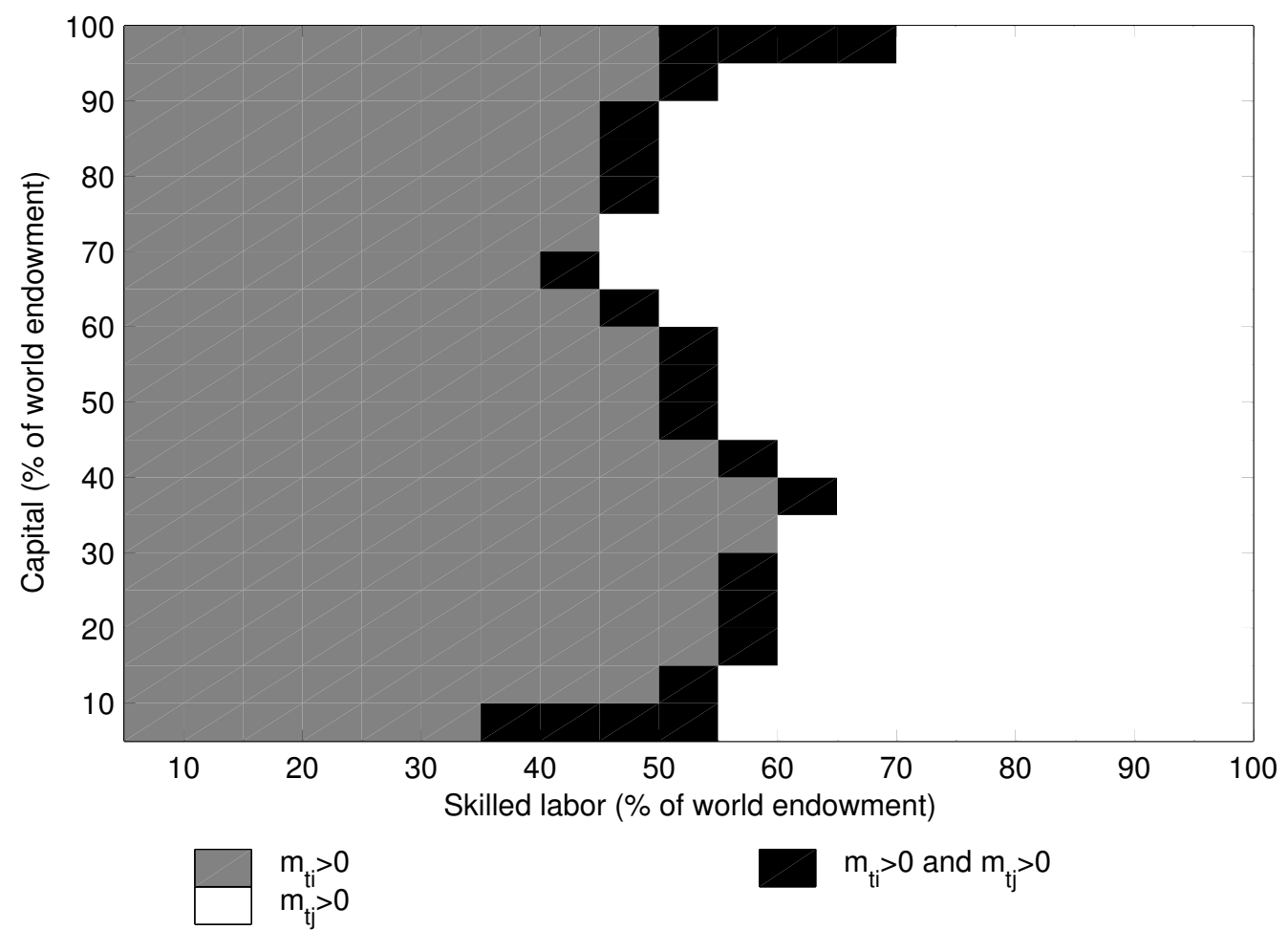

Figure 8: Existence of MNEs in the transport sector; $S_{i}=50 \%$ of world endowment. 


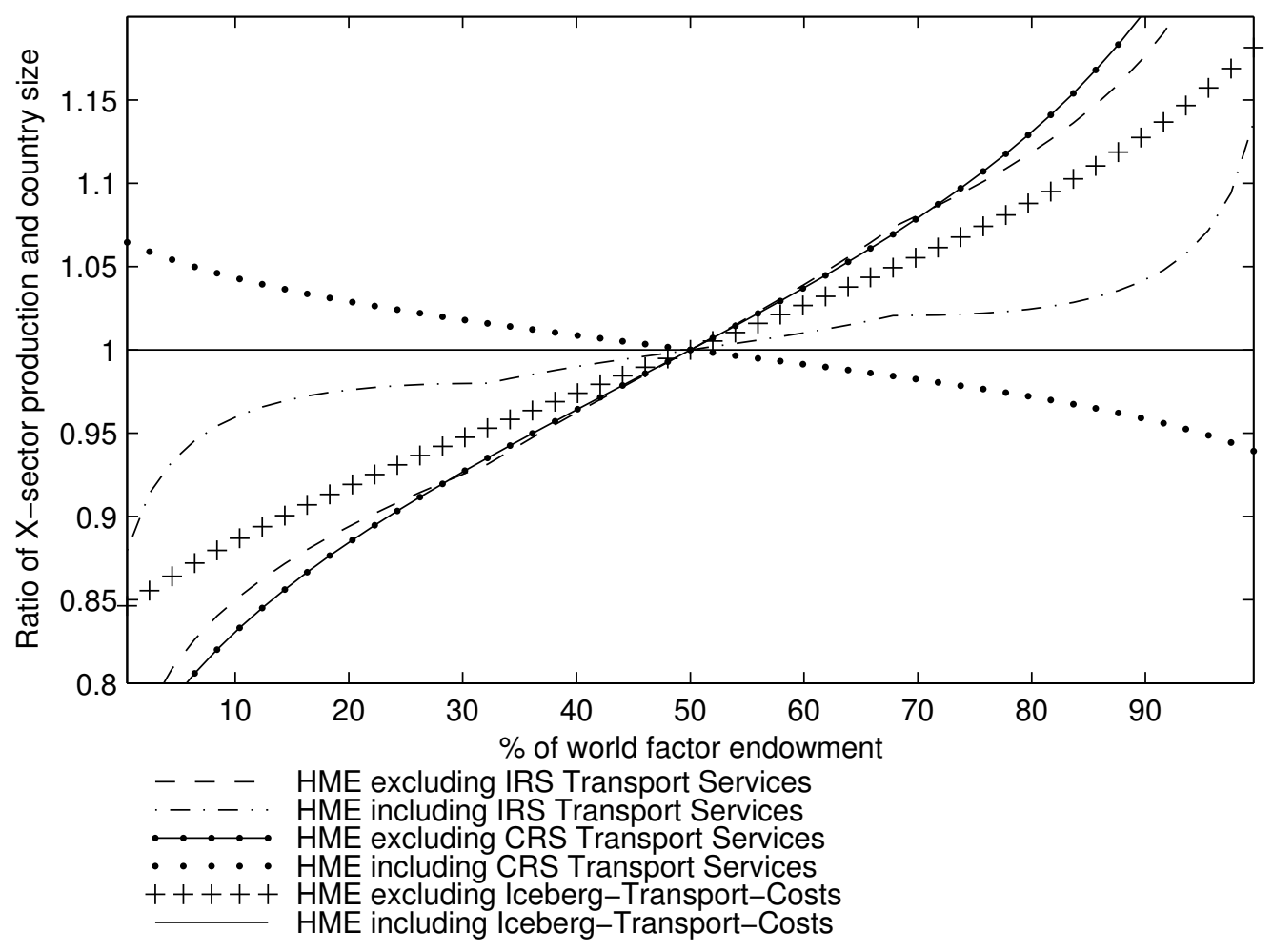

Figure 9: The Home-Market-Effect 


\title{
The Multinationalization of the Transport Sector
}

\section{Supplement \\ (Not intended for publication)}

\author{
Mario Larch*
}

December 1, 2004

\begin{abstract}
This supplement to the paper titled "The Multinationalization of the Transport Sector" provides figures that are not included in the paper in order to save space. First, the location of headquarters services is shown for alternative scenarios of $X$-goods and for both assumptions: (i) the exporter takes care of transport services, and (ii) the importer takes care of transport services. These are Figures 1-14. Figure 15 corresponds to Figure 10 in the paper, where we changed the assumption that the exporter takes care of transport services. In the paper Figures 1-6 where presented for the case of equal countries. In this supplement we present corresponding figures for the volume of trade and income when countries differ in size and/or relative factor endowments. First we present figures for countries that differ in size but not in relative factor endowments, more specifically Figures 16-26 plot the volume of trade and income when one country has 30\% (70\%) of world factor endowments. In Figures 27-39 one country is unskilled labor abundant (70\% of world endowment) or unskilled labor scarce (30\% of world endowment). The remaining two factors are divided equally between the economies. The case where one country is skilled labor abundant/scarce and the case where one country is capital abundant/scarce are plotted in Figures 40-52 and Figures 53-65, respectively.
\end{abstract}

JEL classification: F12; F23

Keywords: Multinationals; Transport sector; Iceberg transport costs; Economies of Scale

*Department of Economics and Statistics, University of Innsbruck, Universitaetsstrasse 15, A6020 Innsbruck, Austria; E-mail: Mario.Larch@uibk.ac.at 


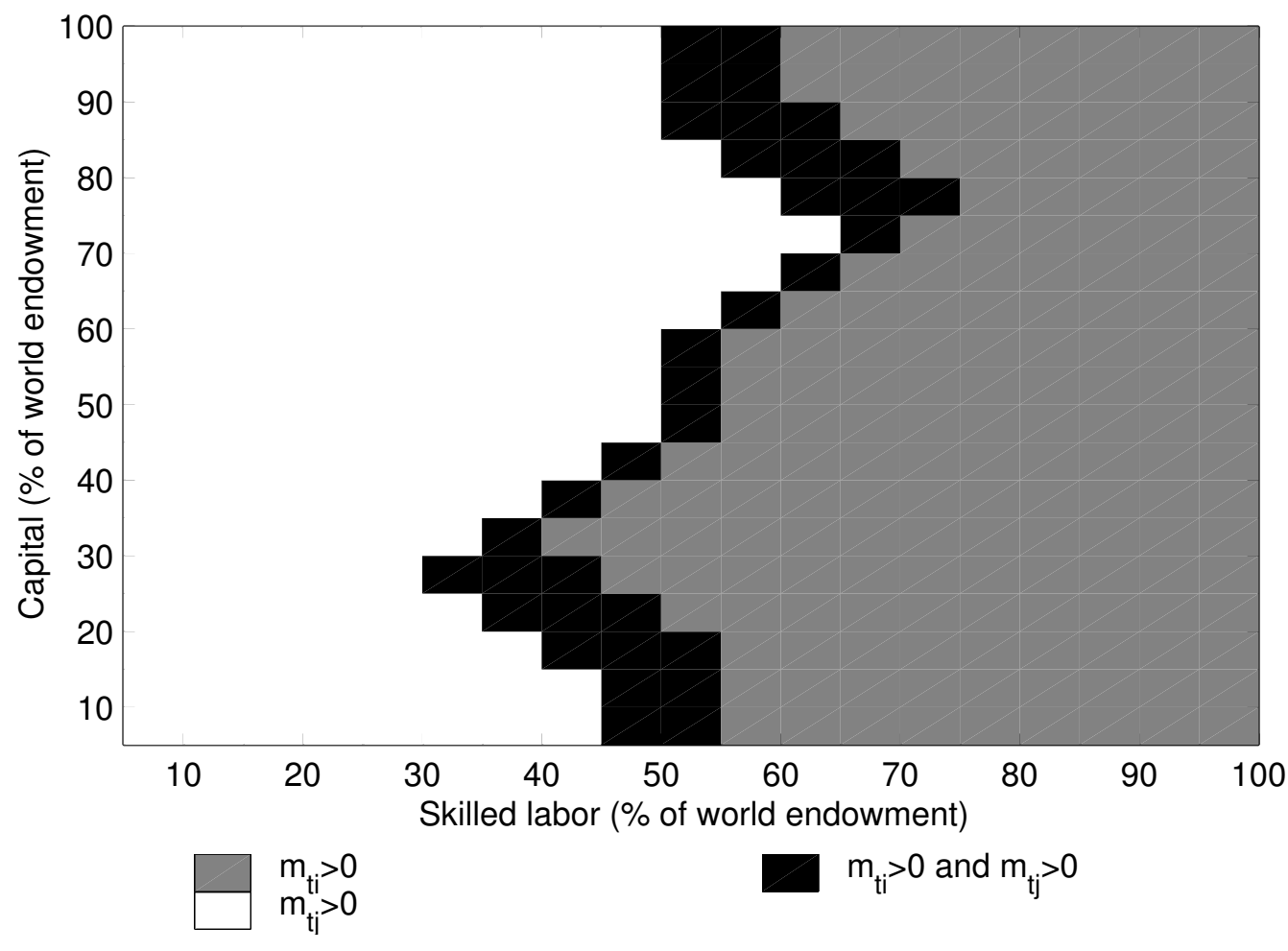

Figure 1: MNEs in the transport sector; Identical factor intensity assumptions; $L_{i}=50 \%$ of world endowment; Importer takes care of transport services.

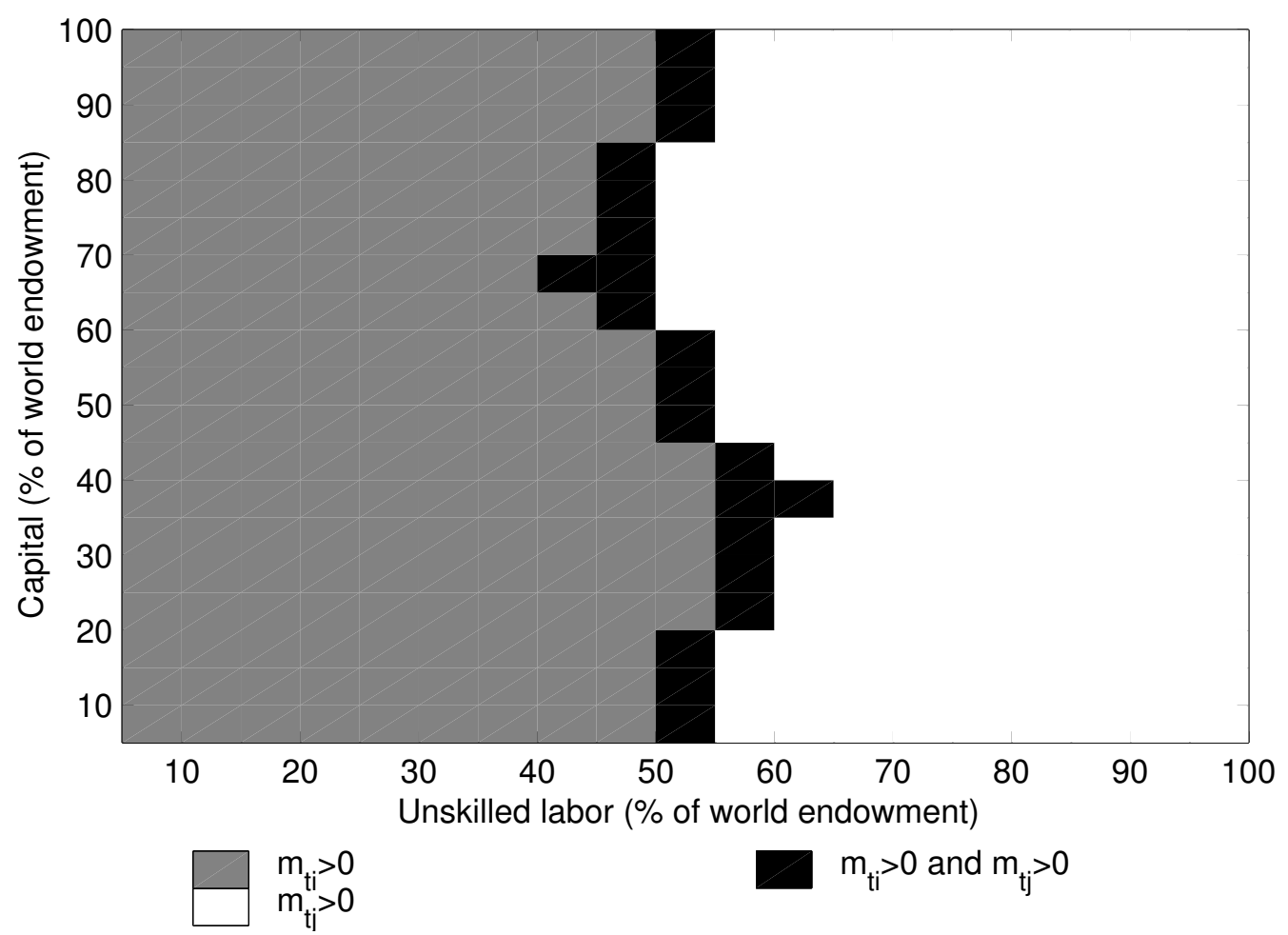

Figure 2: MNEs in the transport sector; Identical factor intensity assumptions; $S_{i}=50 \%$ of world endowment; Importer takes care of transport services. 


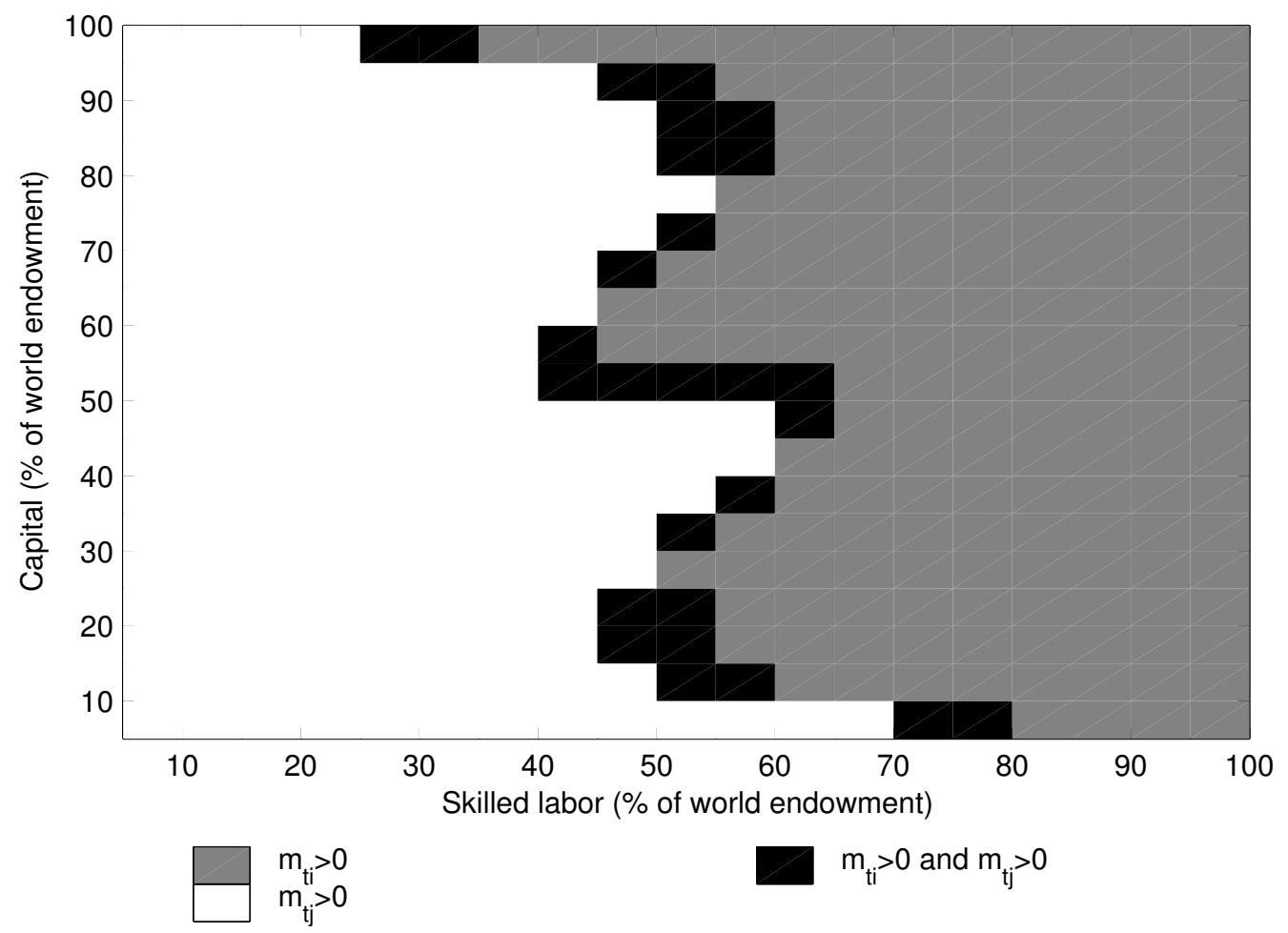

Figure 3: MNEs in the transport sector; $X$ is agriculture; $L_{i}=50 \%$ of world endowment; Exporter takes care of transport services.

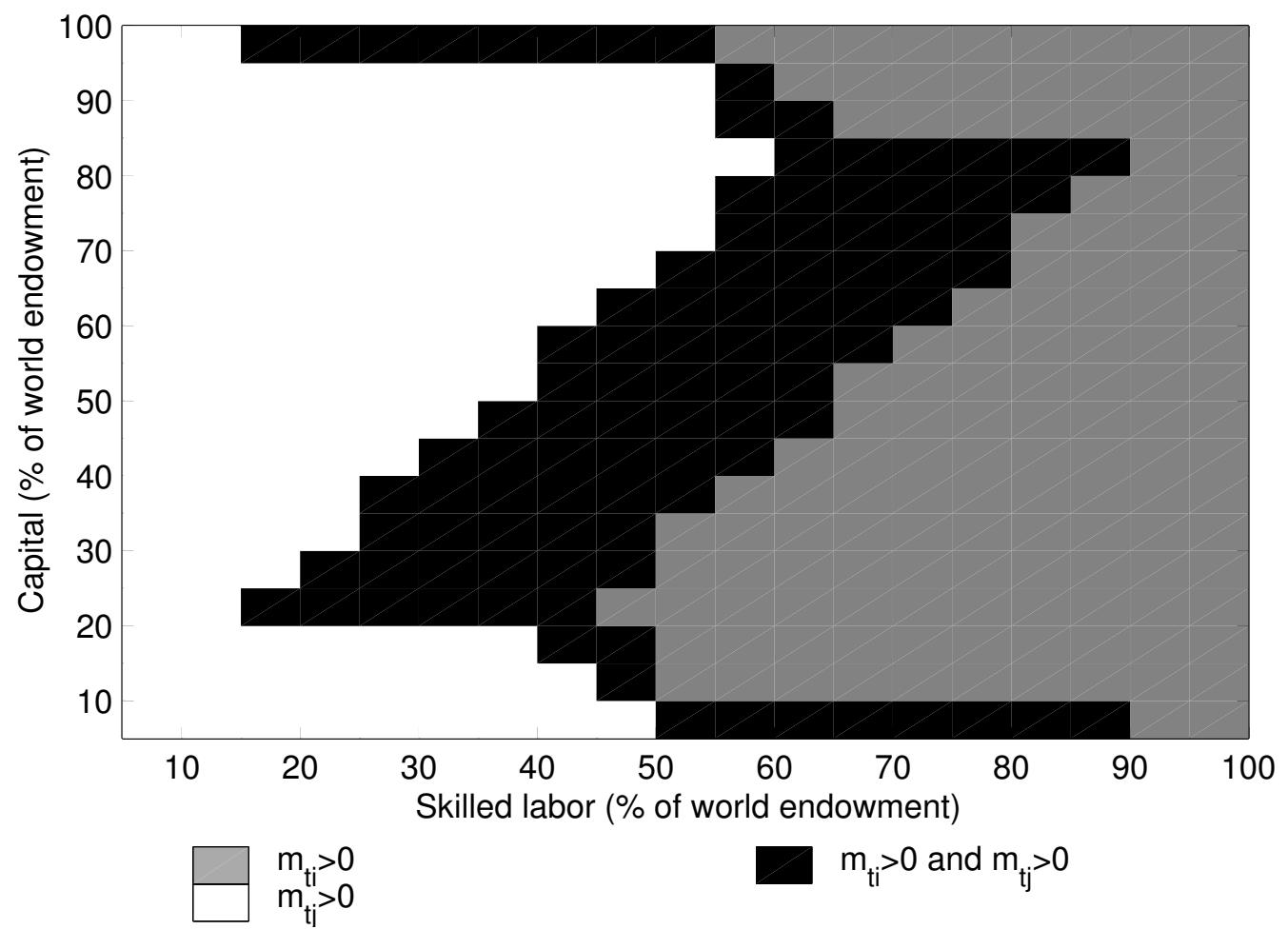

Figure 4: MNEs in the transport sector; $X$ is agriculture; $L_{i}=50 \%$ of world endowment; Importer takes care of transport services. 


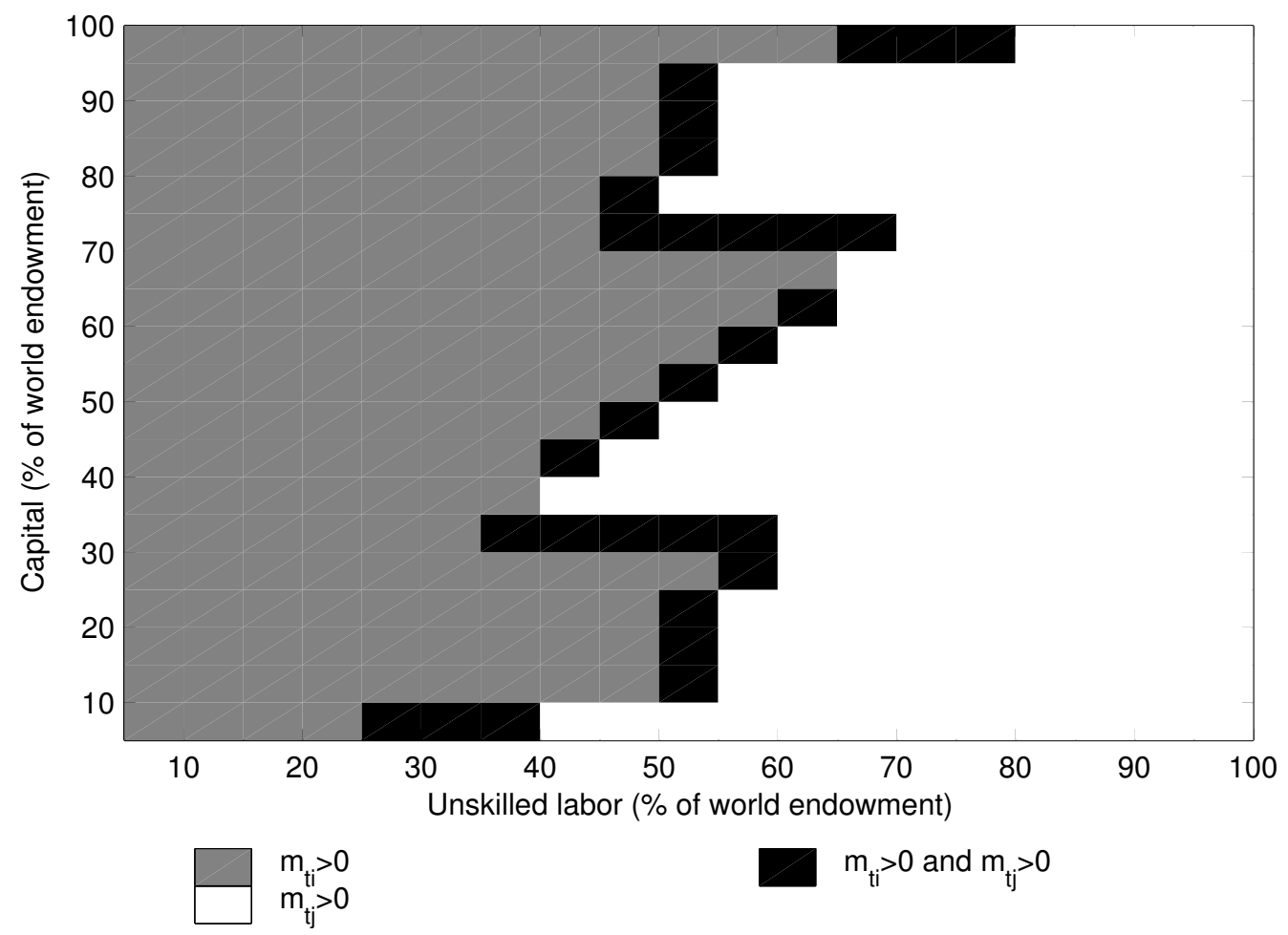

Figure 5: MNEs in the transport sector; $X$ is agriculture; $S_{i}=50 \%$ of world endowment; Exporter takes care of transport services.

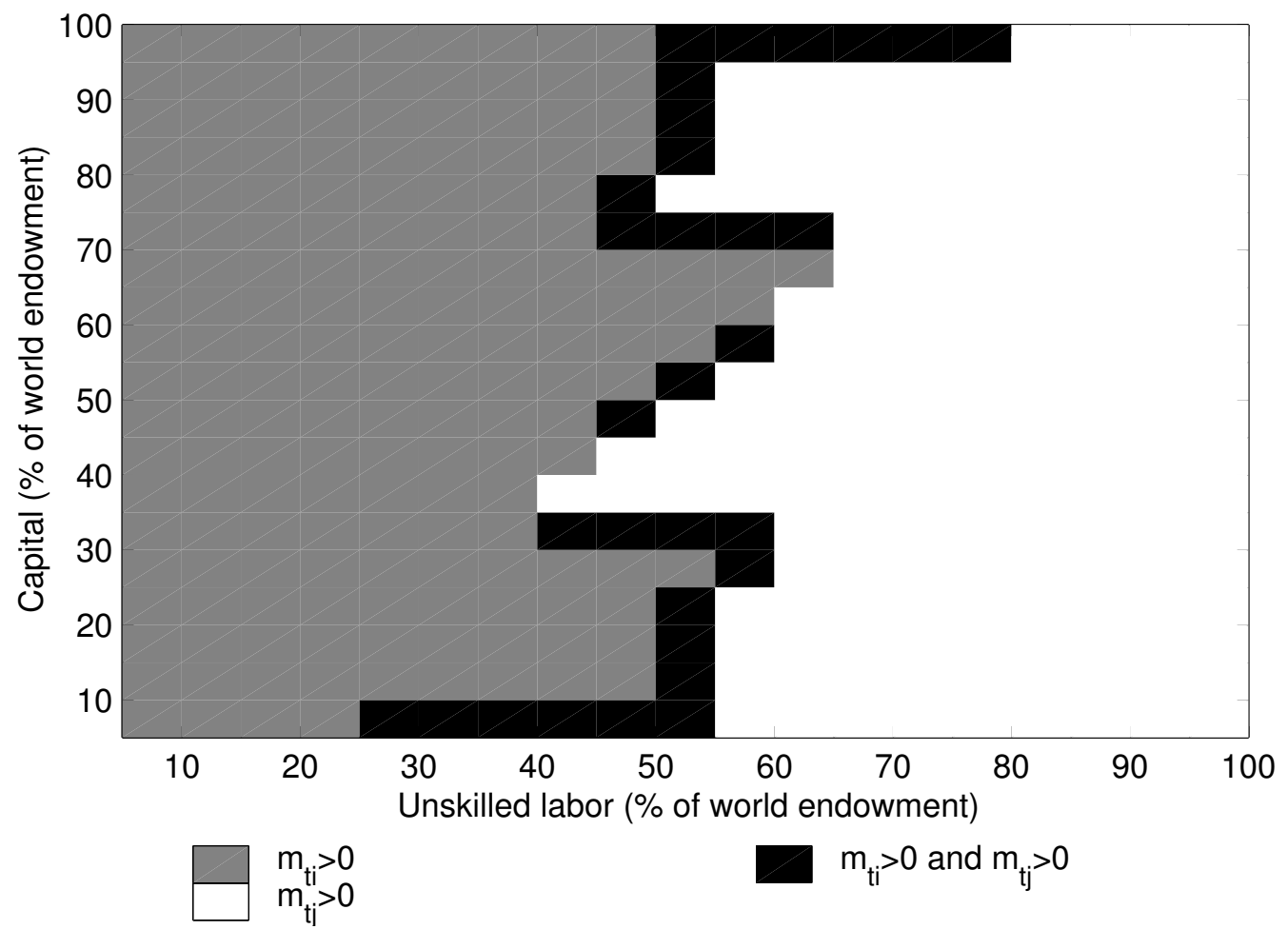

Figure 6: MNEs in the transport sector; $X$ is agriculture; $S_{i}=50 \%$ of world endowment; Importer takes care of transport services. 


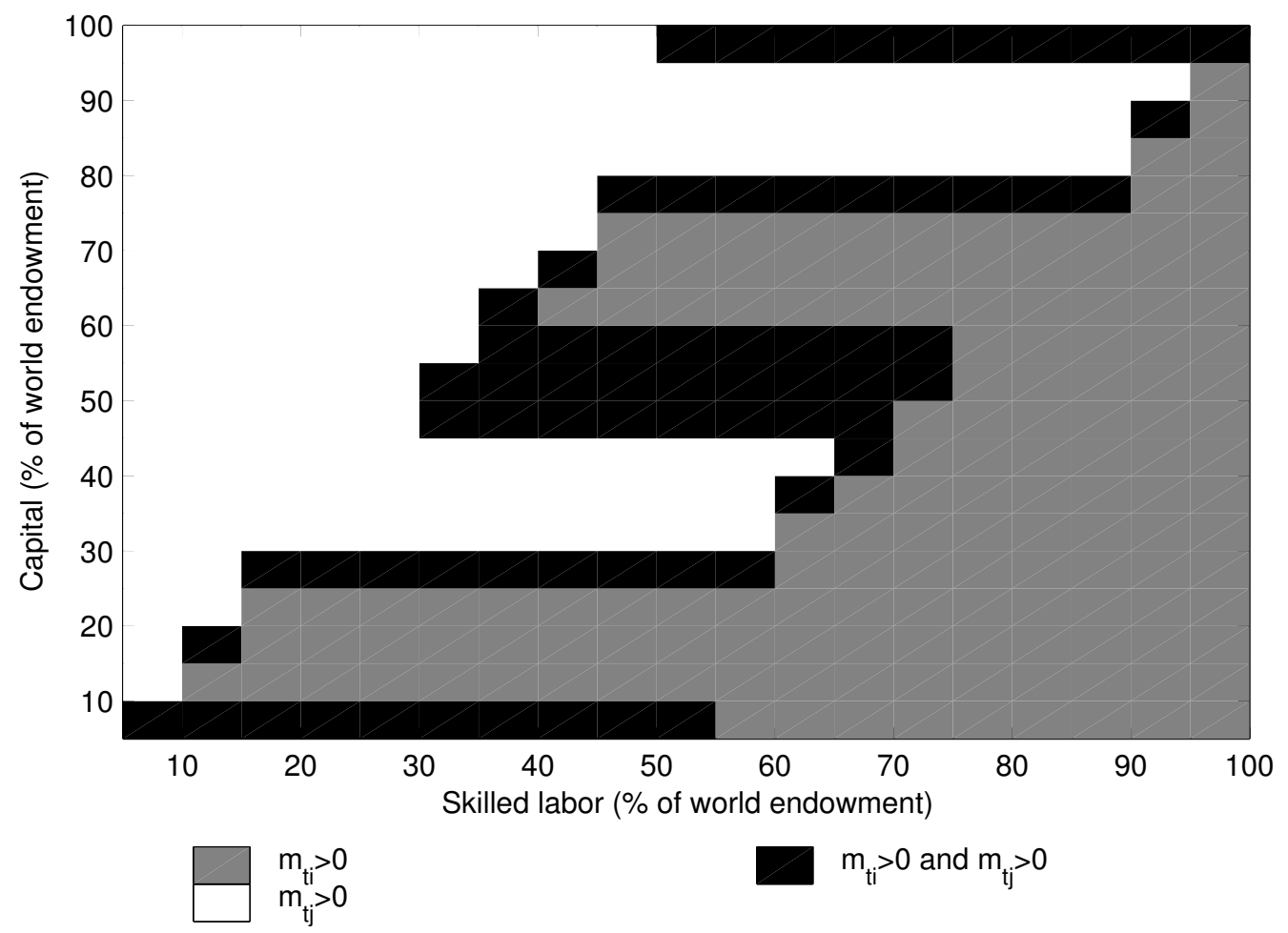

Figure 7: MNEs in the transport sector; $X$ is natural resources; $L_{i}=50 \%$ of world endowment; Exporter takes care of transport services.

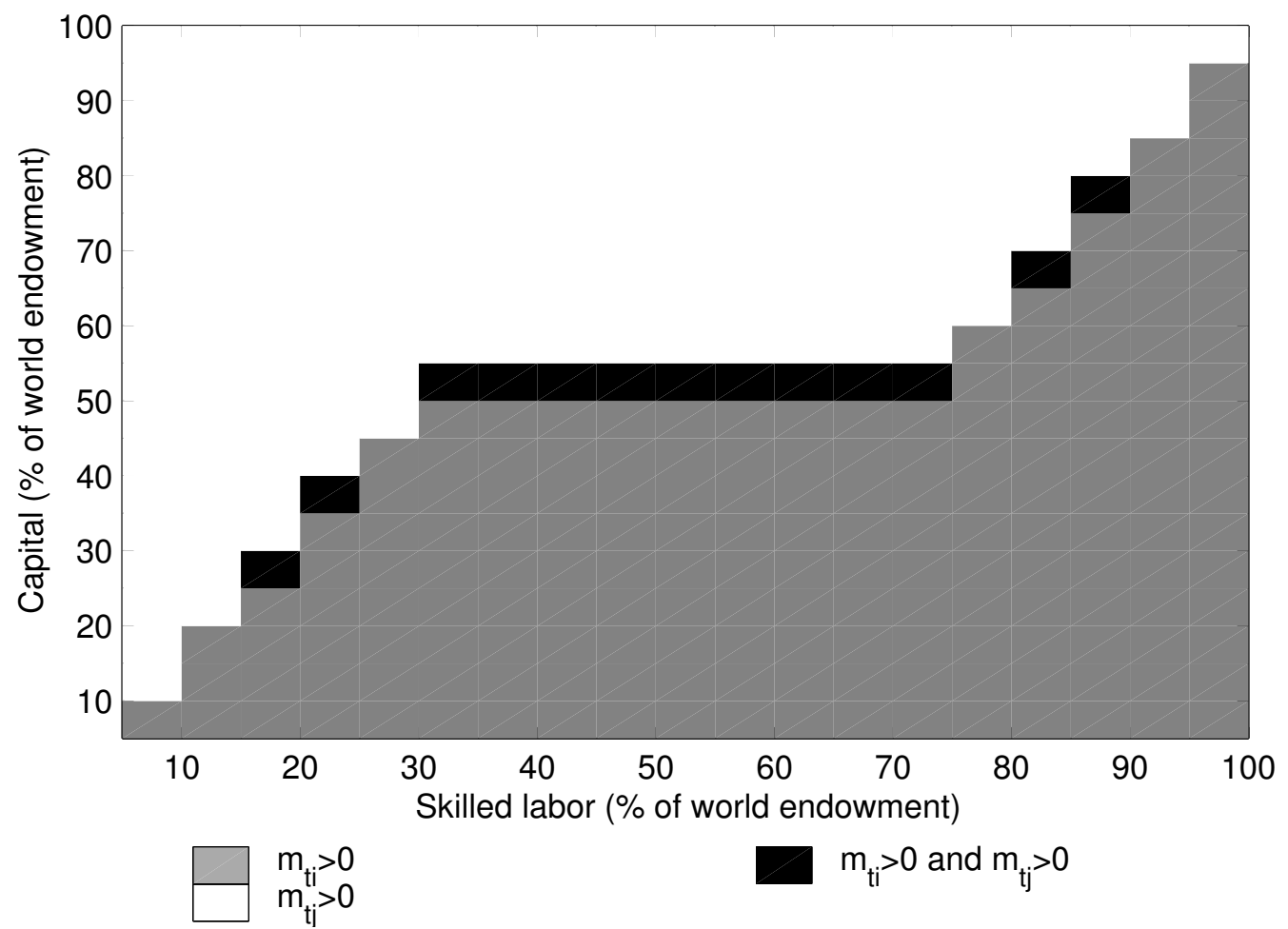

Figure 8: MNEs in the transport sector; $X$ is natural resources; $L_{i}=50 \%$ of world endowment; Importer takes care of transport services. 


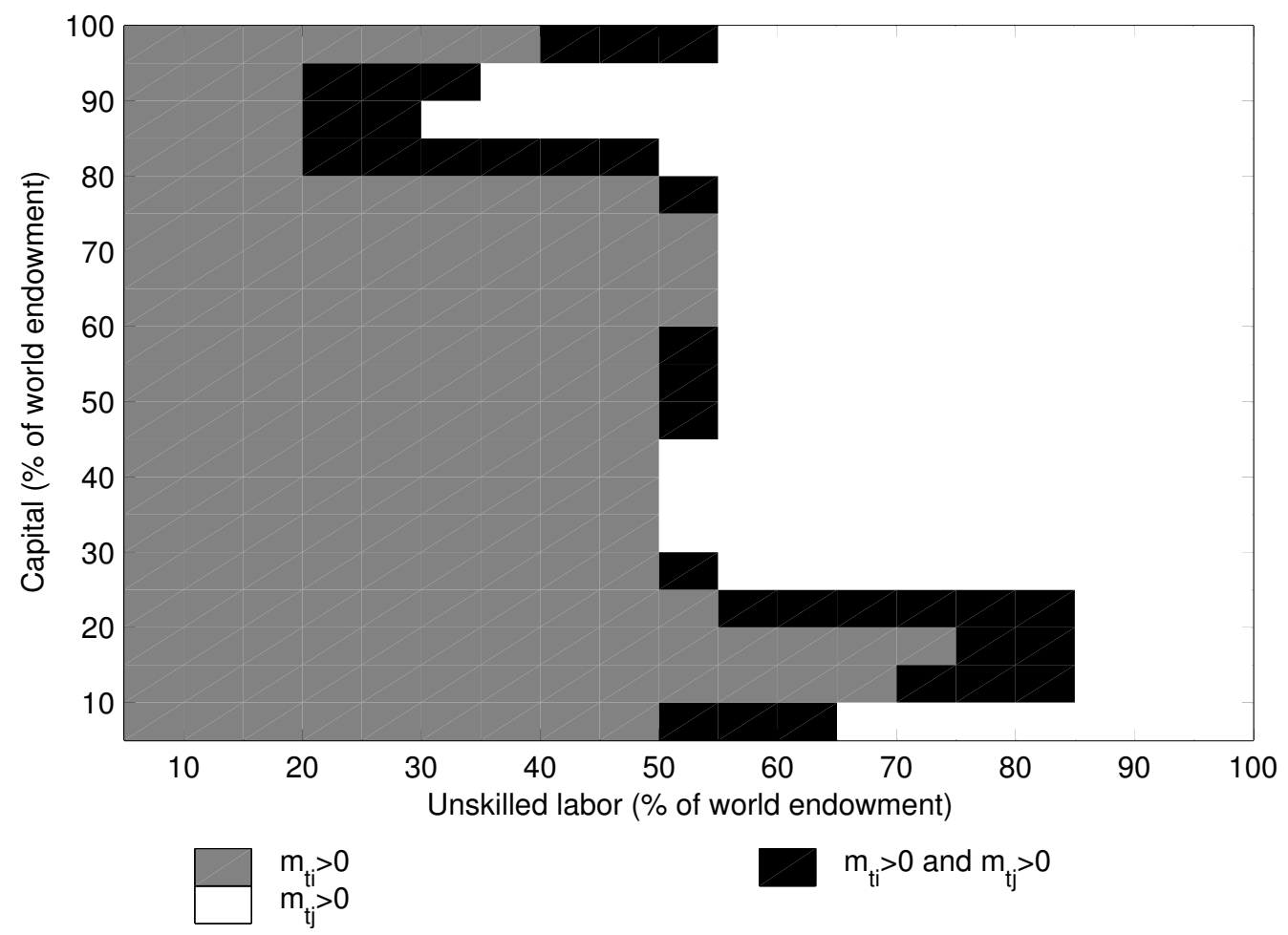

Figure 9: MNEs in the transport sector; $X$ is natural resources; $S_{i}=50 \%$ of world endowment; Exporter takes care of transport services.

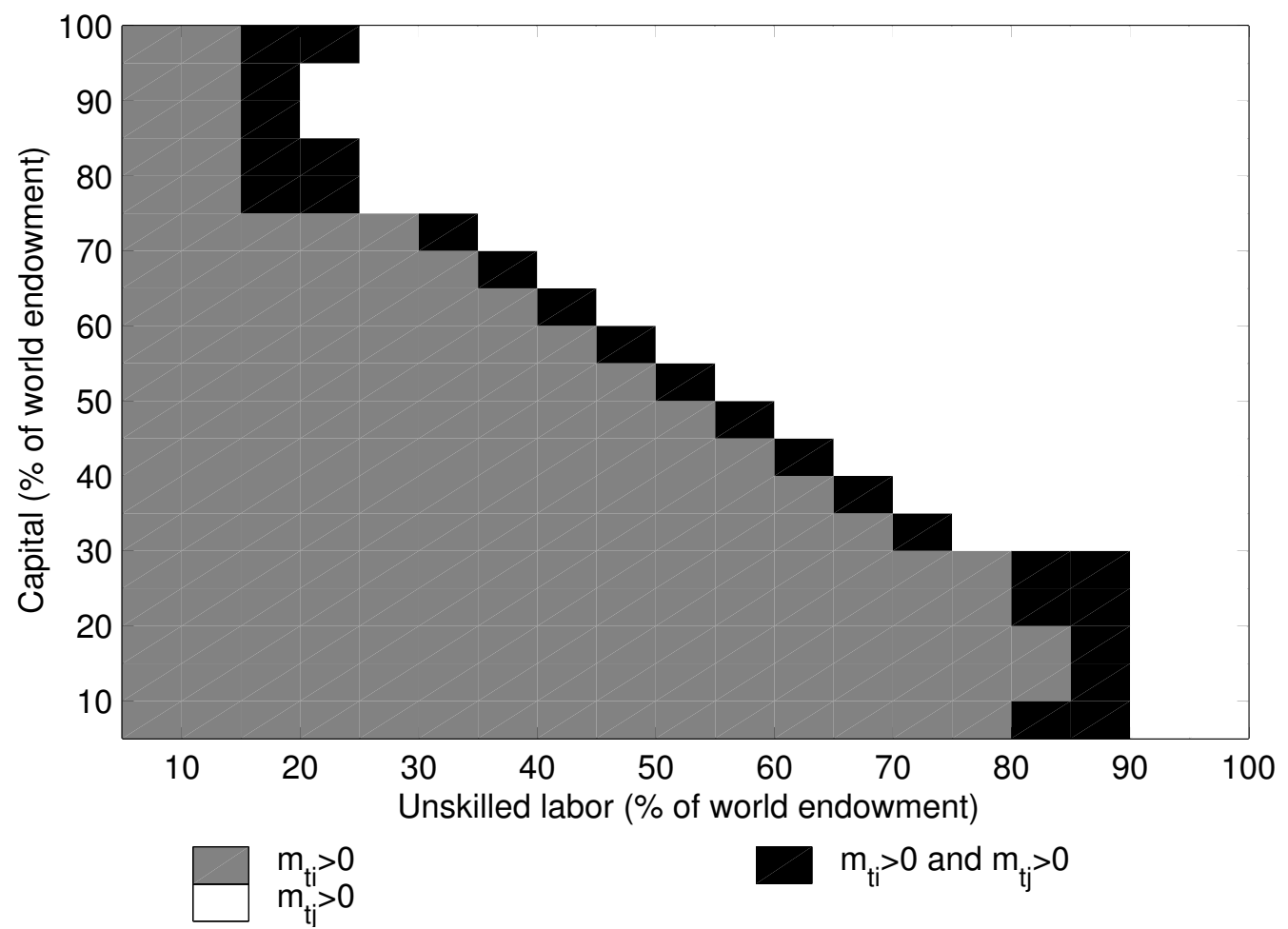

Figure 10: MNEs in the transport sector; $X$ is natural resources; $S_{i}=50 \%$ of world endowment; Importer takes care of transport services. 


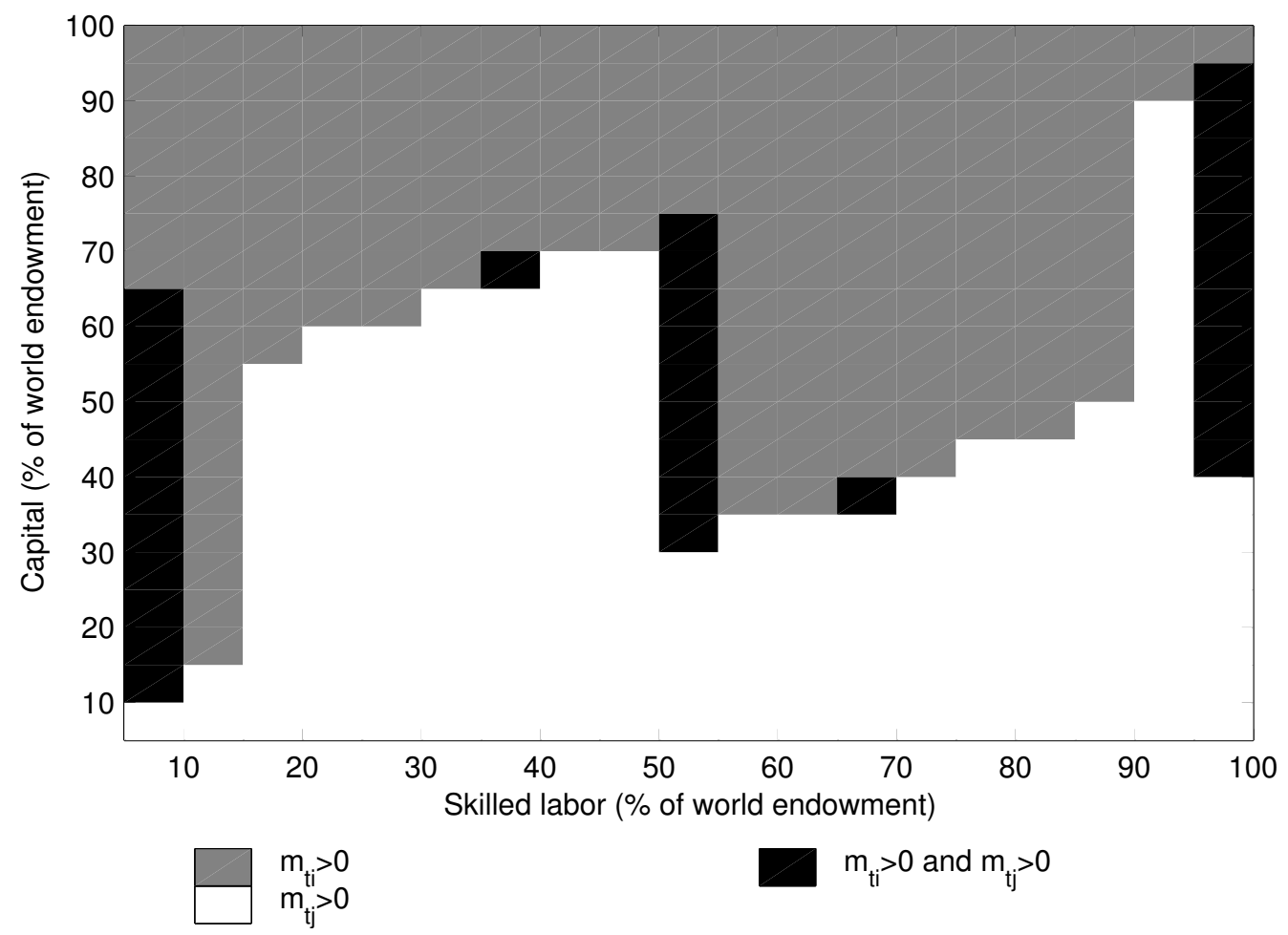

Figure 11: MNEs in the transport sector; $X$ is high-tech industry; $L_{i}=50 \%$ of world endowment; Exporter takes care of transport services.

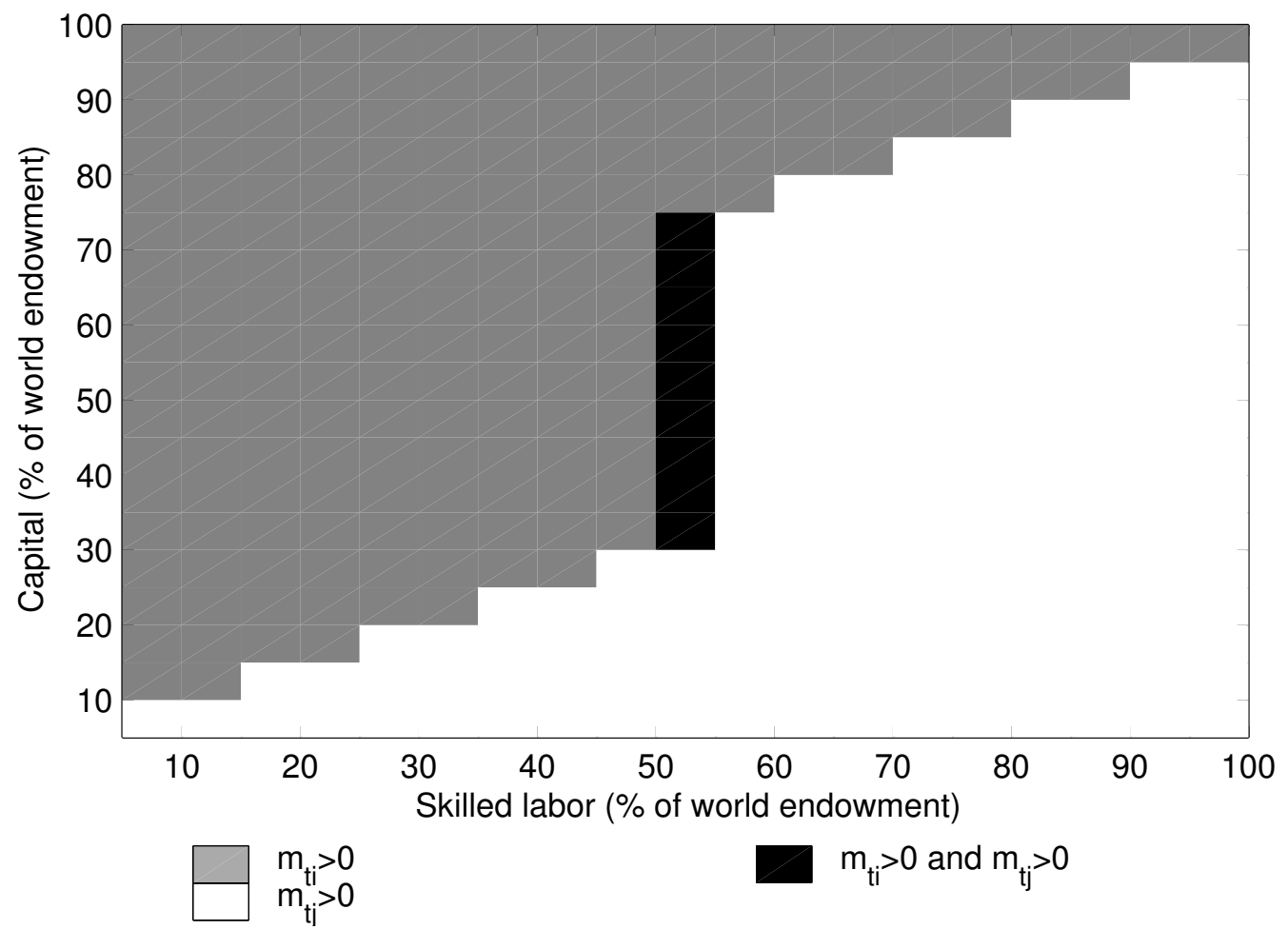

Figure 12: MNEs in the transport sector; $X$ is high-tech industry; $L_{i}=50 \%$ of world endowment; Importer takes care of transport services. 


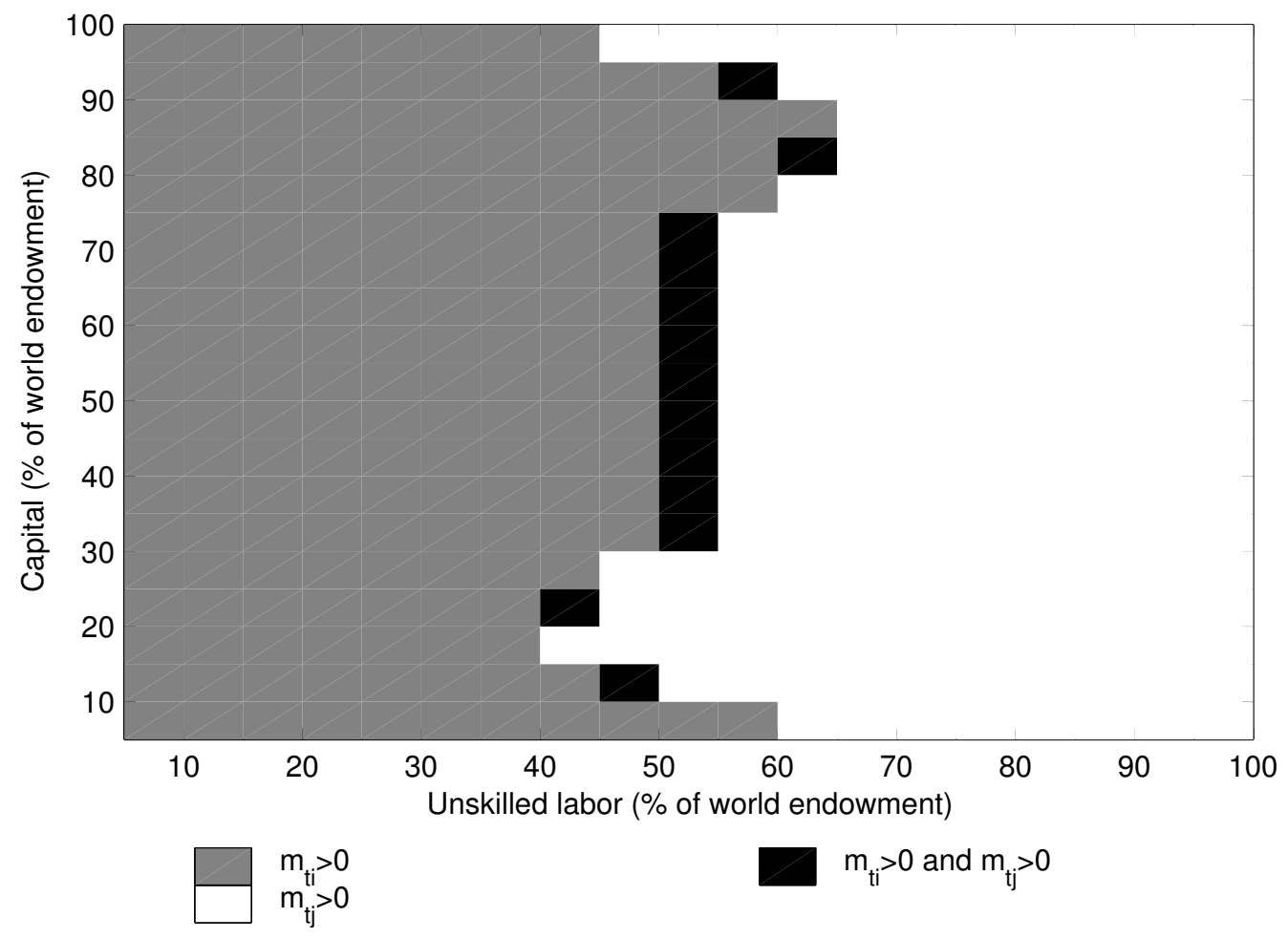

Figure 13: MNEs in the transport sector; $X$ is high-tech industry; $S_{i}=50 \%$ of world endowment; Exporter takes care of transport services.

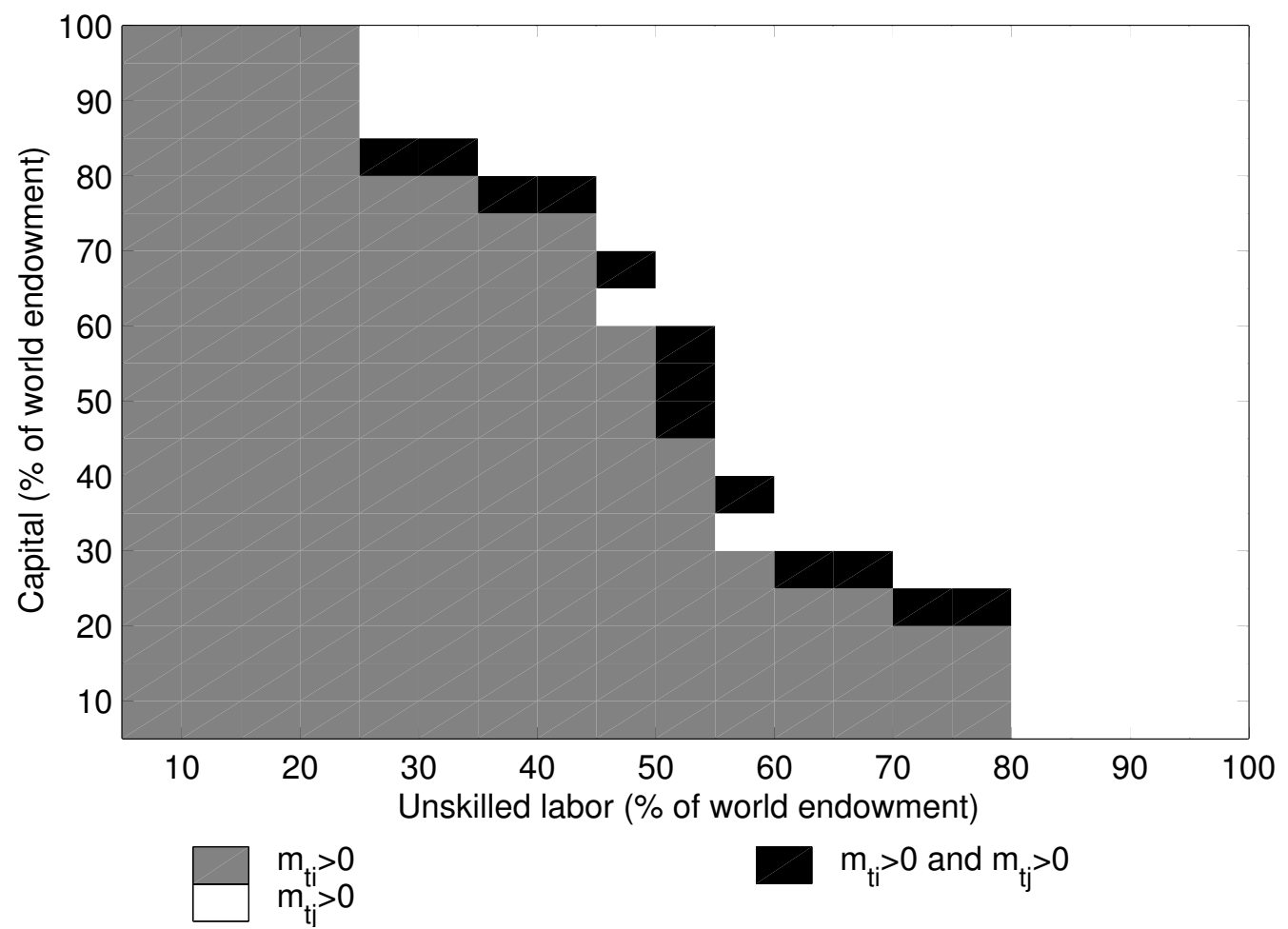

Figure 14: MNEs in the transport sector; $X$ is high-tech industry; $S_{i}=50 \%$ of world endowment; Importer takes care of transport services. 


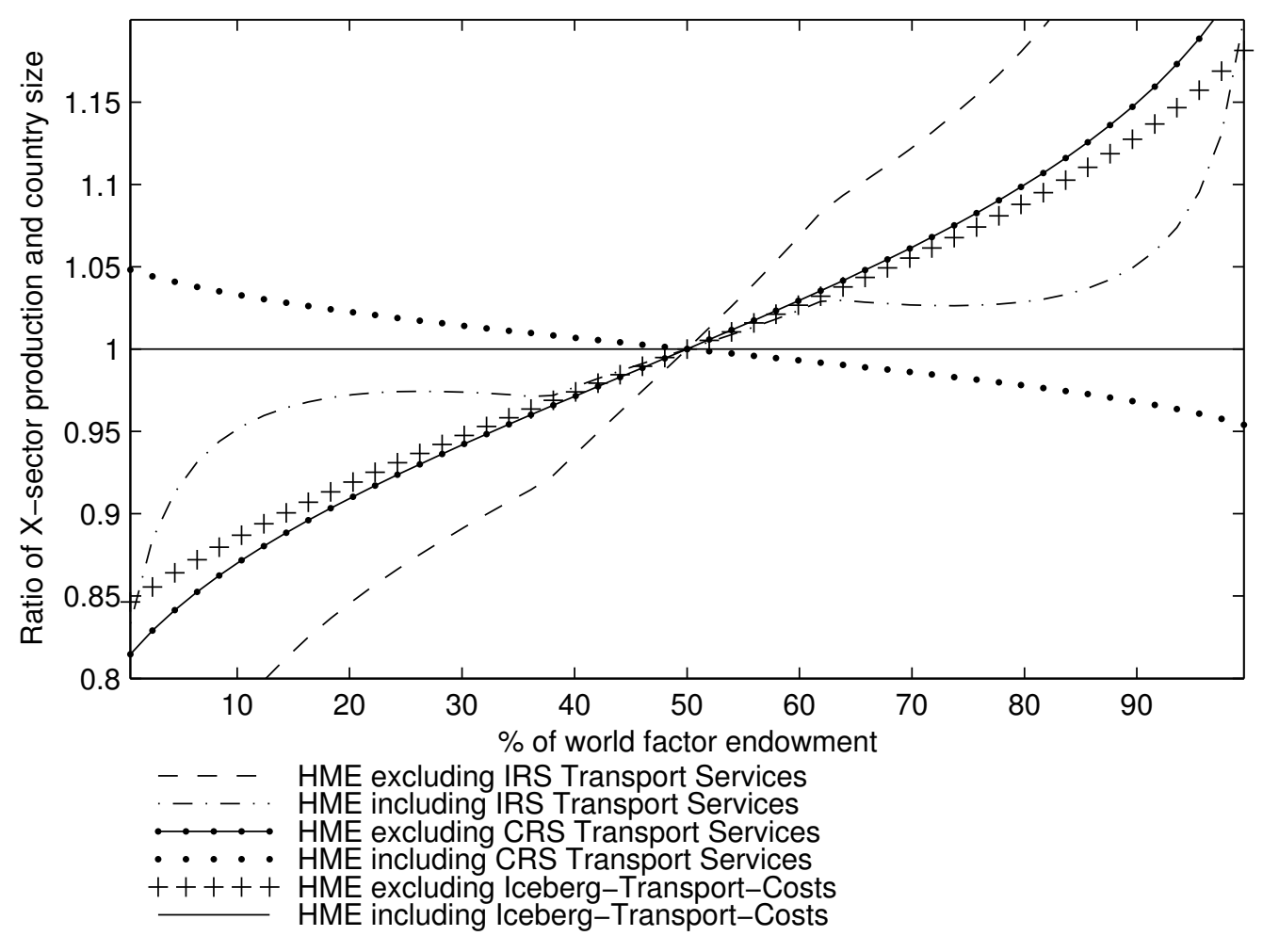

Figure 15: The Home-Market-Effect, Importer takes care of transport services.

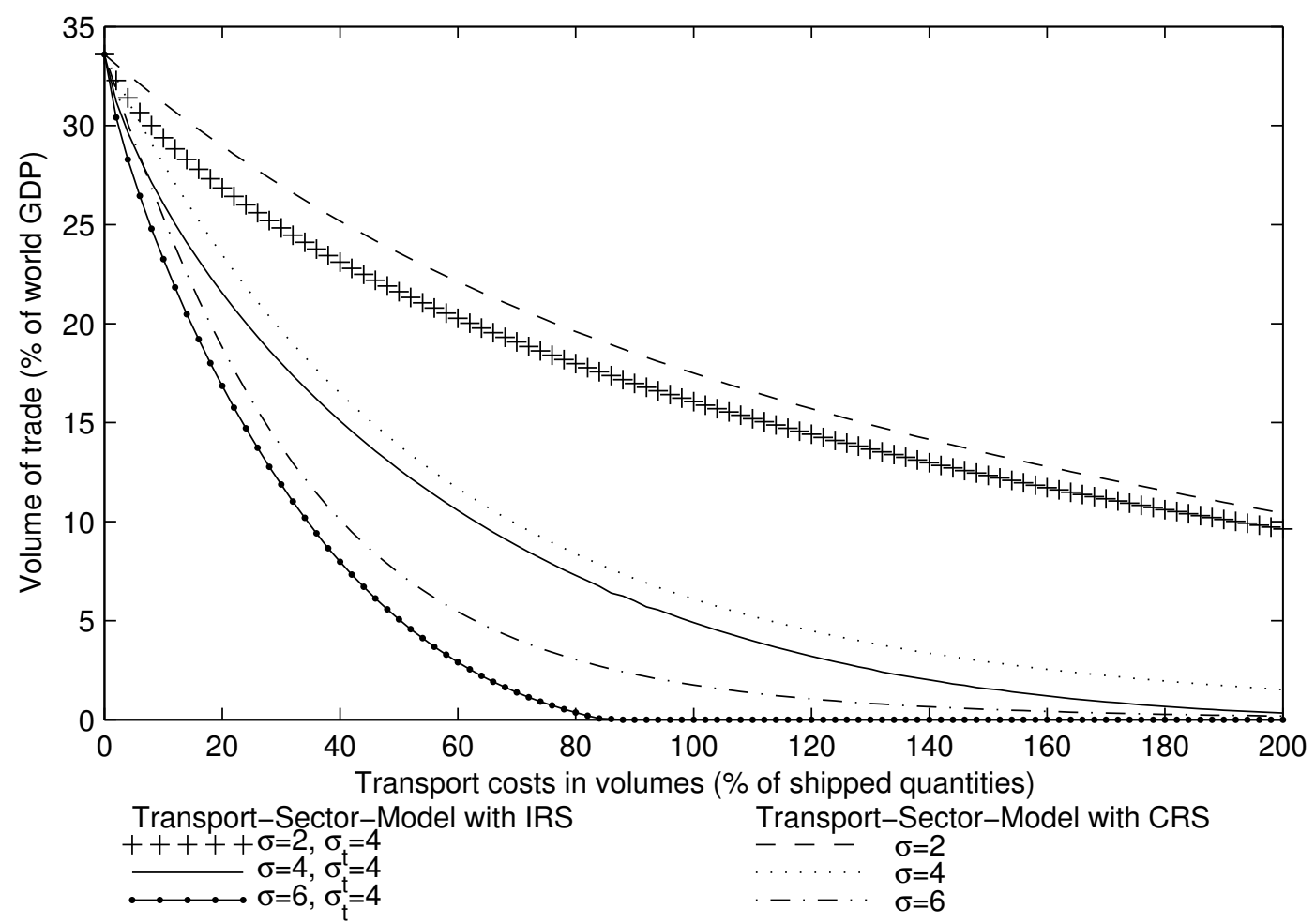

Figure 16: Volume of trade as \% of world GDP if $\sigma$ changes, $i$ has $70 \%$ of world endowments and importer takes care of transport services. 


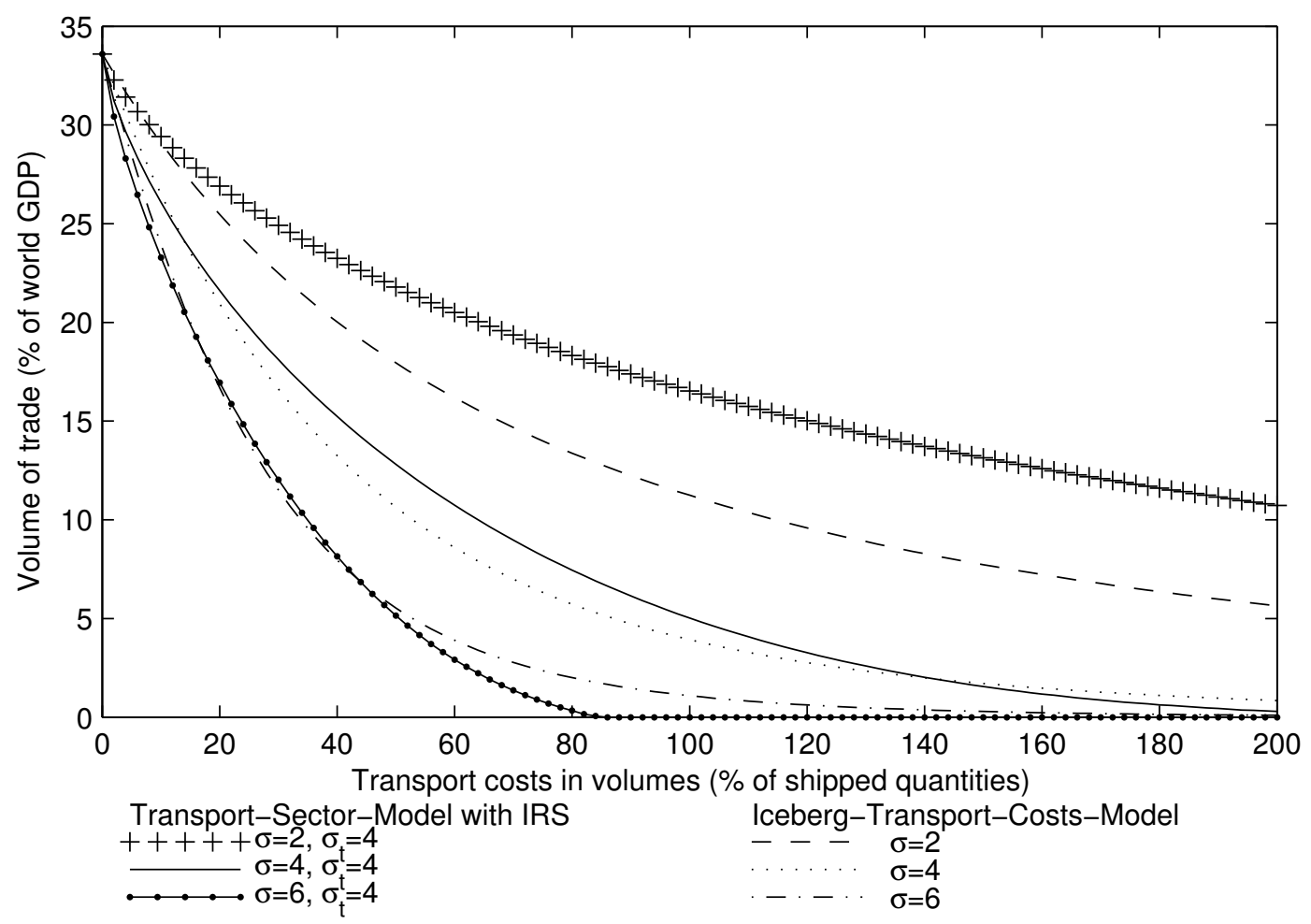

Figure 17: Volume of trade as \% of world GDP if $\sigma$ changes, $i$ has $70 \%$ of world endowments and exporter takes care of transport services.

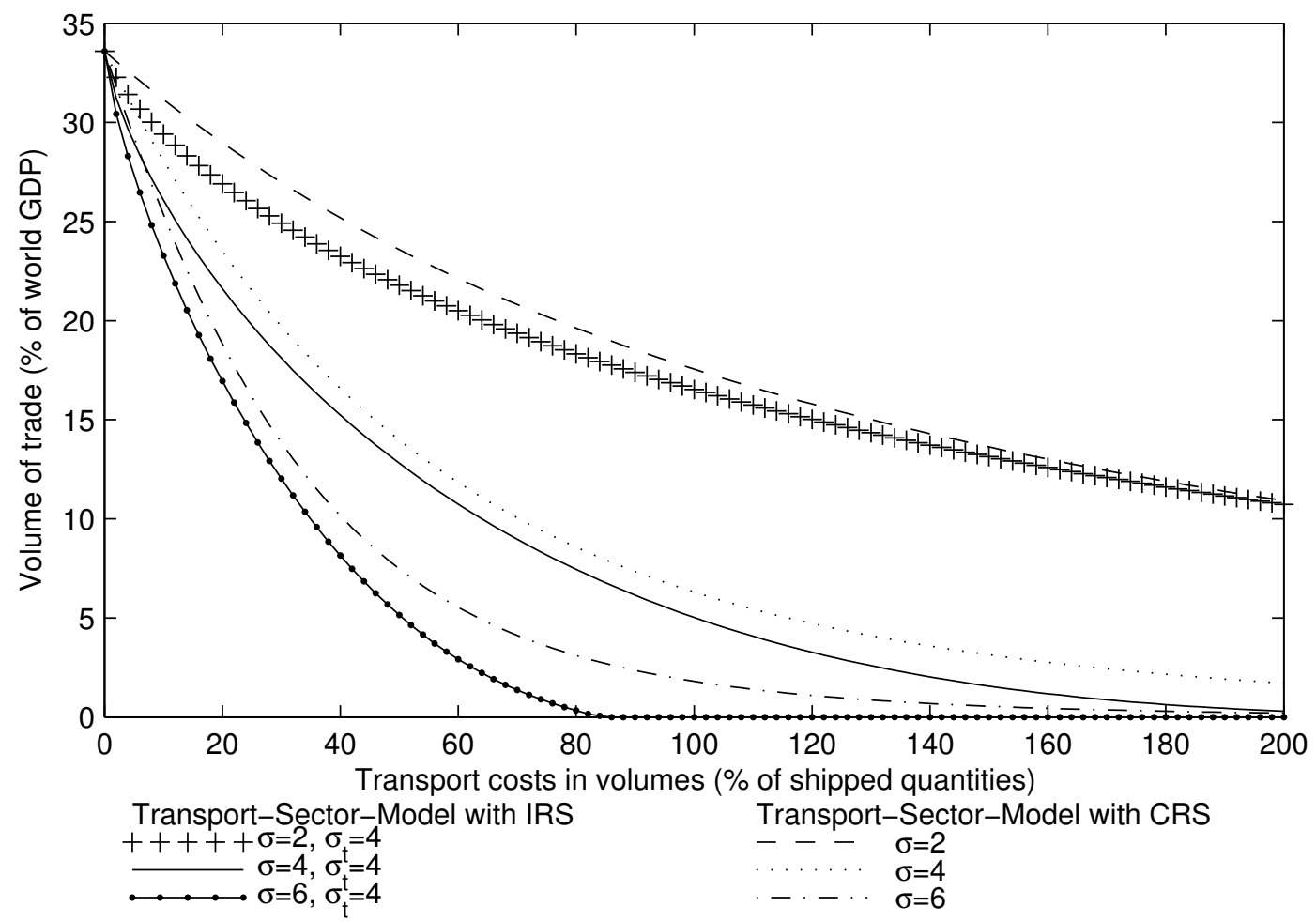

Figure 18: Volume of trade as $\%$ of world GDP if $\sigma$ changes, $i$ has $70 \%$ of world endowments and exporter takes care of transport services. 


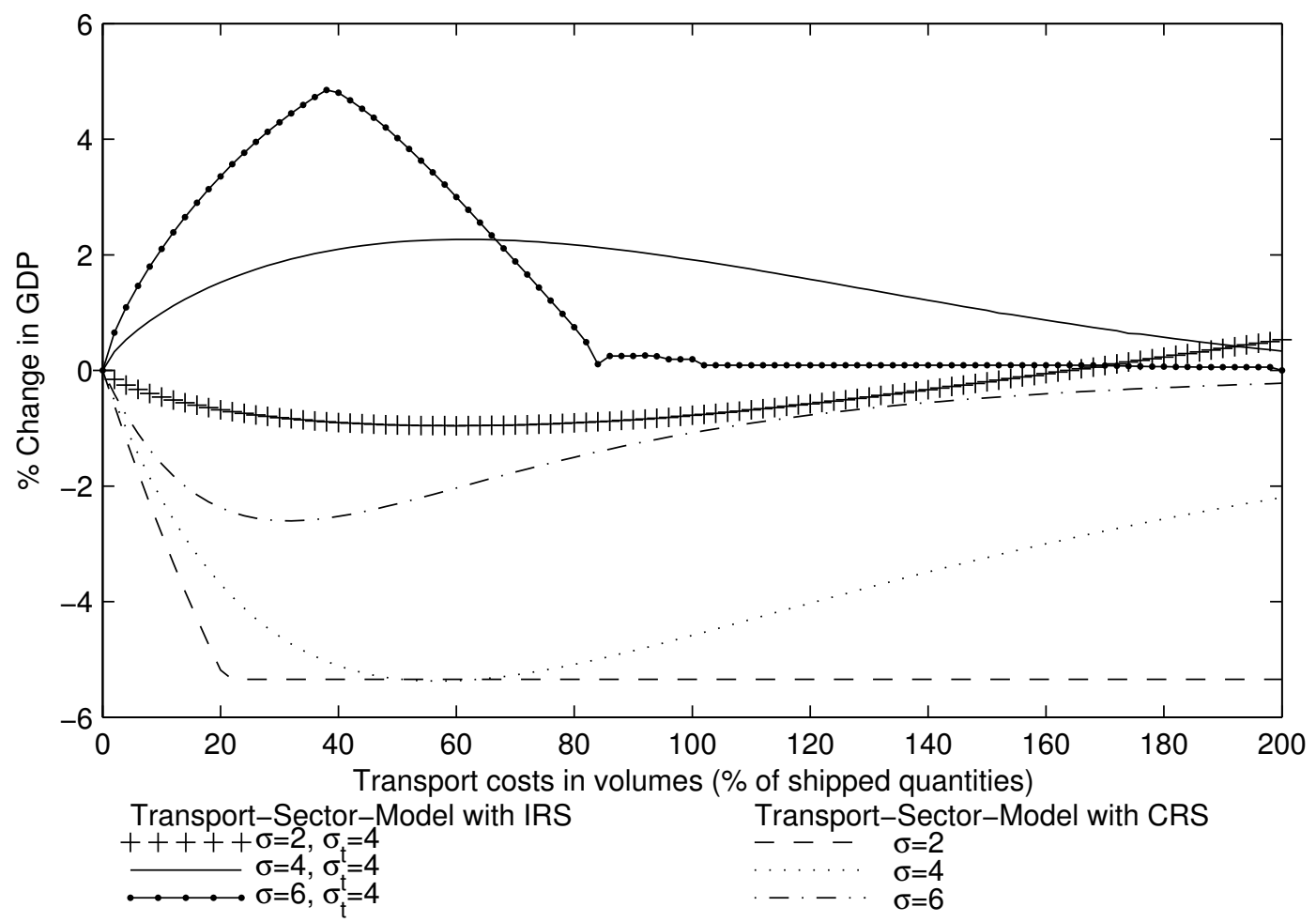

Figure 19: GDP changes in $\%$ if $\sigma$ changes, $i$ has $30 \%$ of world endowments and importer takes care of transport services.

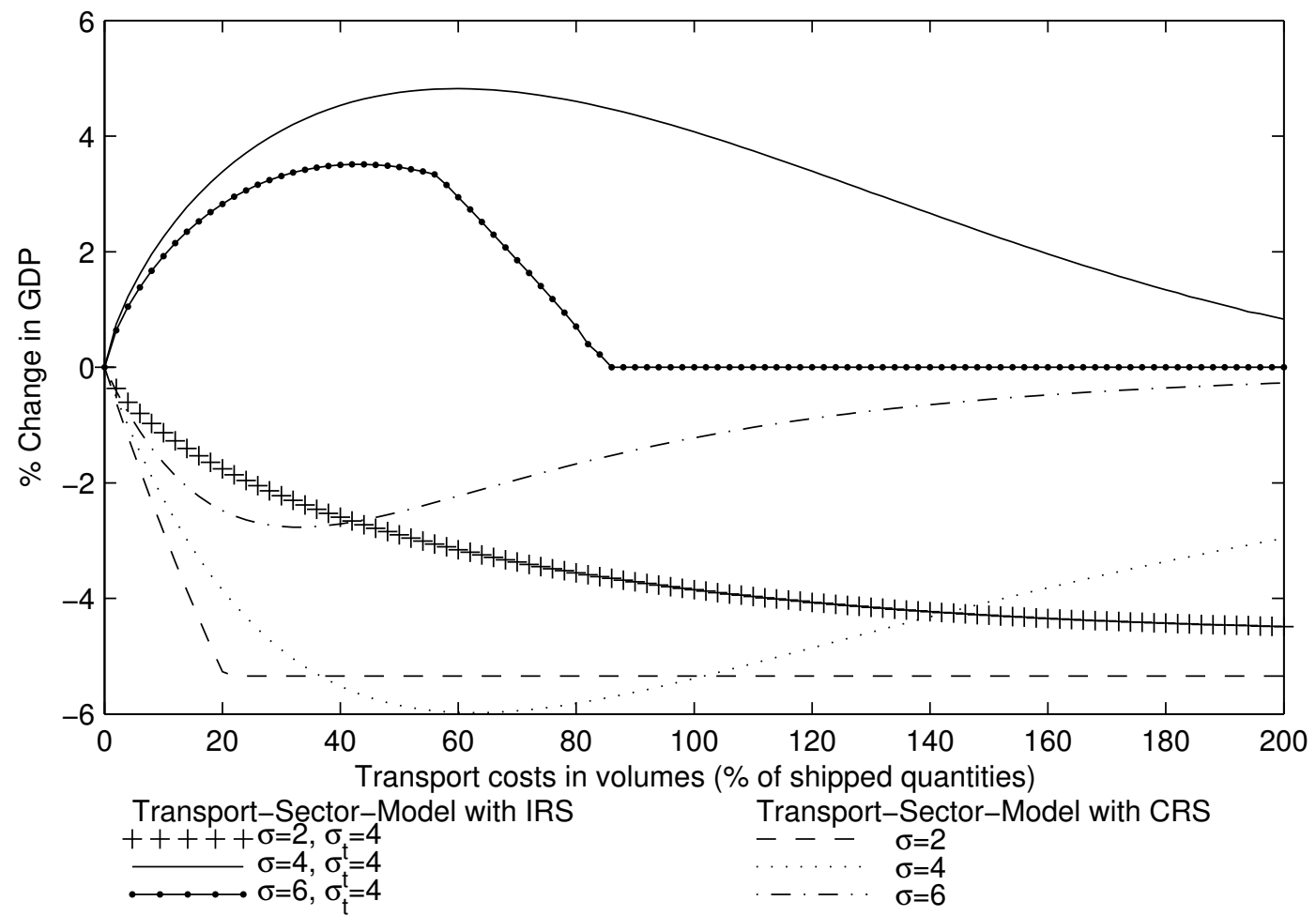

Figure 20: GDP changes in $\%$ if $\sigma$ changes, $i$ has $30 \%$ of world endowments and exporter takes care of transport services. 


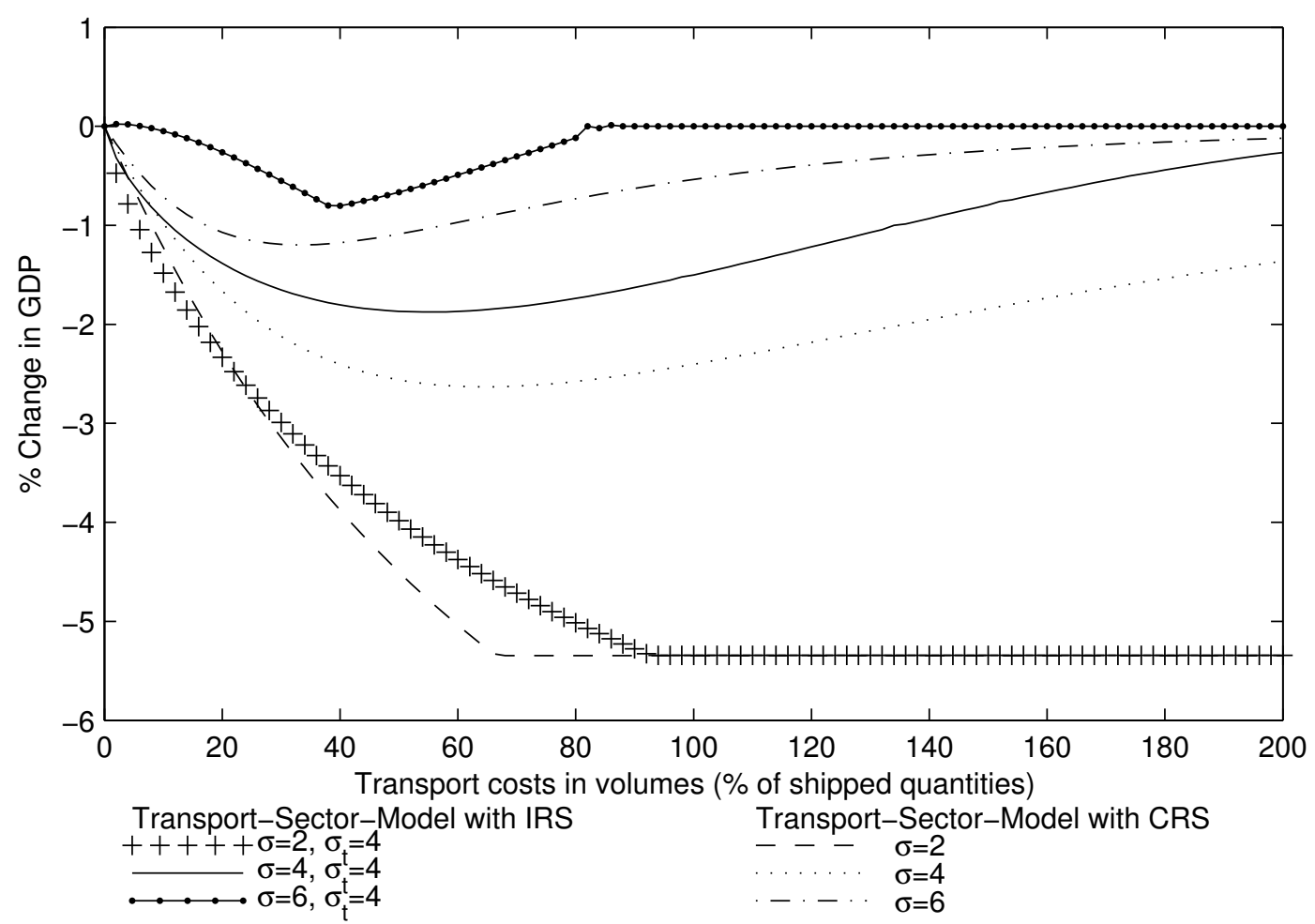

Figure 21: GDP changes in $\%$ if $\sigma$ changes, $i$ has $70 \%$ of world endowments and importer takes care of transport services.

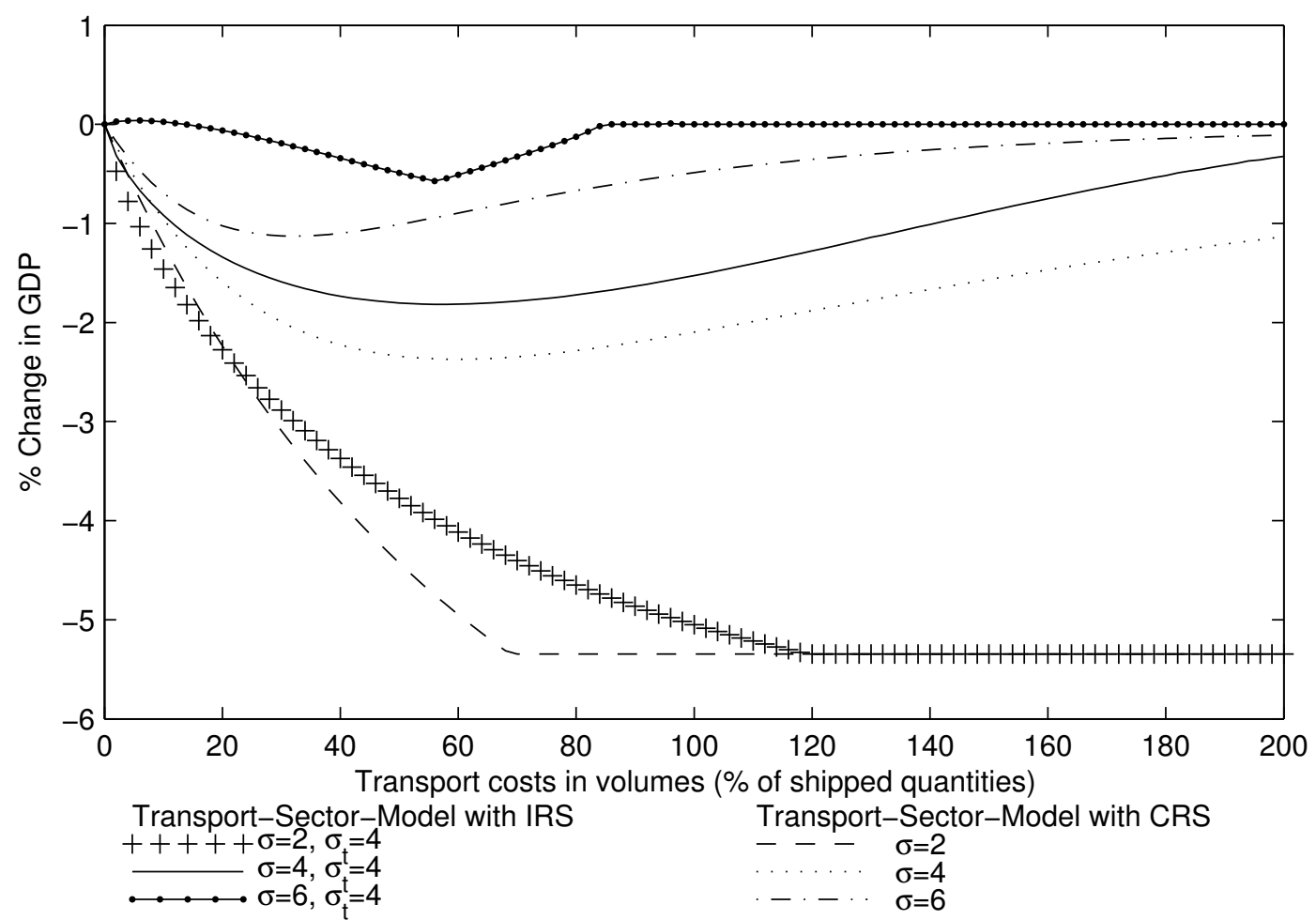

Figure 22: GDP changes in $\%$ if $\sigma$ changes, $i$ has $70 \%$ of world endowments and exporter takes care of transport services. 


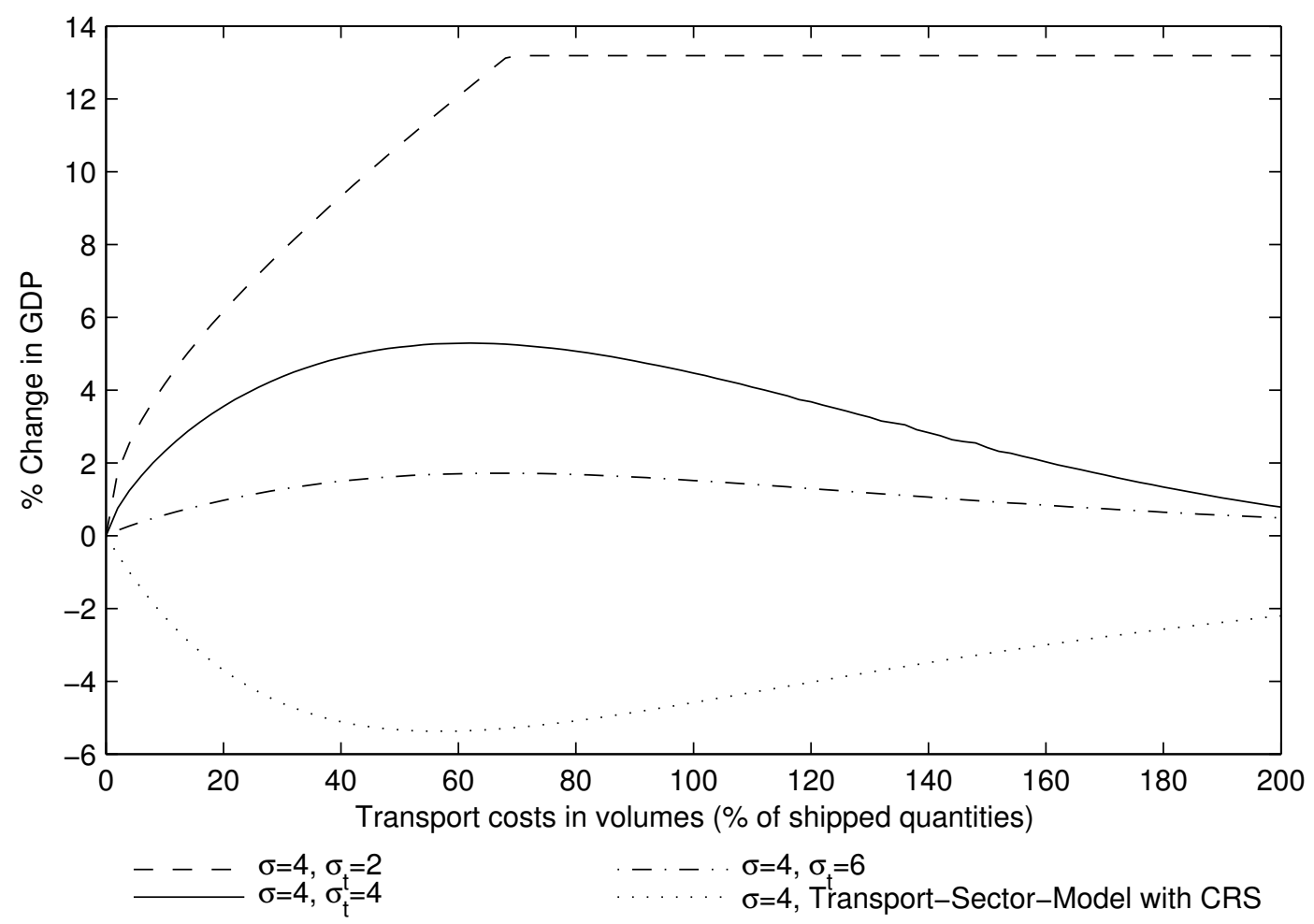

Figure 23: GDP changes in $\%$ if $\sigma_{t}$ changes, $i$ has 30\% of world endowments and importer takes care of transport services.

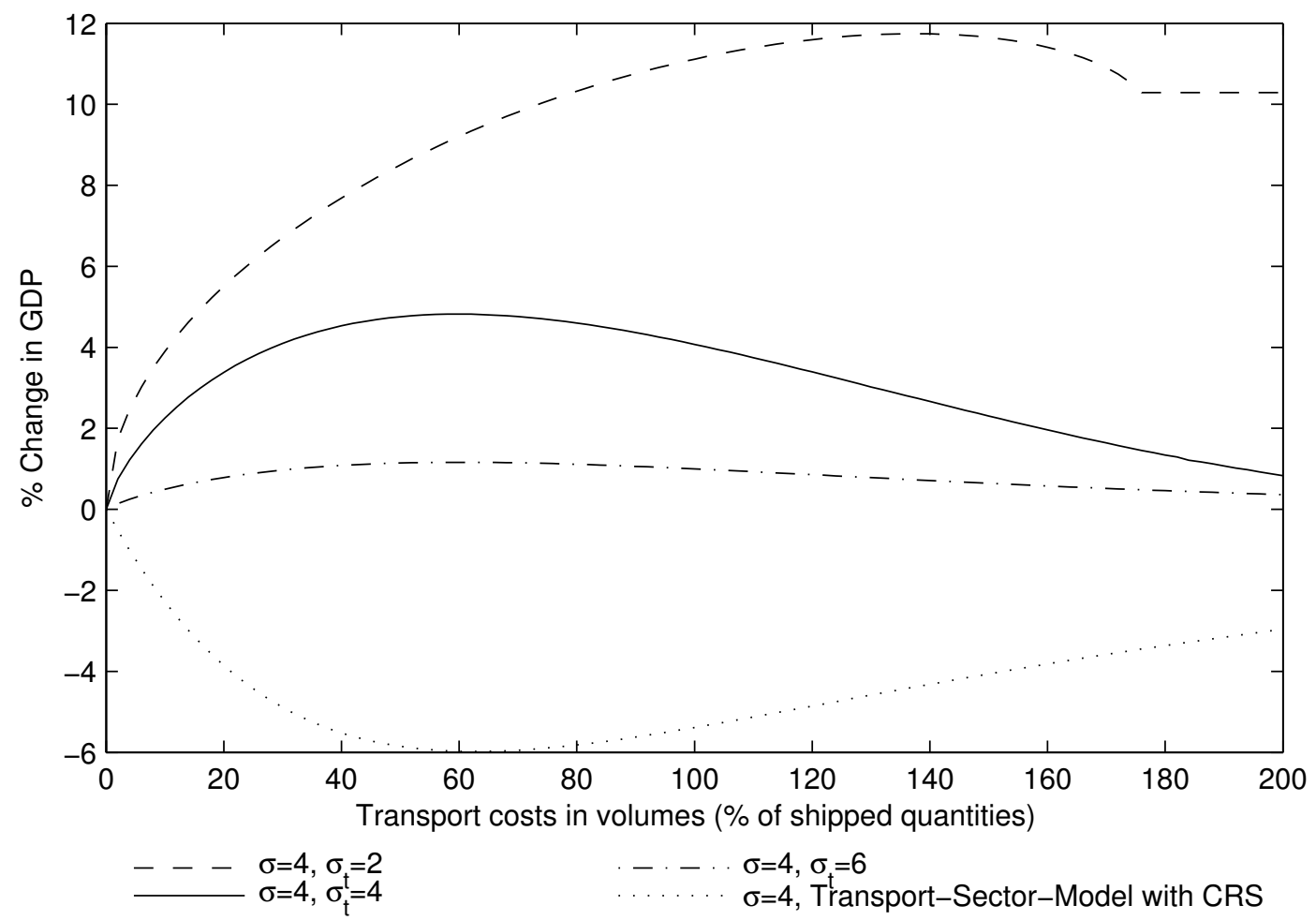

Figure 24: GDP changes in $\%$ if $\sigma_{t}$ changes, $i$ has 30\% of world endowments and exporter takes care of transport services. 


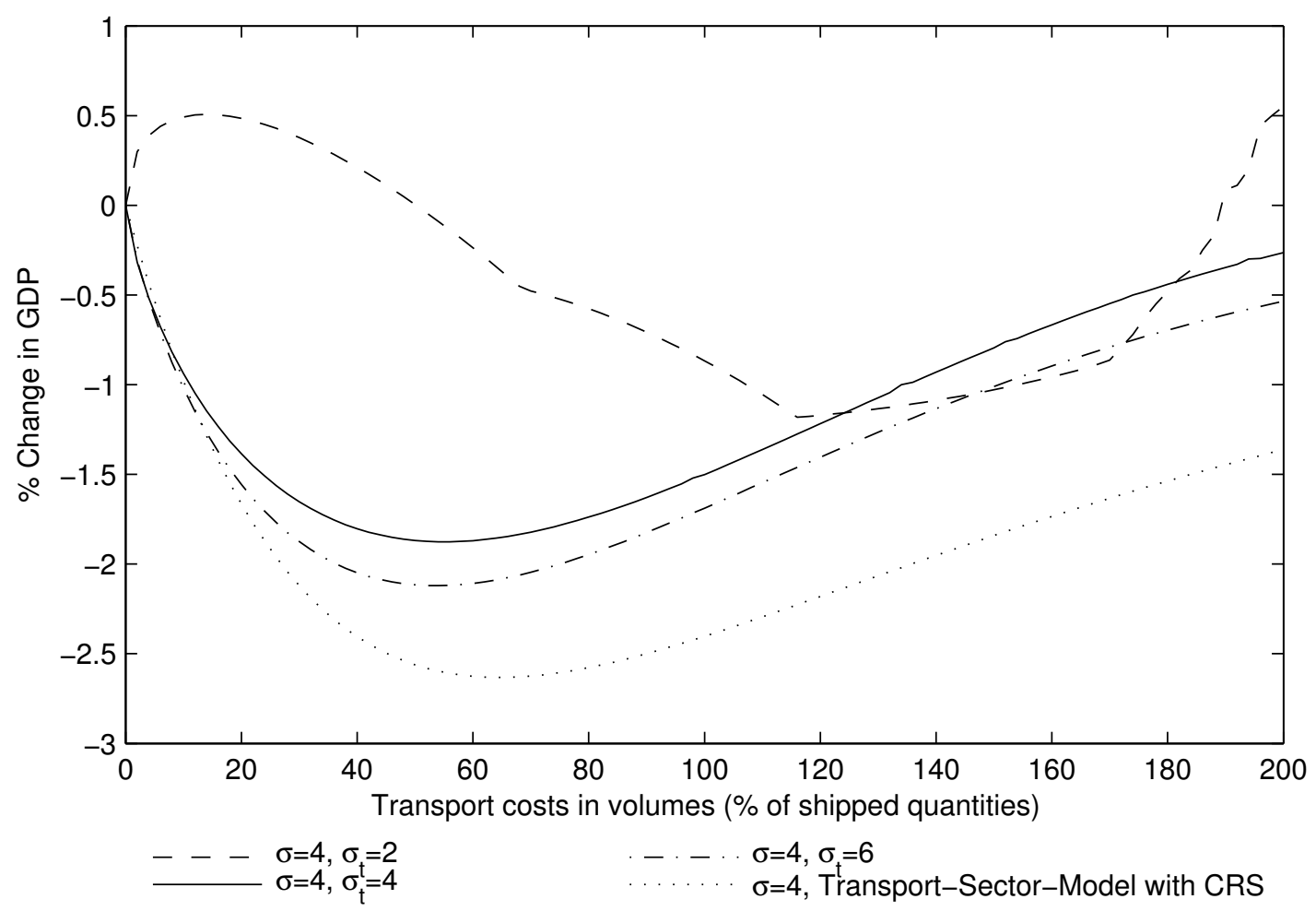

Figure 25: GDP changes in $\%$ if $\sigma_{t}$ changes, $i$ has $70 \%$ of world endowments and importer takes care of transport services.

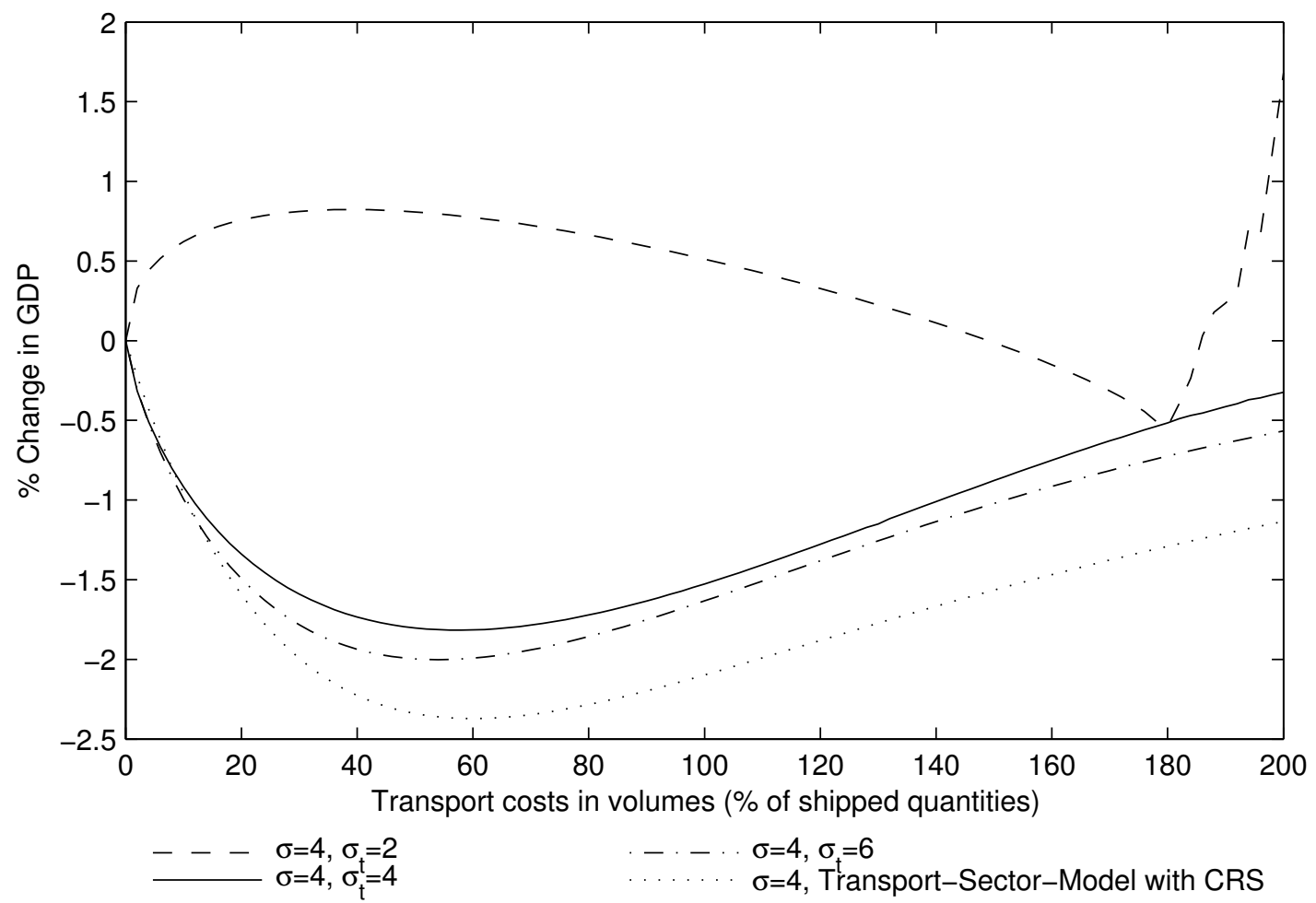

Figure 26: GDP changes in $\%$ if $\sigma_{t}$ changes, $i$ has $70 \%$ of world endowments and exporter takes care of transport services. 


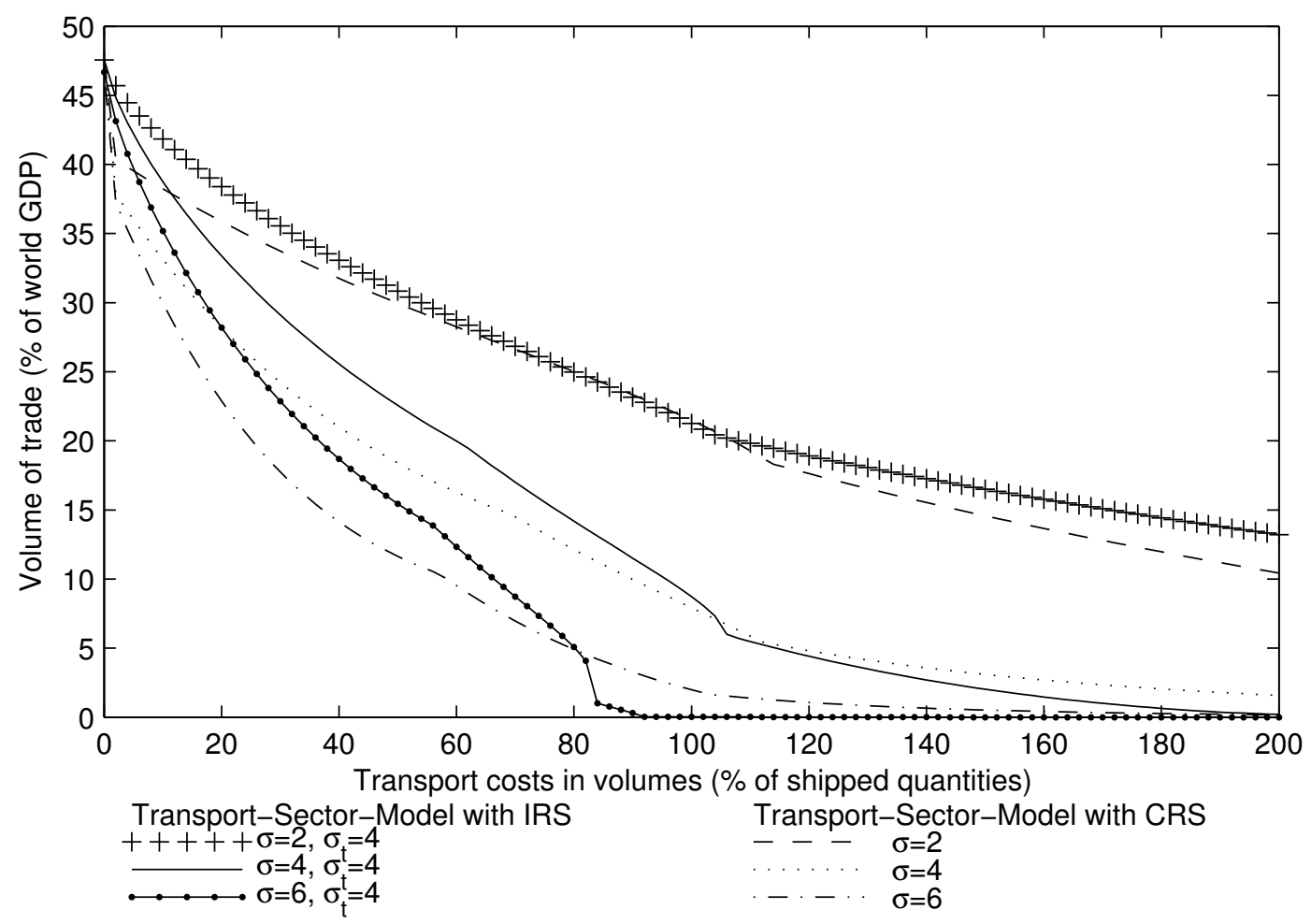

Figure 27: Volume of trade as \% of world GDP if $\sigma$ changes, $i$ has $70 \%$ of unskilled labor world endowment and importer takes care of transport services.

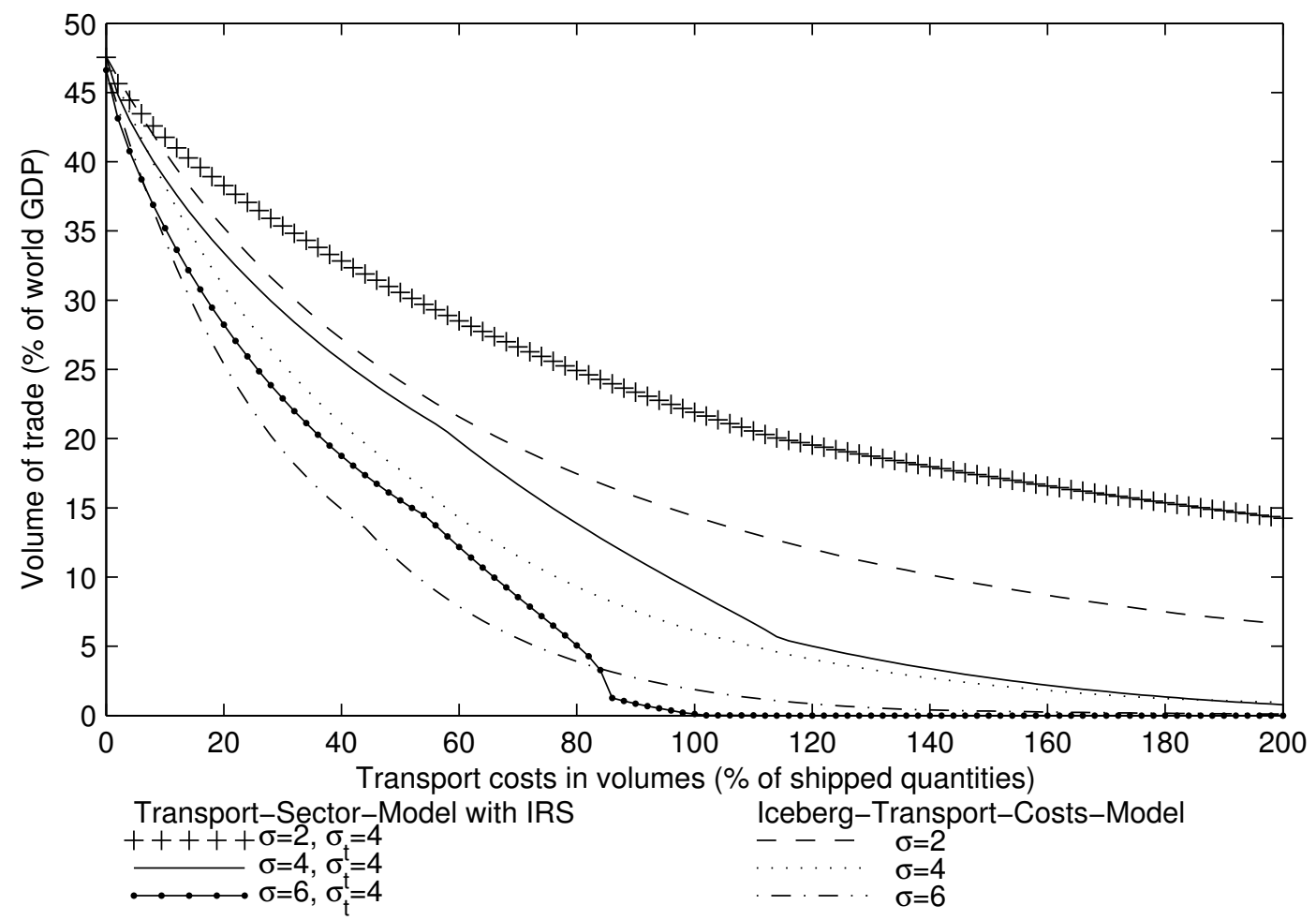

Figure 28: Volume of trade as \% of world GDP if $\sigma$ changes, $i$ has $70 \%$ of unskilled labor world endowment, exporter takes care of transport services. 


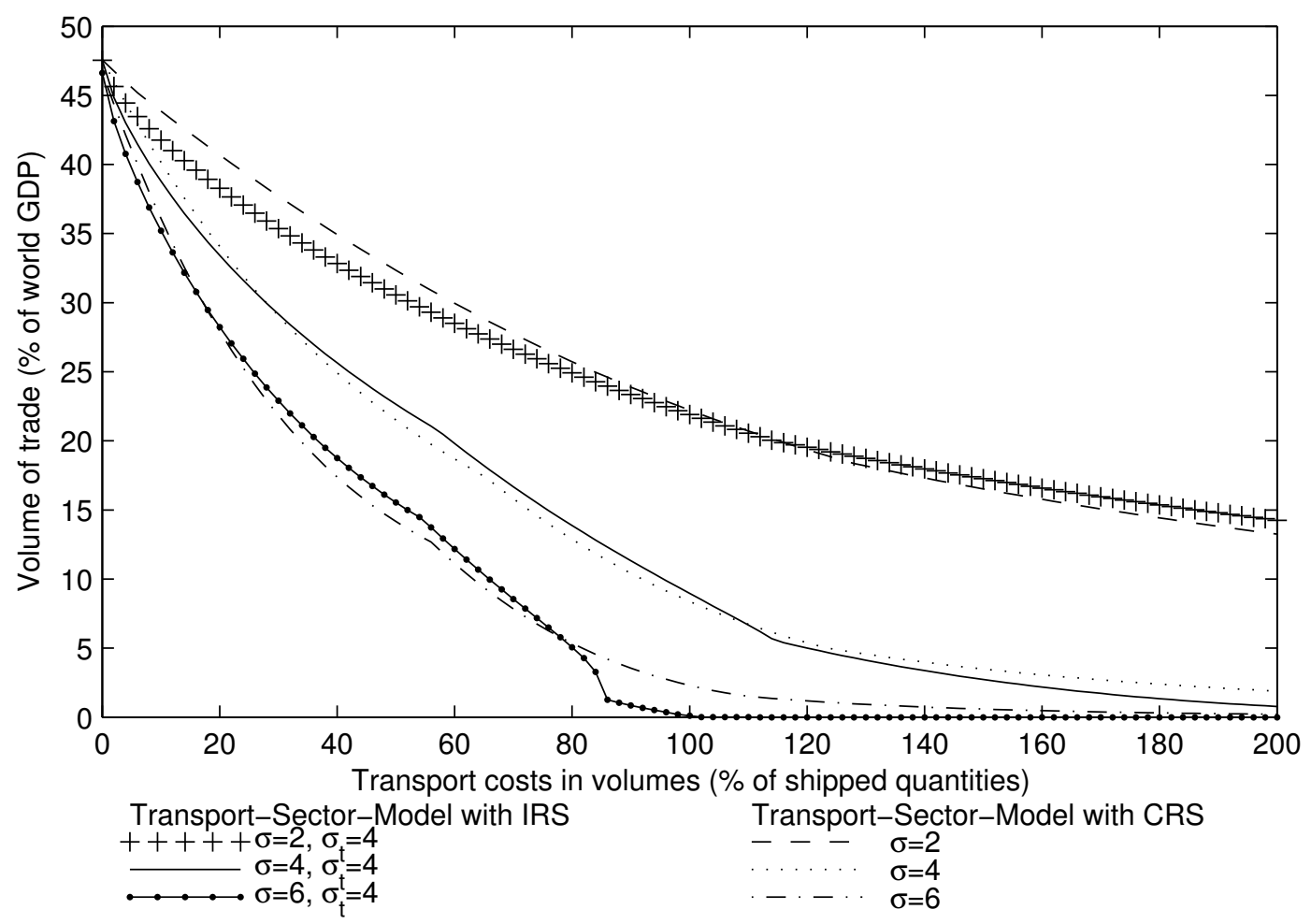

Figure 29: Volume of trade as \% of world GDP if $\sigma$ changes, $i$ has $70 \%$ of unskilled labor world endowment and exporter takes care of transport services.

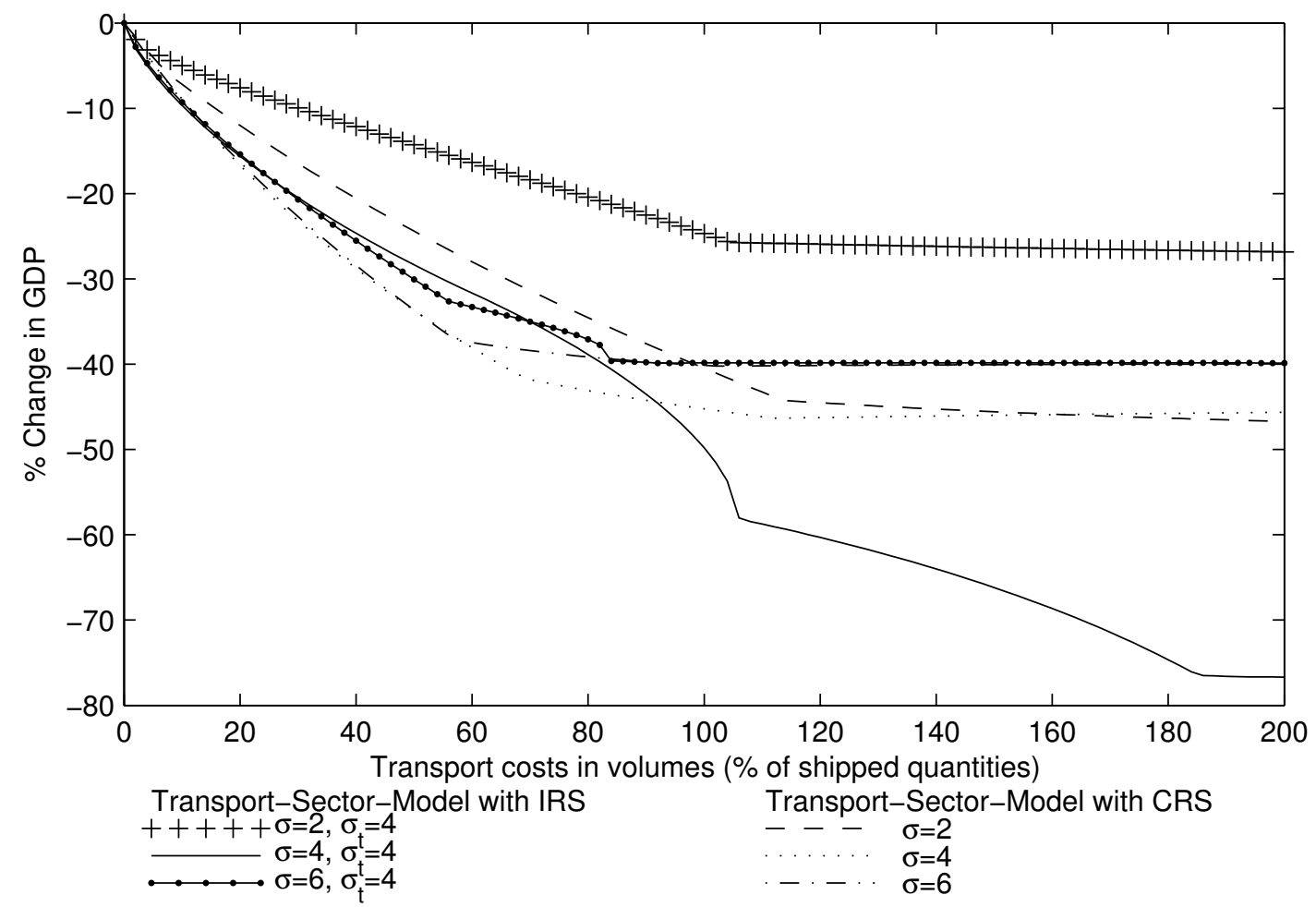

Figure 30: GDP changes in $\%$ if $\sigma$ changes, $i$ has $30 \%$ of unskilled labor world endowment and importer takes care of transport services. 


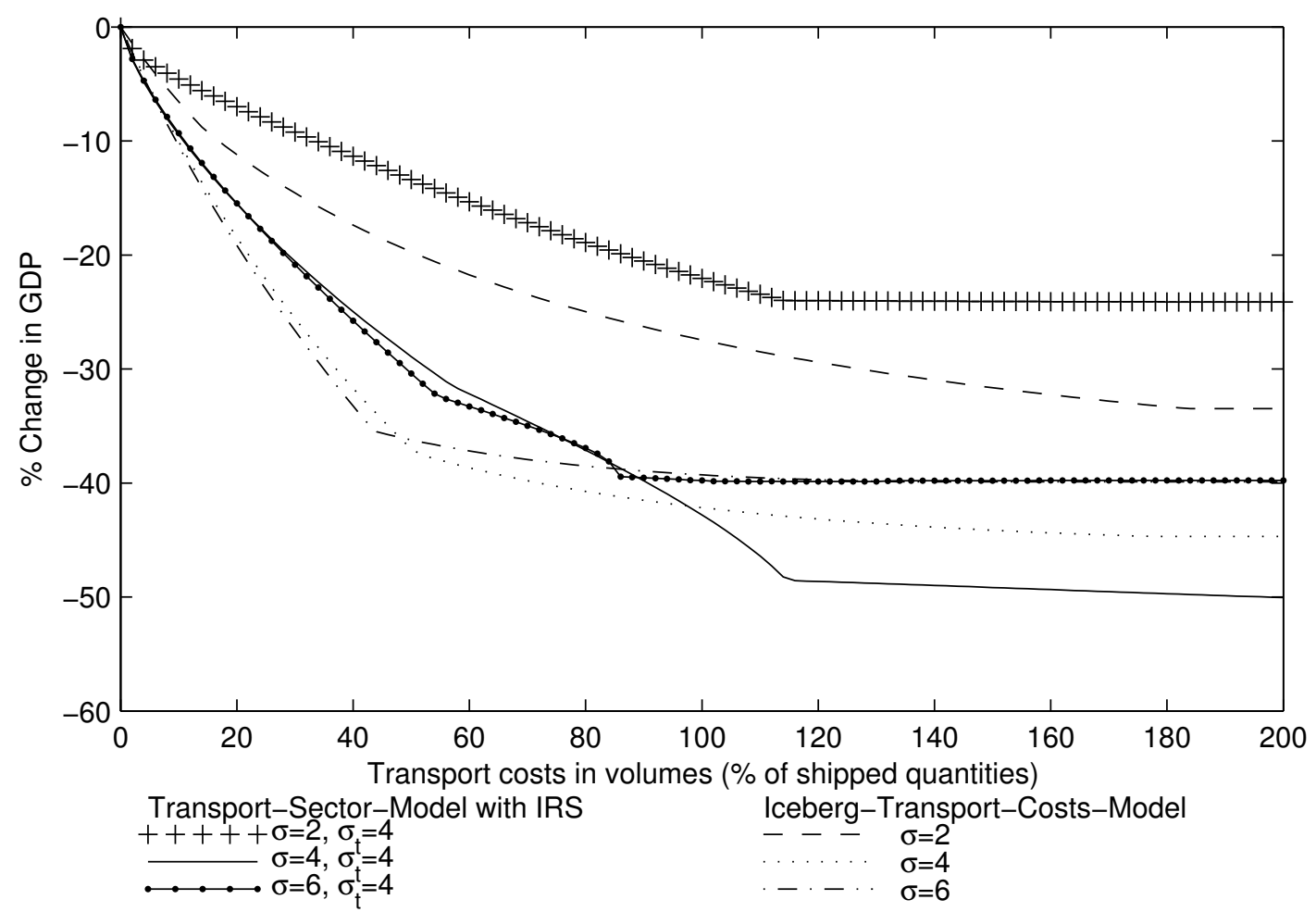

Figure 31: GDP changes in $\%$ if $\sigma$ changes, $i$ has $30 \%$ of unskilled labor world endowment and exporter takes care of transport services.

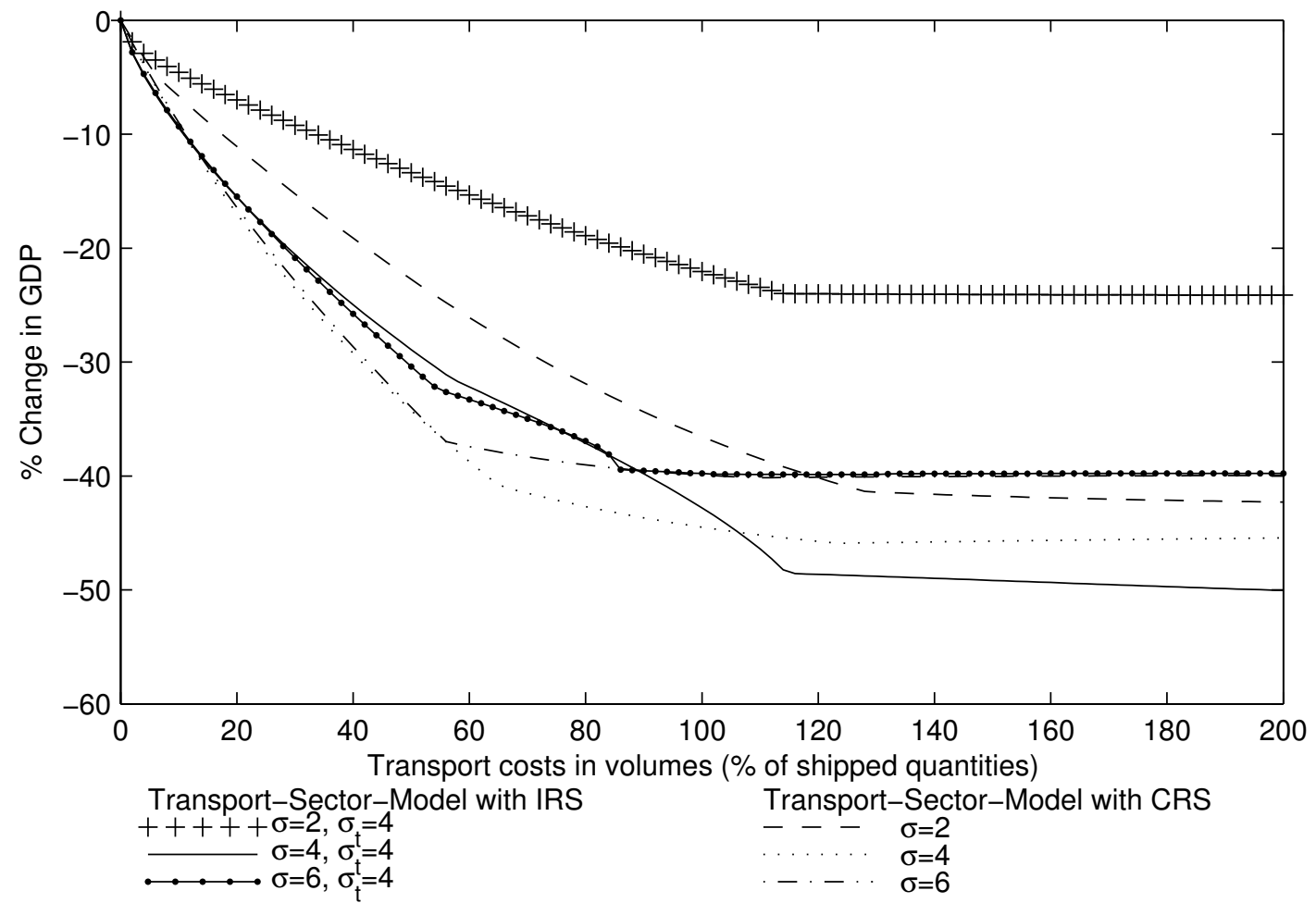

Figure 32: GDP changes in $\%$ if $\sigma$ changes, $i$ has $30 \%$ of unskilled labor world endowment and exporter takes care of transport services. 


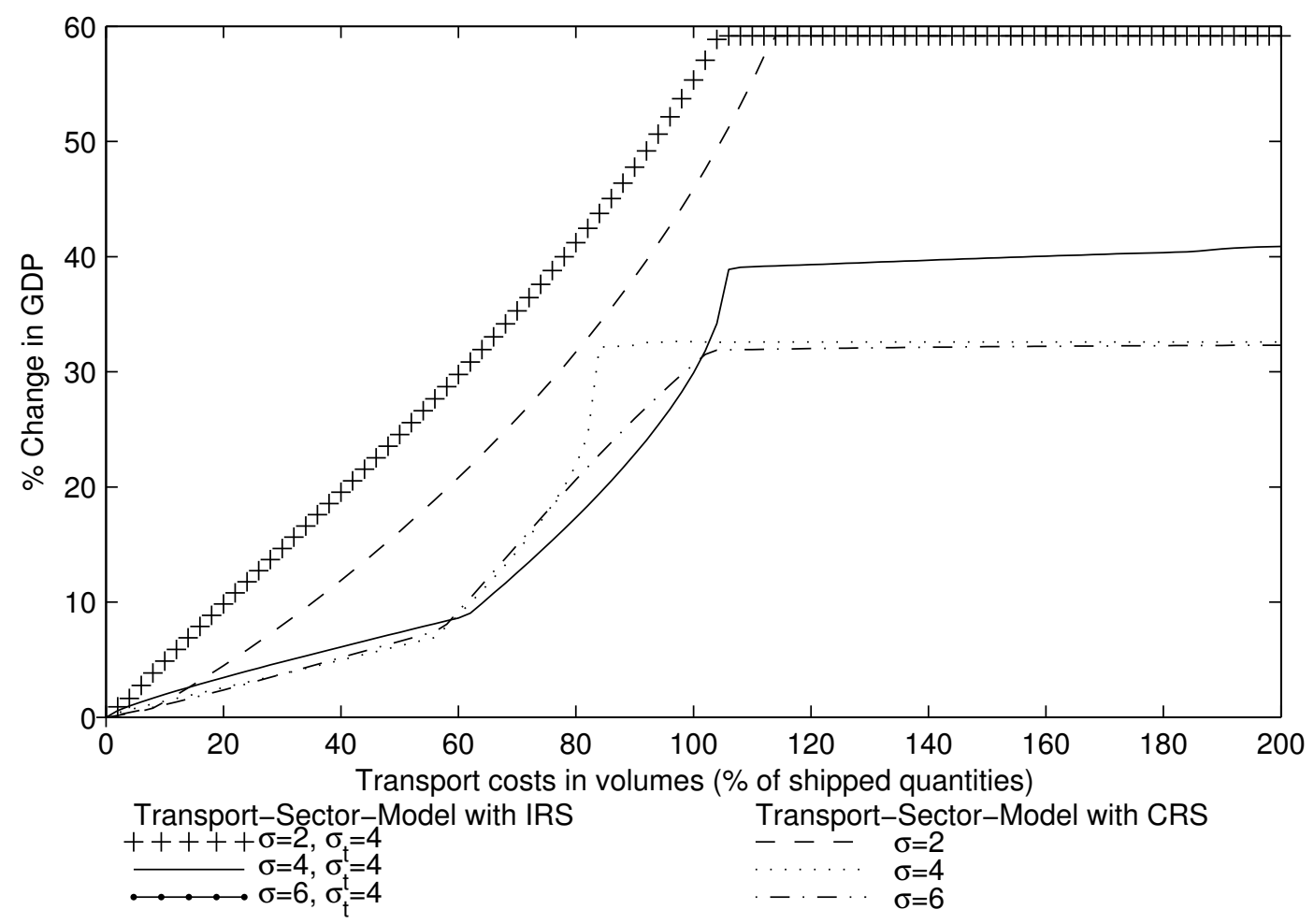

Figure 33: GDP changes in \% if $\sigma$ changes, $i$ has $70 \%$ of unskilled labor world endowment and importer takes care of transport services.

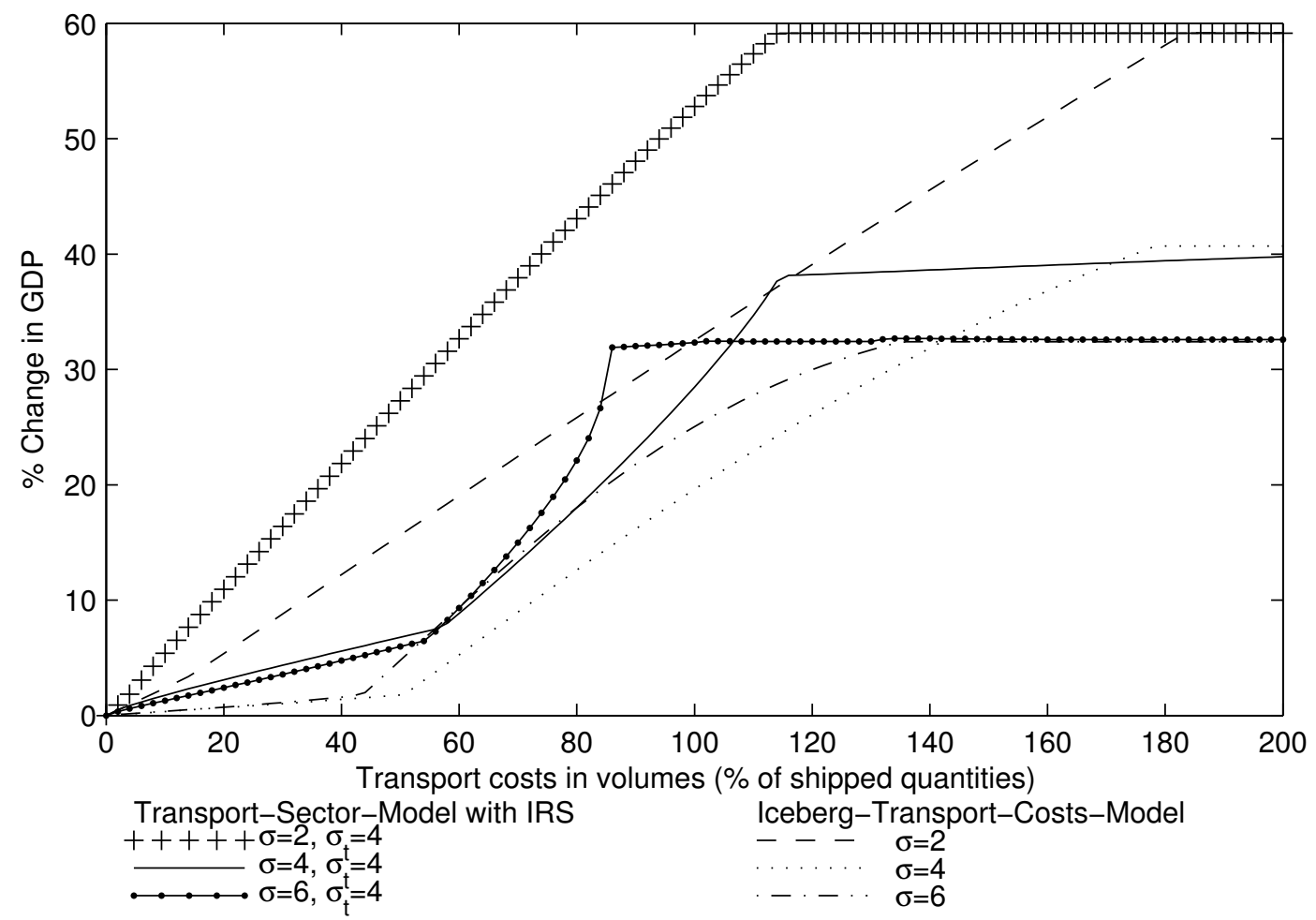

Figure 34: GDP changes in $\%$ if $\sigma$ changes, $i$ has $70 \%$ of unskilled labor world endowment and exporter takes care of transport services. 


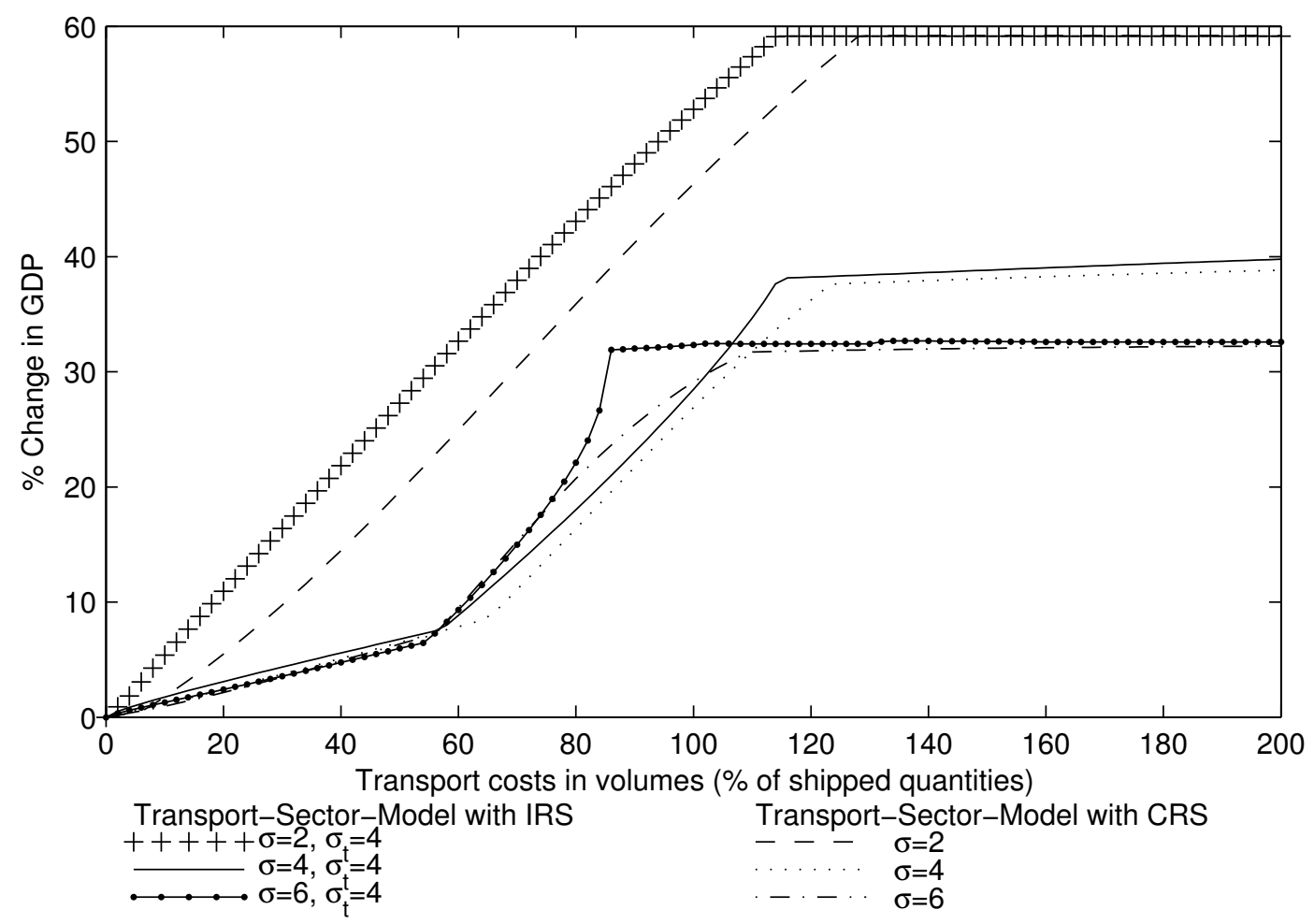

Figure 35: GDP changes in \% if $\sigma$ changes, $i$ has $70 \%$ of unskilled labor world endowment and exporter takes care of transport services.

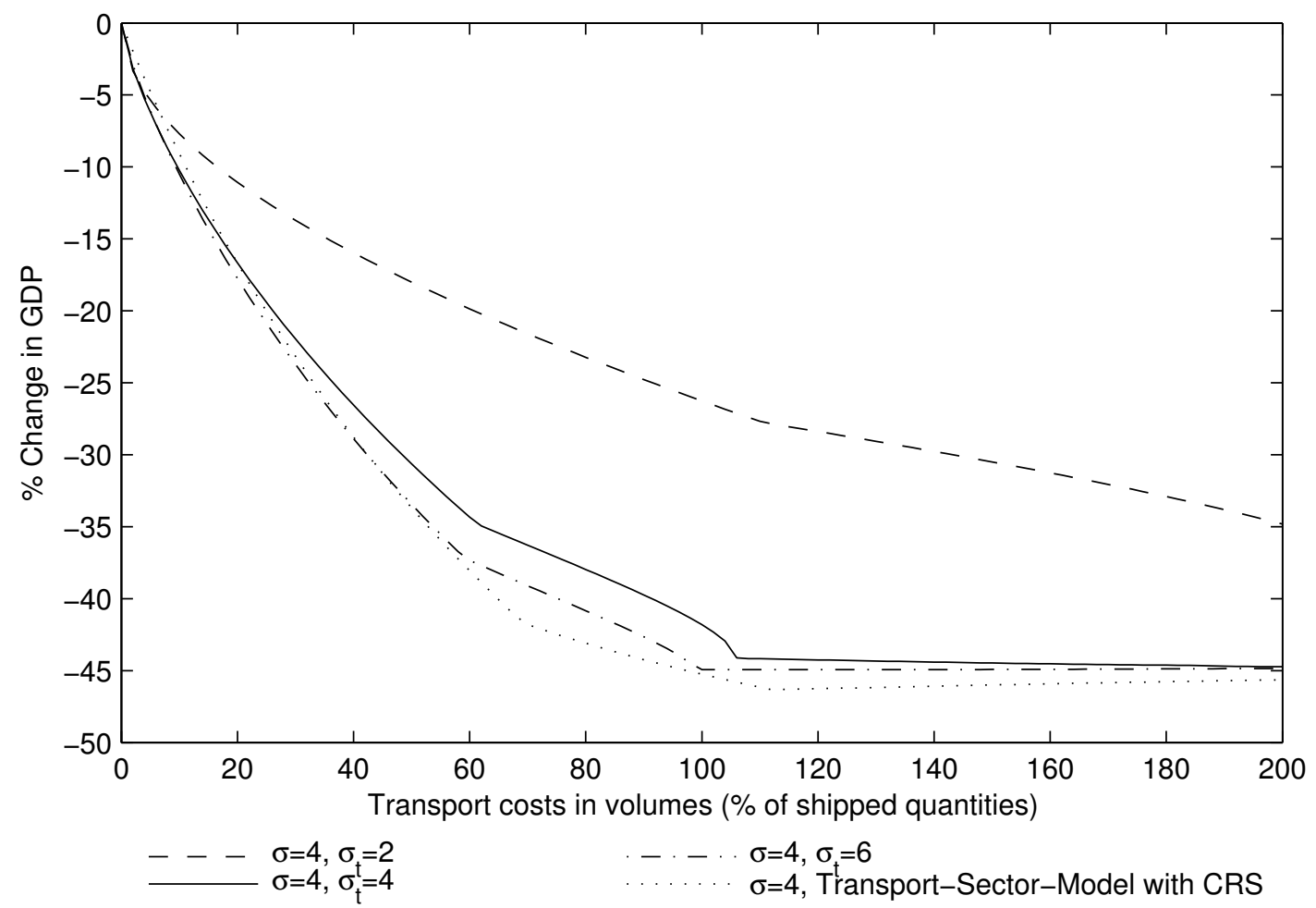

Figure 36: GDP changes in $\%$ if $\sigma_{t}$ changes, $i$ has $30 \%$ of unskilled labor world endowment and importer takes care of transport services. 


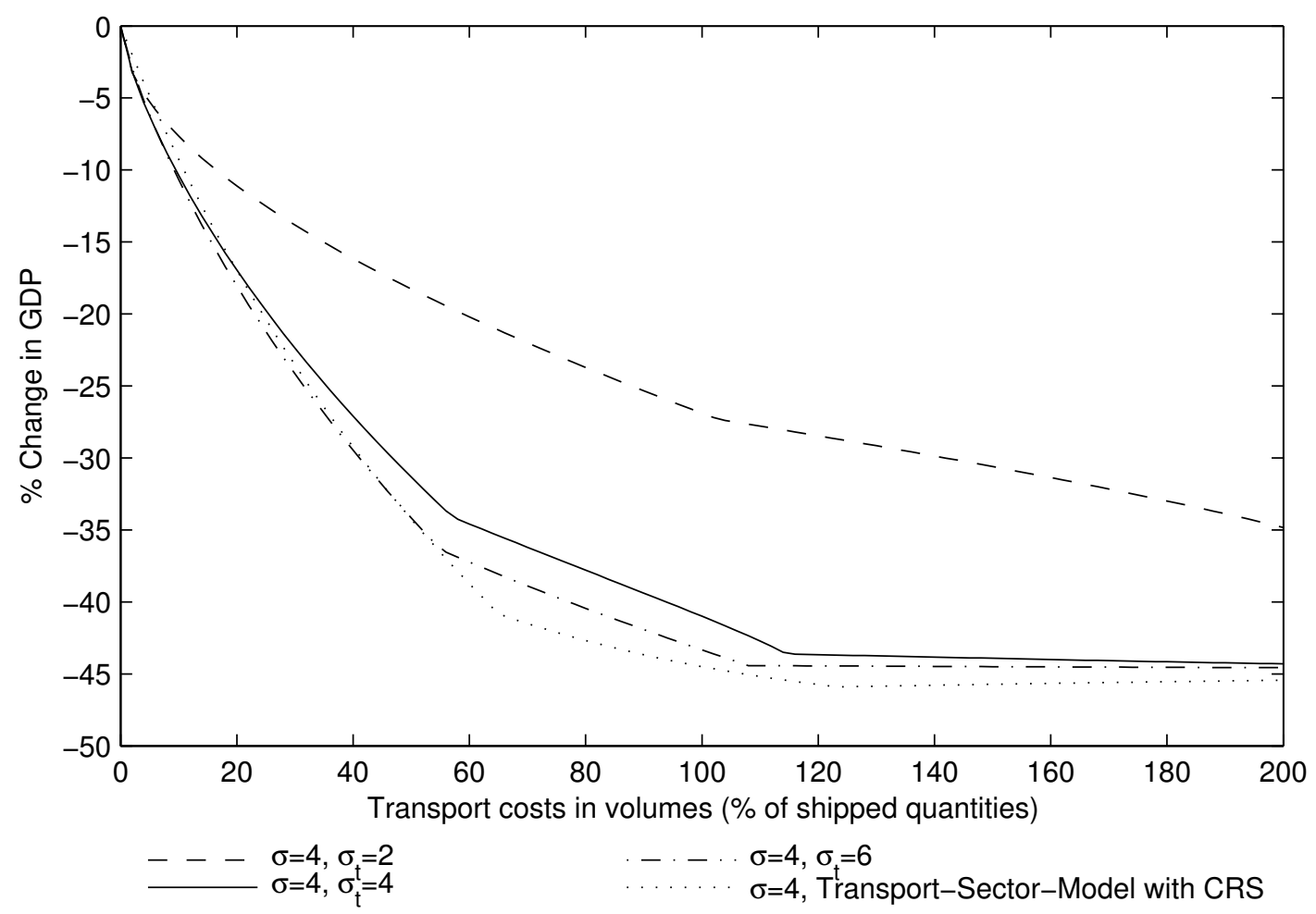

Figure 37: GDP changes in $\%$ if $\sigma_{t}$ changes, $i$ has $30 \%$ of unskilled labor world endowment and exporter takes care of transport services.

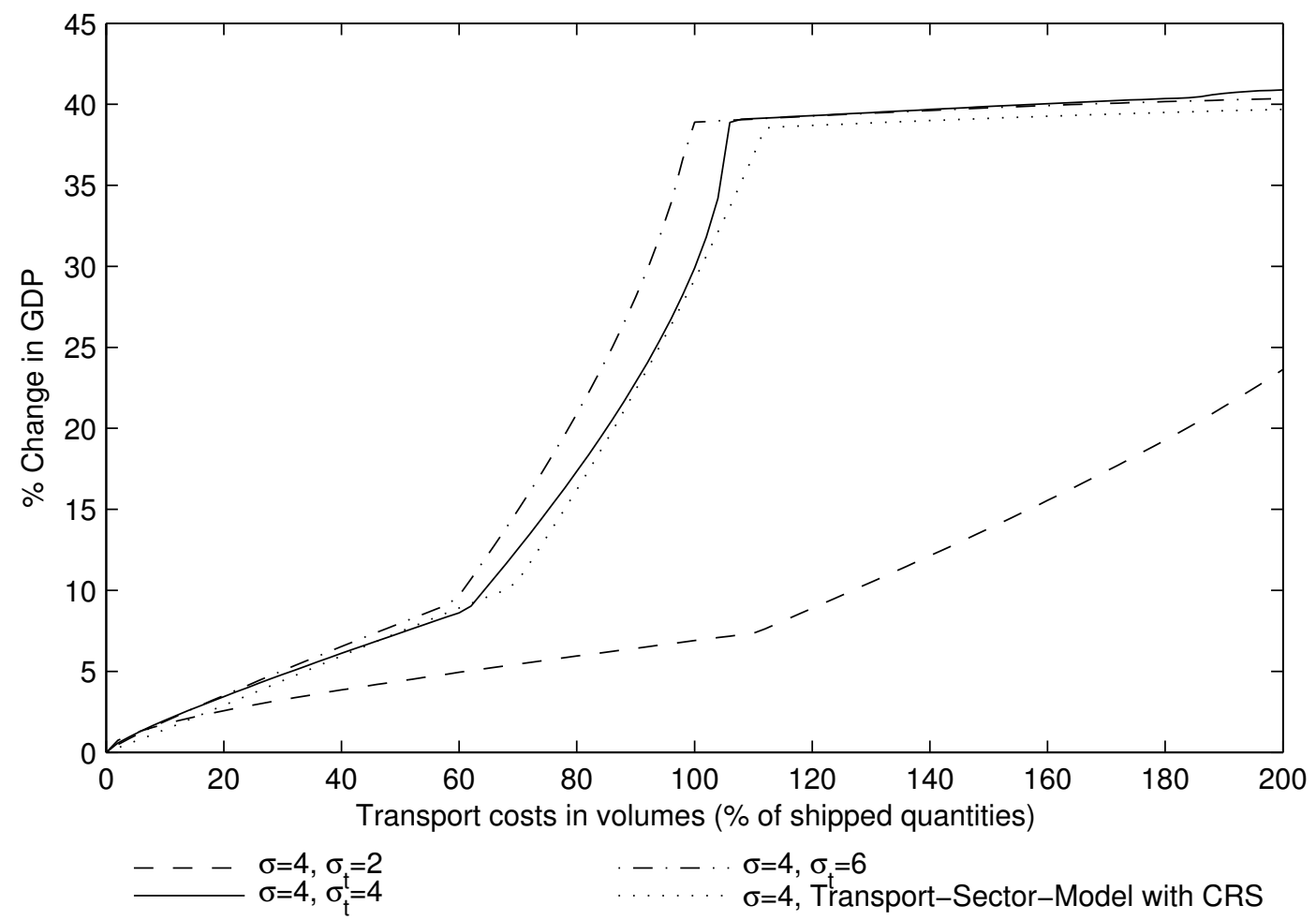

Figure 38: GDP changes in $\%$ if $\sigma_{t}$ changes, $i$ has $70 \%$ of unskilled labor world endowment and importer takes care of transport services. 


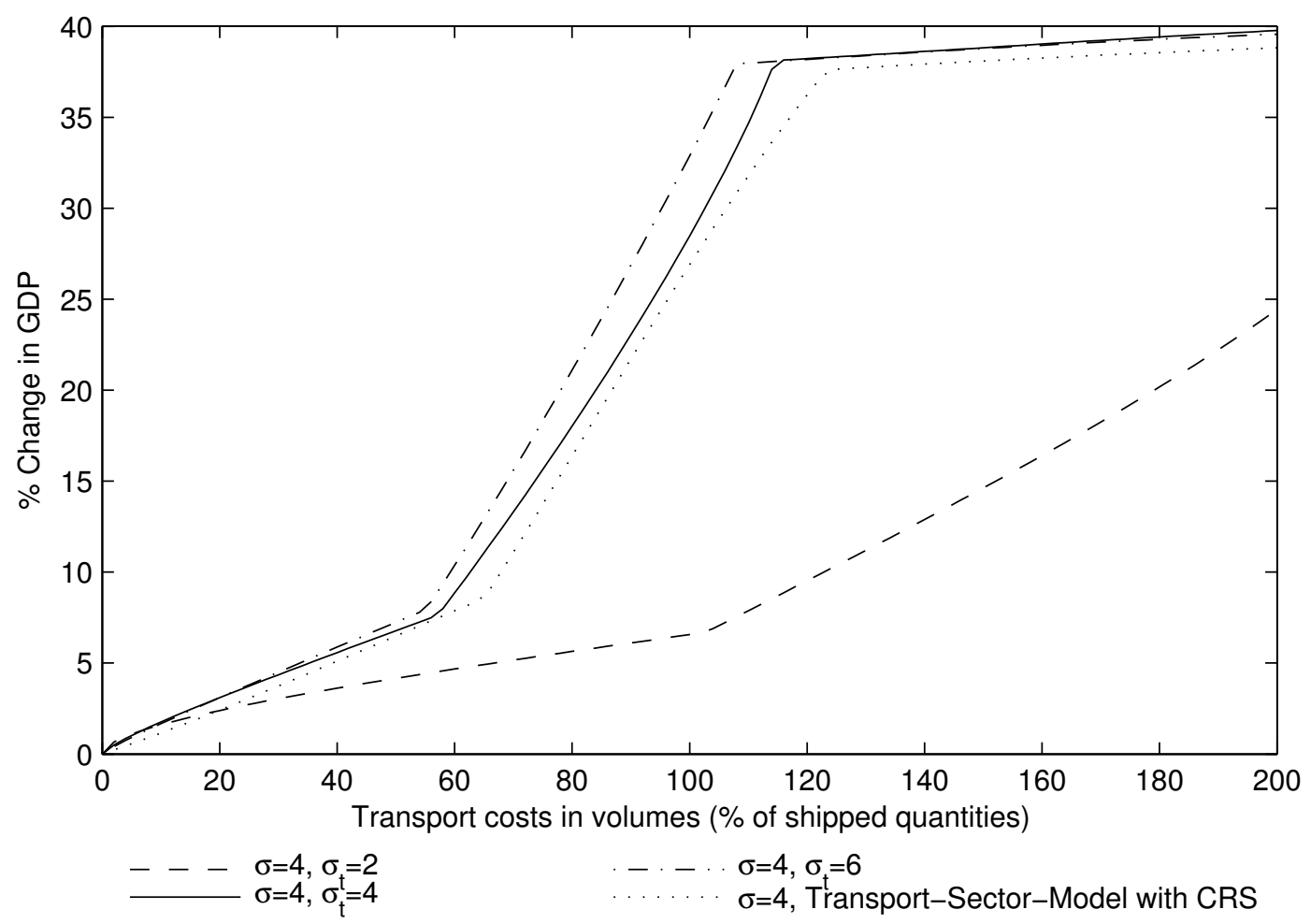

Figure 39: GDP changes in $\%$ if $\sigma_{t}$ changes, $i$ has $70 \%$ of unskilled labor world endowment and exporter takes care of transport services.

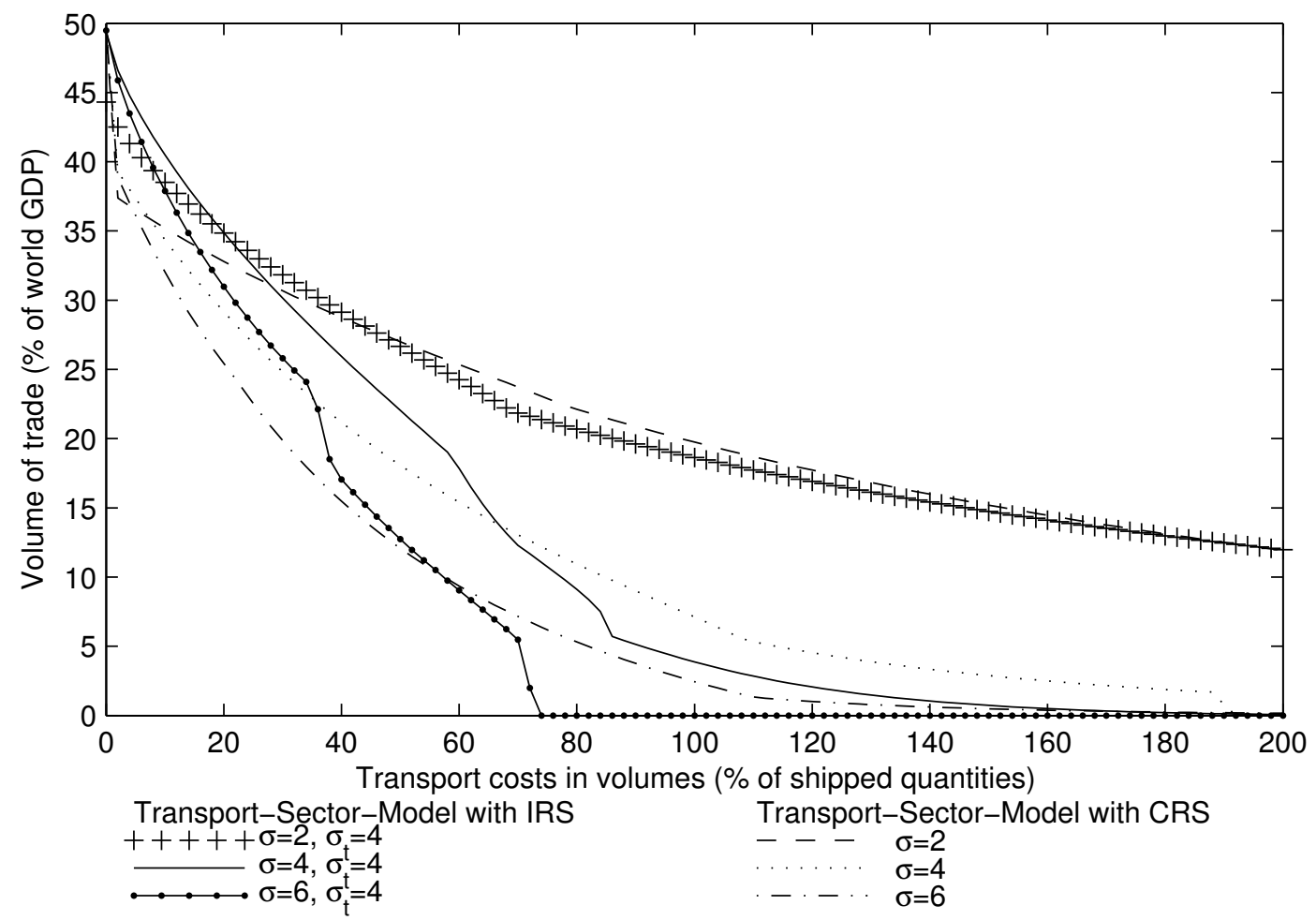

Figure 40: Volume of trade as \% of world GDP if $\sigma$ changes, $i$ has $70 \%$ of capital world endowment and importer takes care of transport services. 


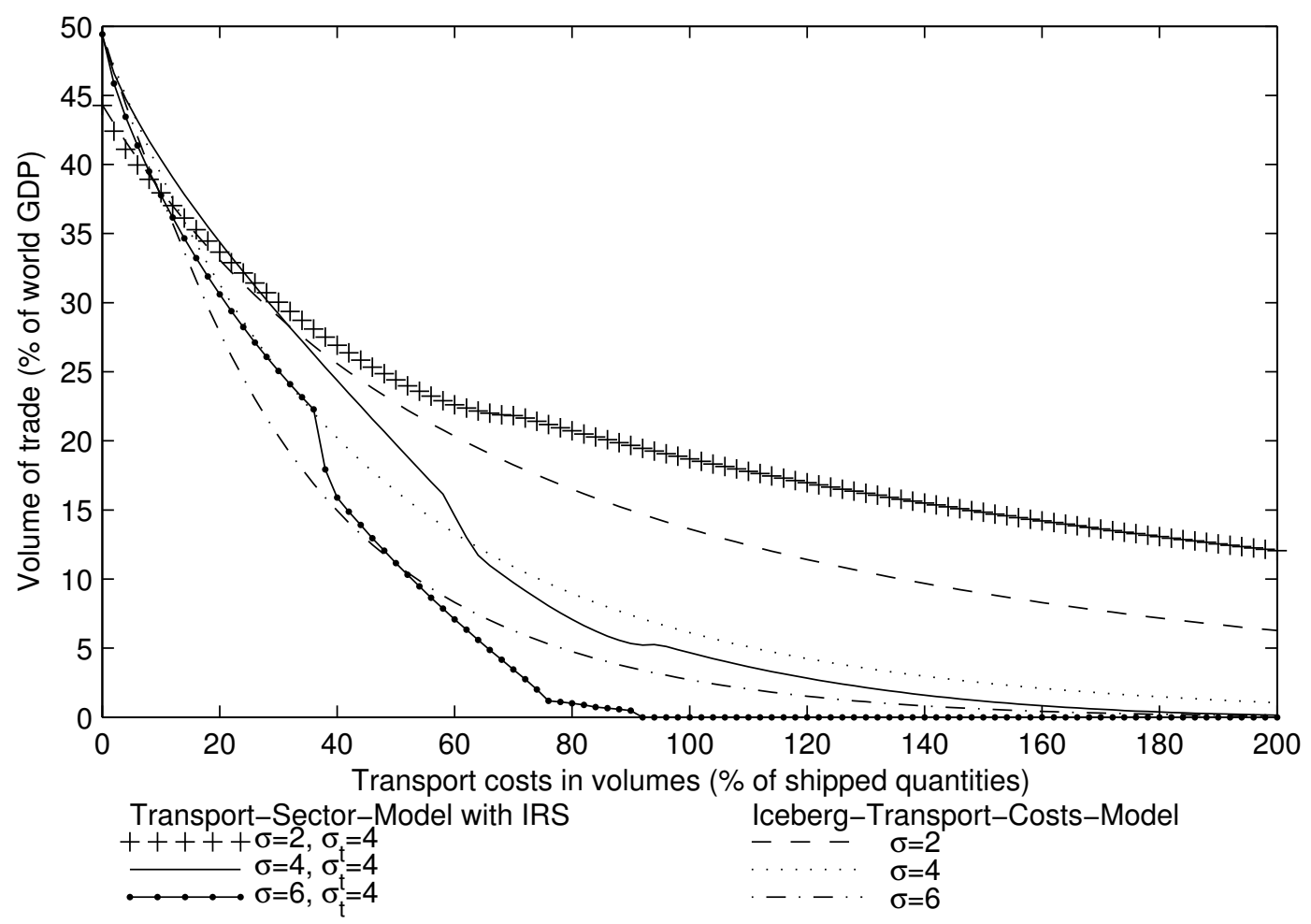

Figure 41: Volume of trade as \% of world GDP if $\sigma$ changes, $i$ has $70 \%$ of capital world endowment, exporter takes care of transport services.

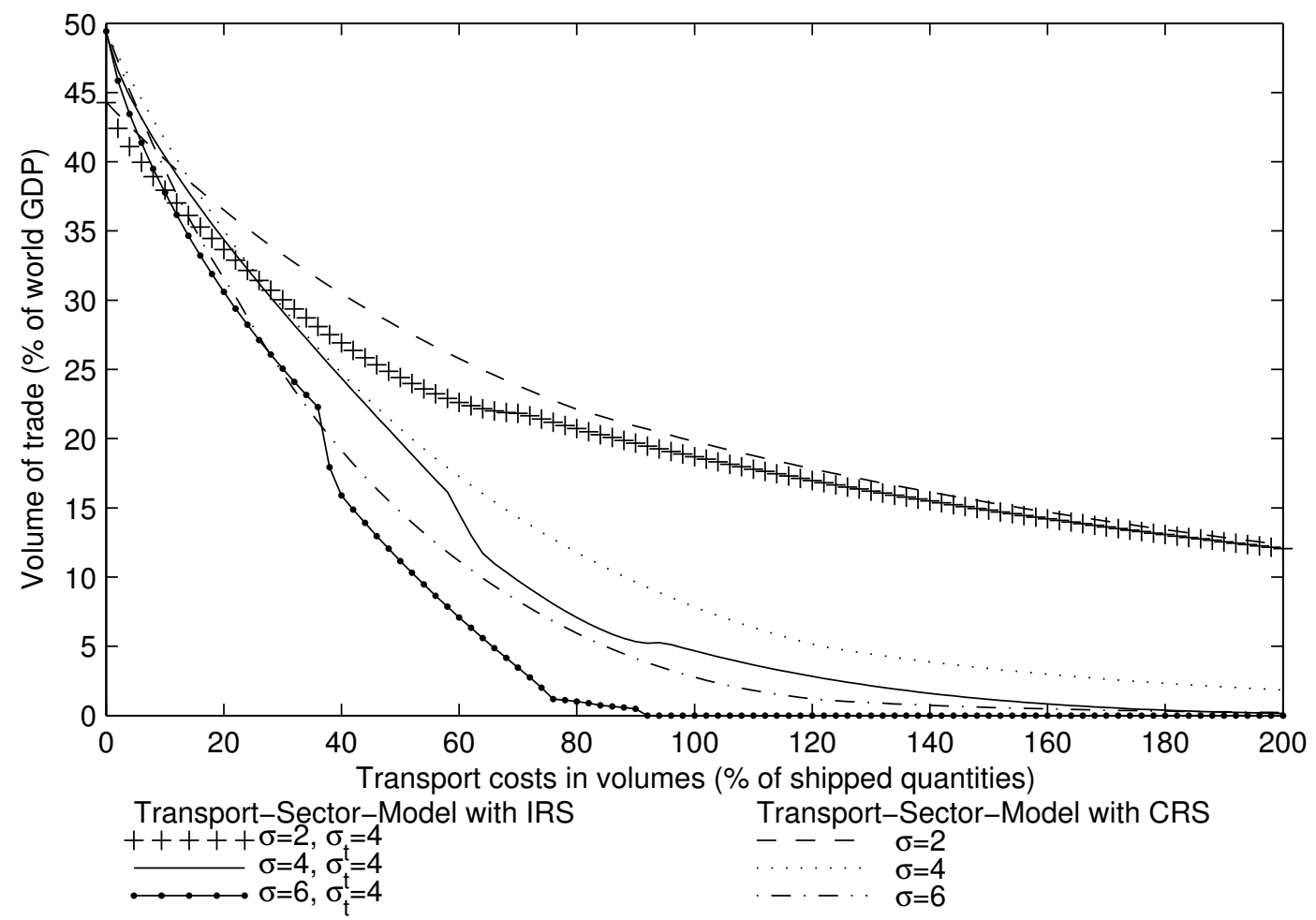

Figure 42: Volume of trade as \% of world GDP if $\sigma$ changes, $i$ has $70 \%$ of capital world endowments and exporter takes care of transport services. 


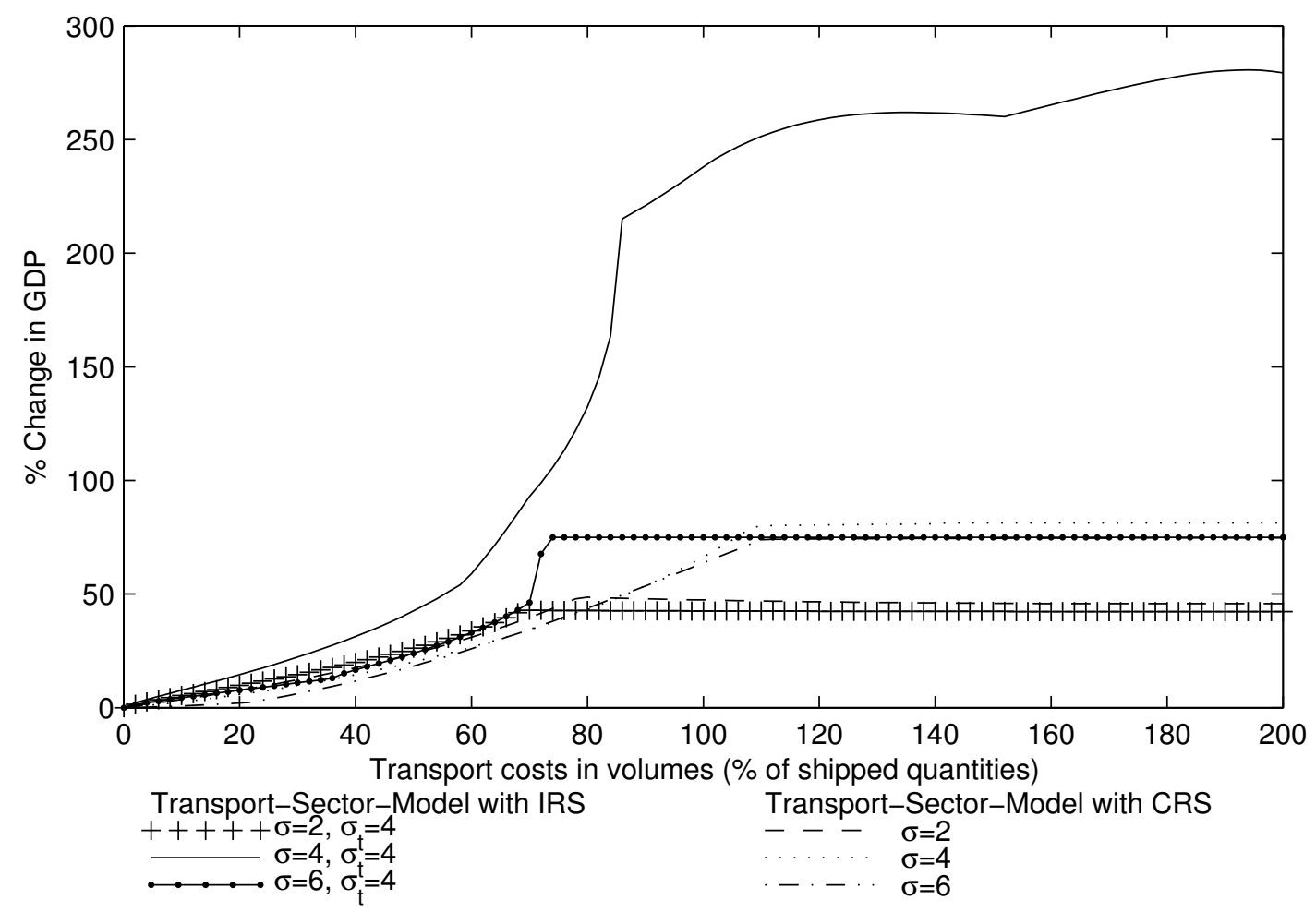

Figure 43: GDP changes in $\%$ if $\sigma$ changes, $i$ has $30 \%$ of capital world endowments and importer takes care of transport services.

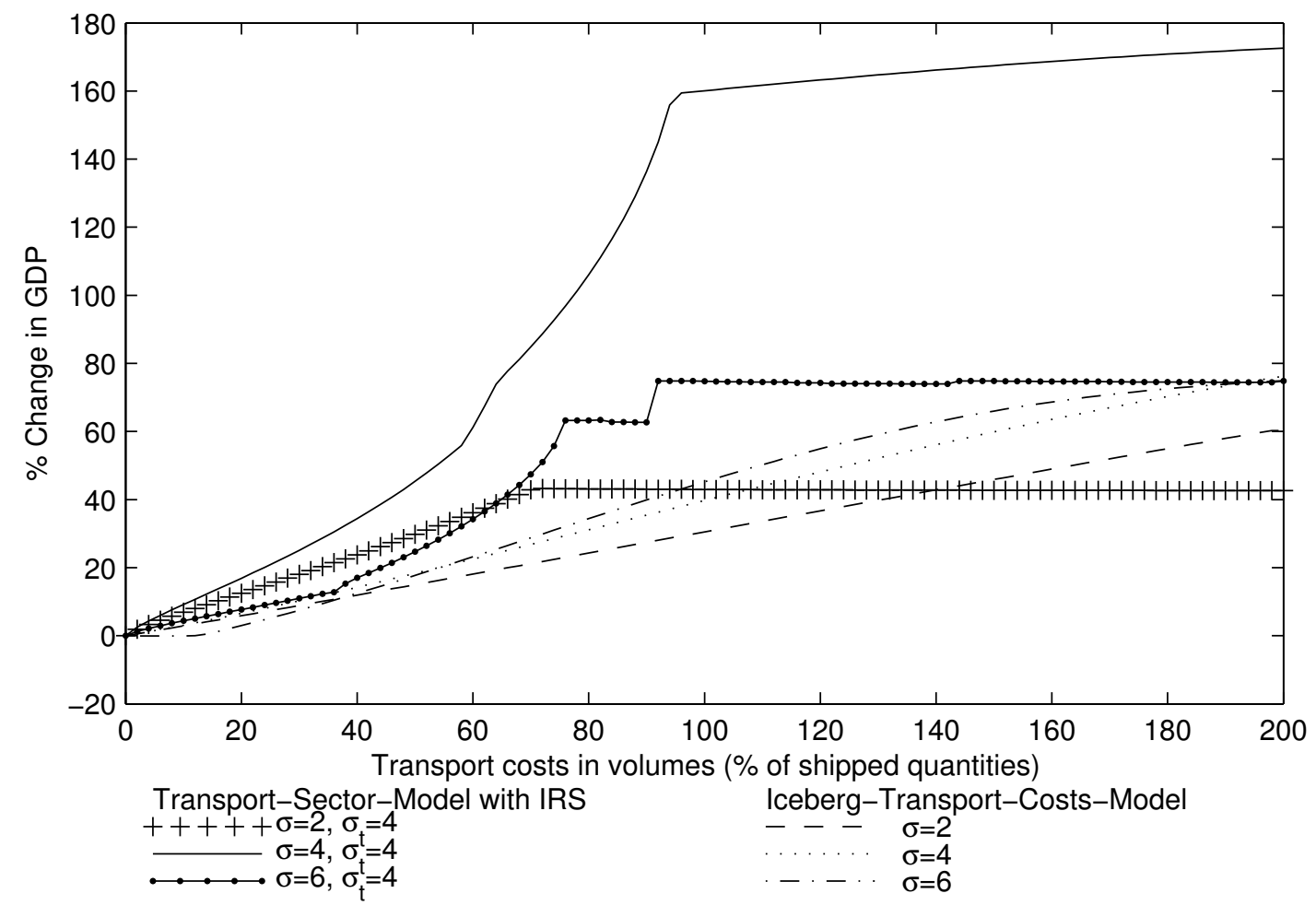

Figure 44: GDP changes in $\%$ if $\sigma$ changes, $i$ has $30 \%$ of capital world endowment and exporter takes care of transport services. 


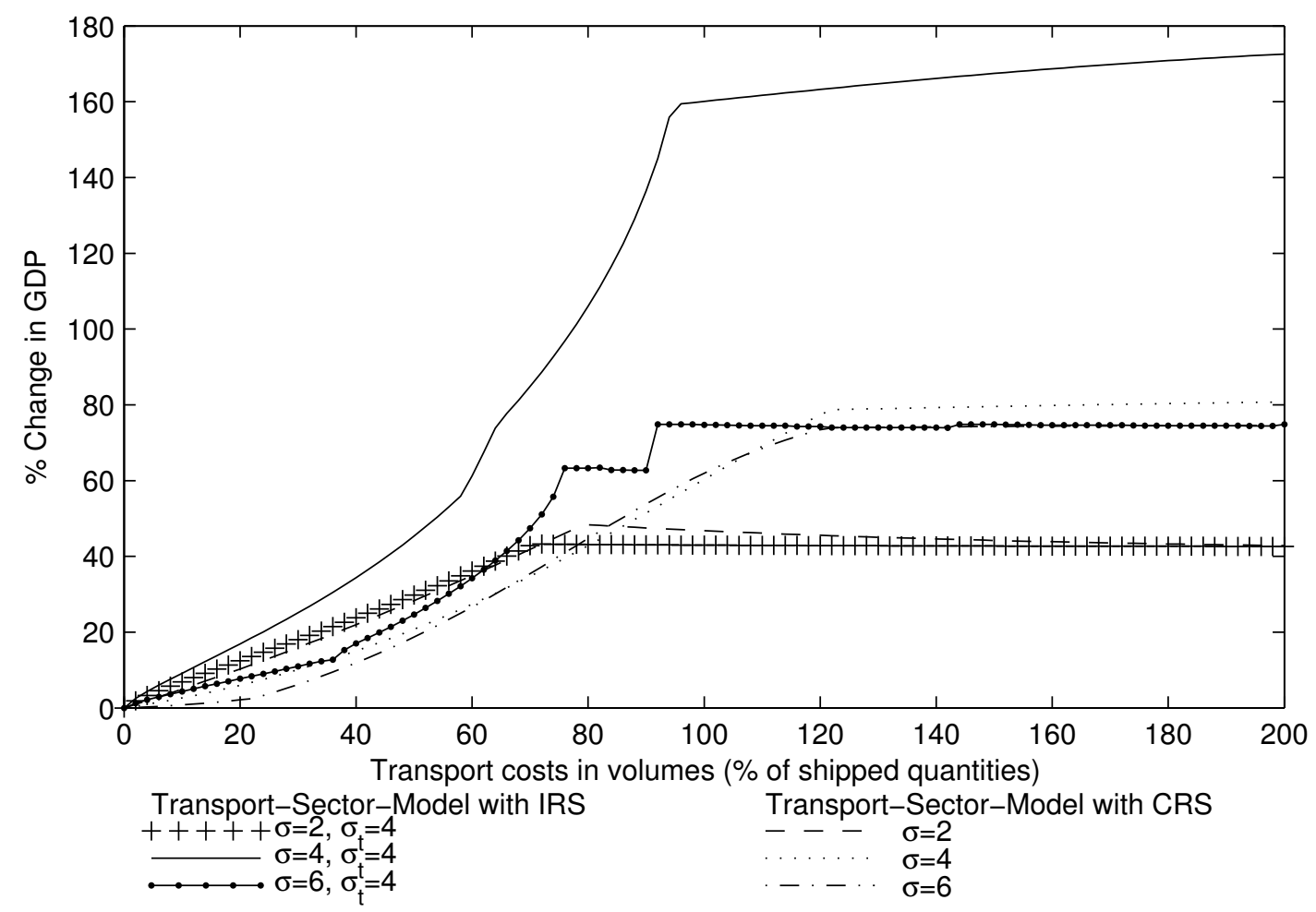

Figure 45: GDP changes in $\%$ if $\sigma$ changes, $i$ has $30 \%$ of capital world endowment and exporter takes care of transport services.

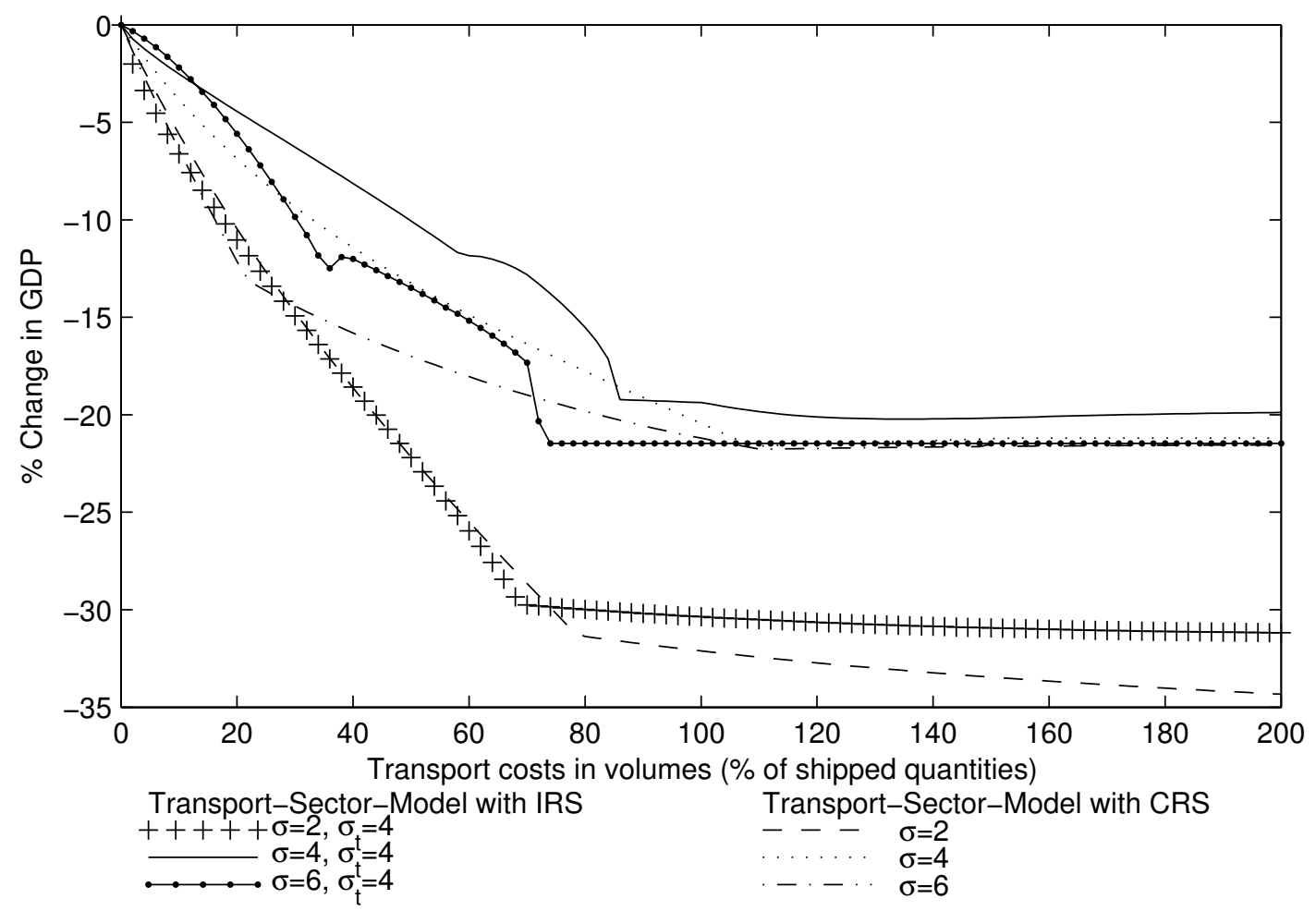

Figure 46: GDP changes in \% if $\sigma$ changes, $i$ has $70 \%$ of capital world endowments and importer takes care of transport services. 


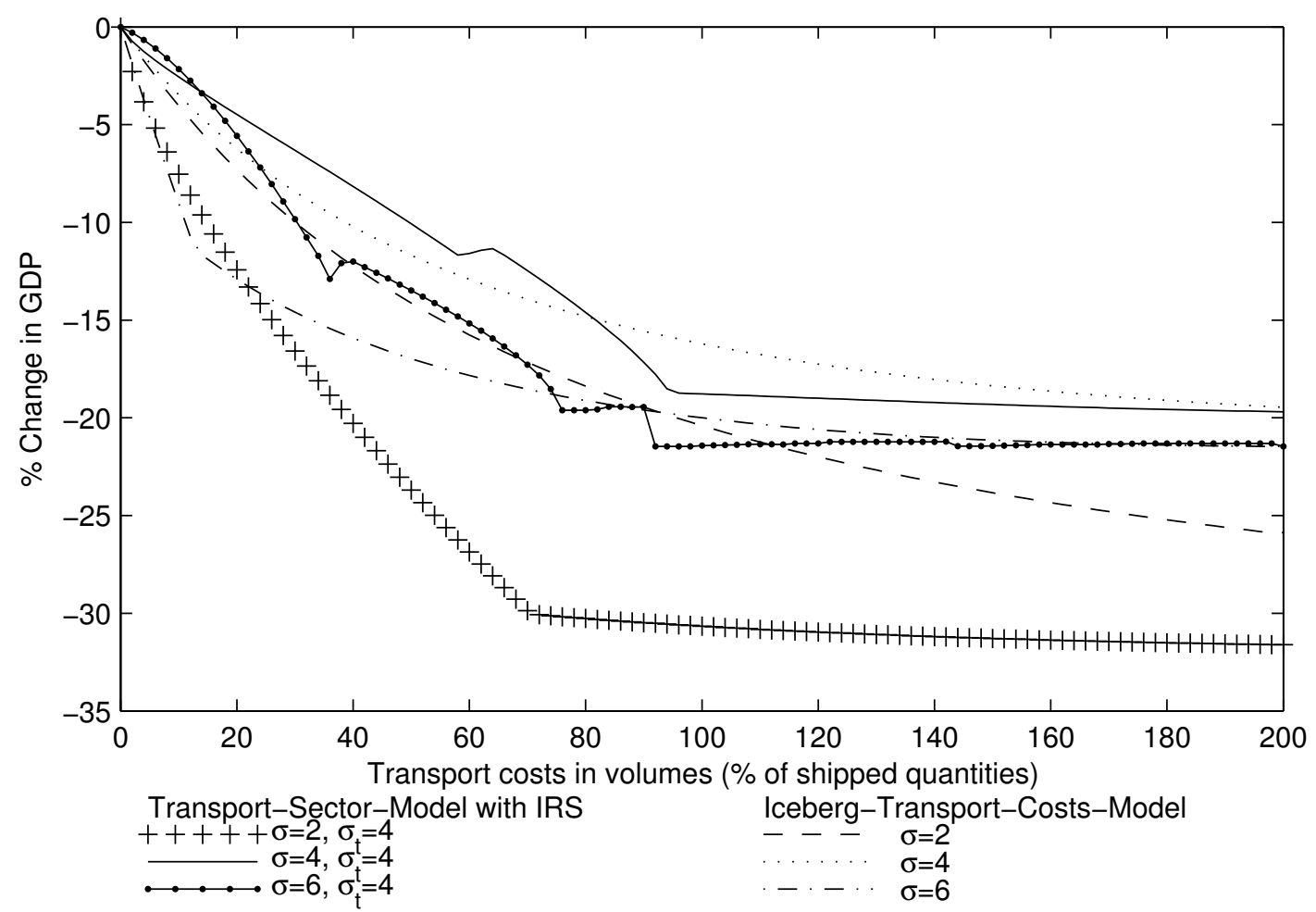

Figure 47: GDP changes in $\%$ if $\sigma$ changes, $i$ has $70 \%$ of capital world endowment and exporter takes care of transport services.

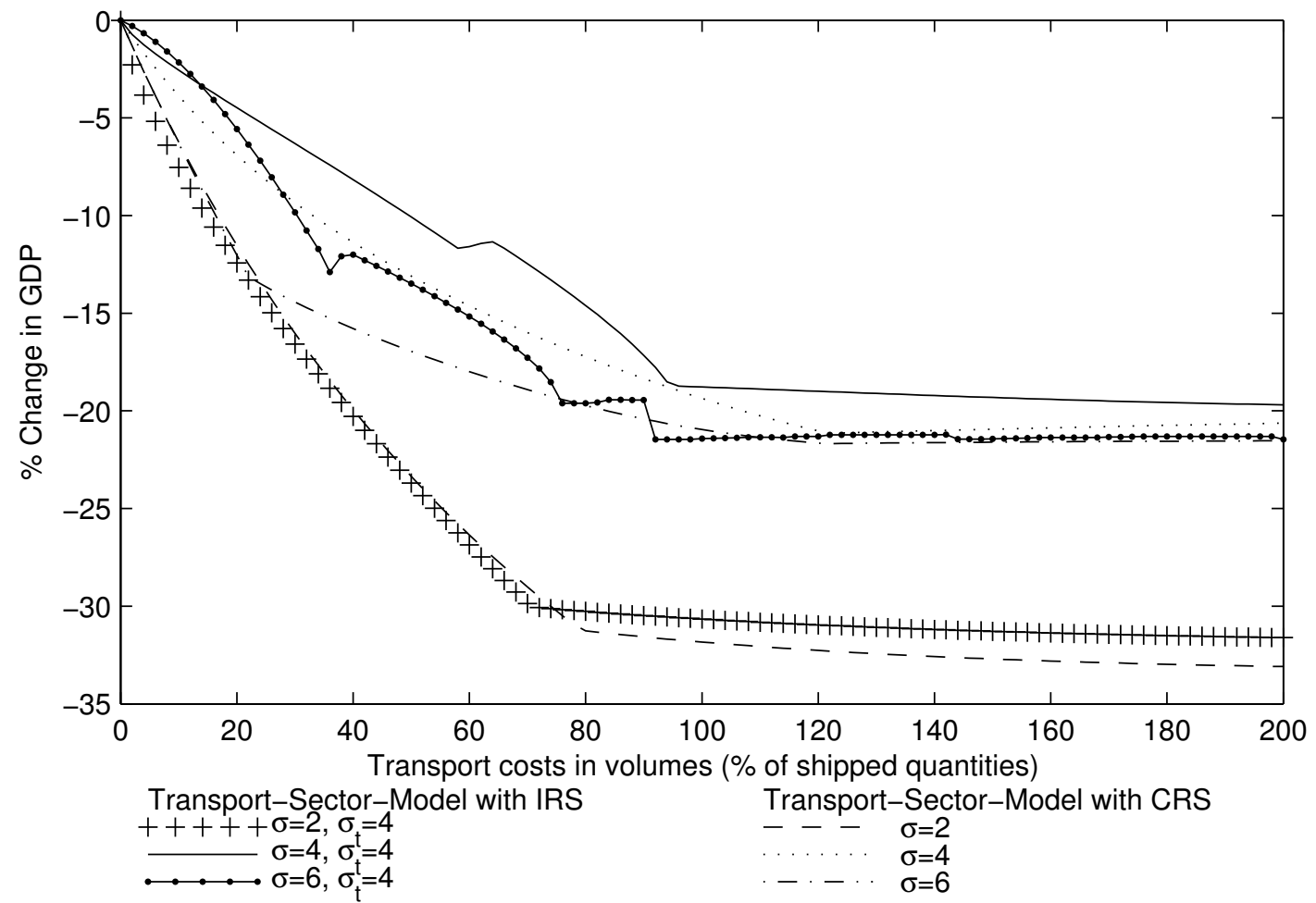

Figure 48: GDP changes in $\%$ if $\sigma$ changes, $i$ has $70 \%$ of capital world endowment and exporter takes care of transport services. 


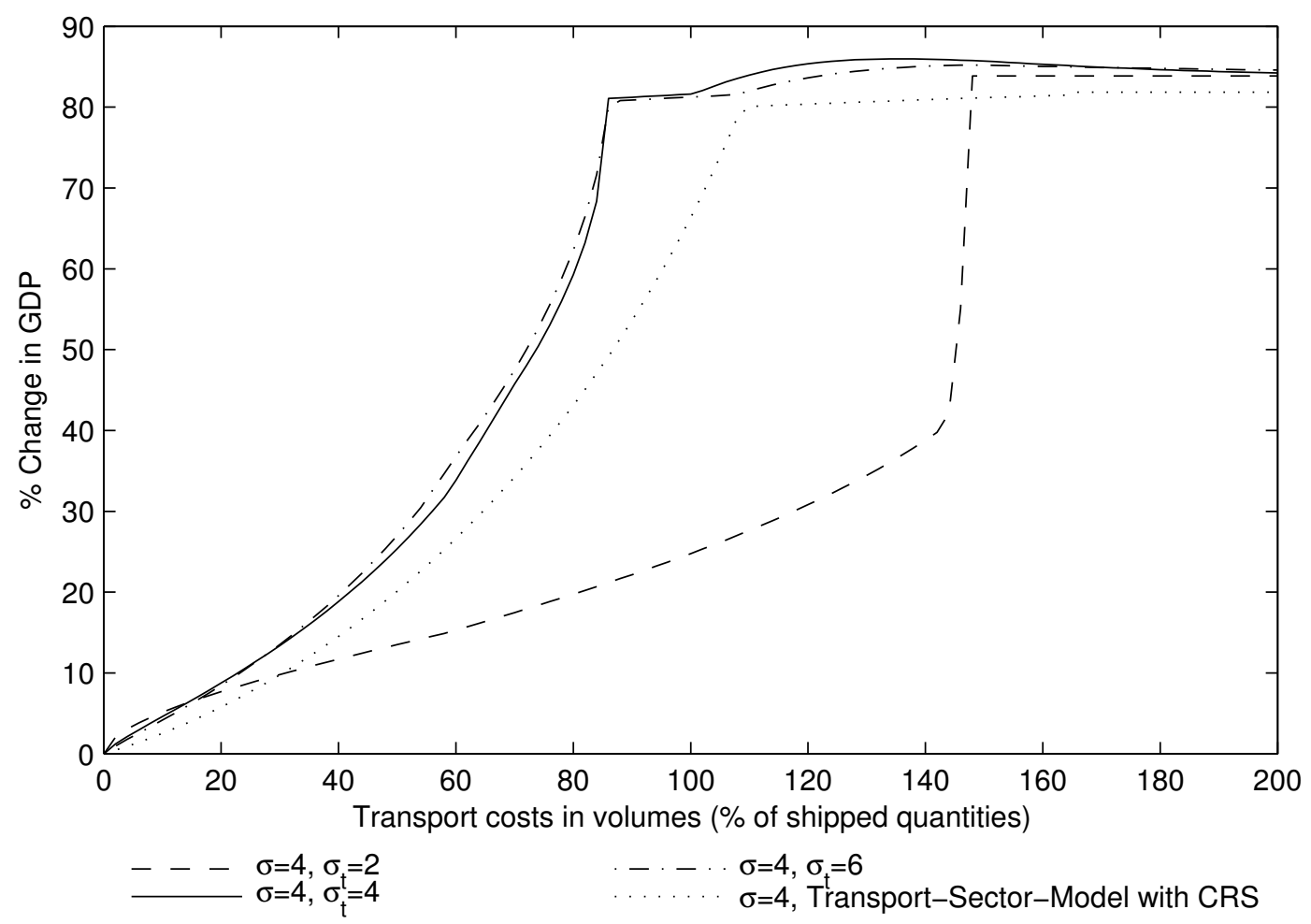

Figure 49: GDP changes in $\%$ if $\sigma_{t}$ changes, $i$ has $30 \%$ of capital world endowments and importer takes care of transport services.

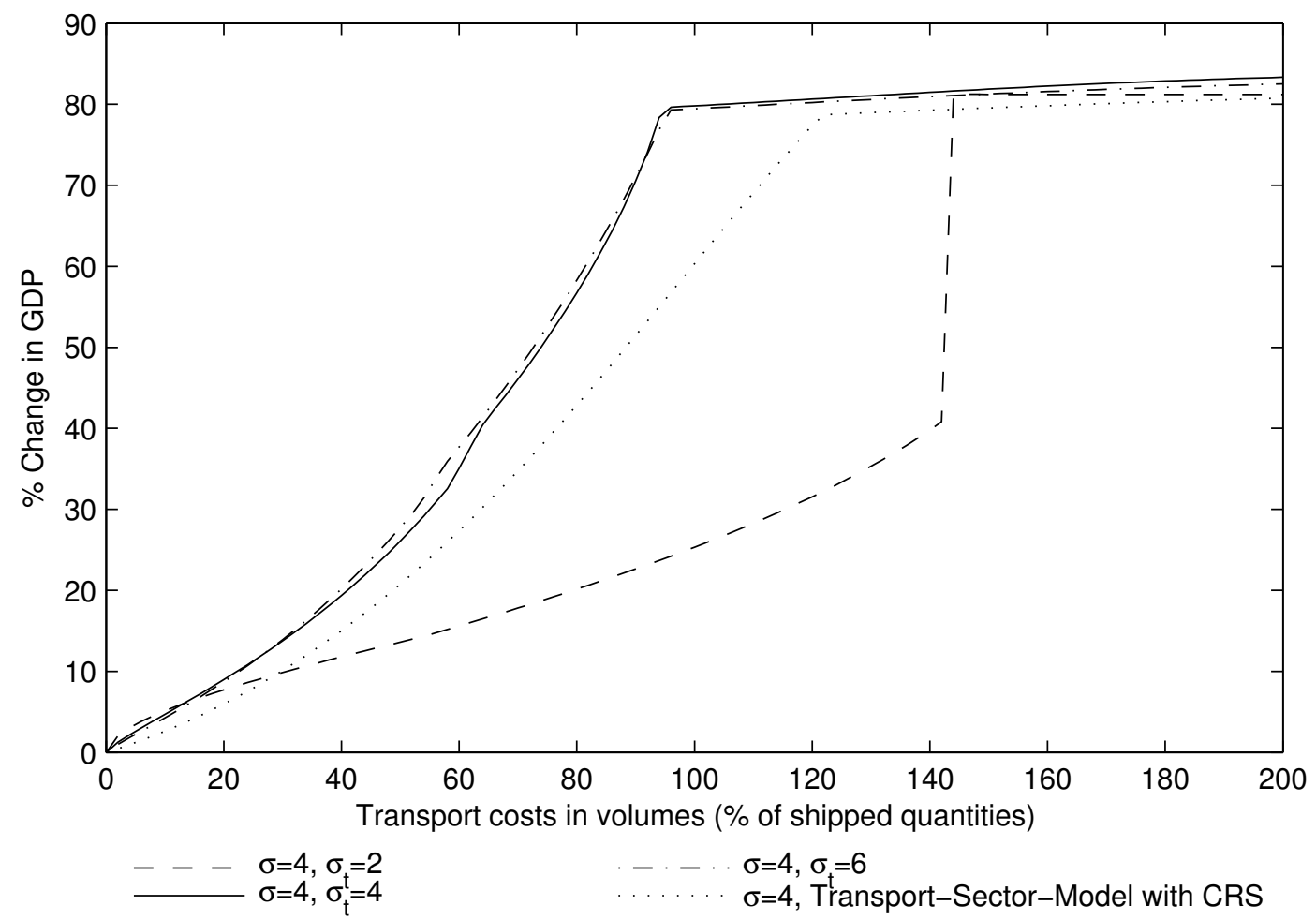

Figure 50: GDP changes in $\%$ if $\sigma_{t}$ changes, $i$ has $30 \%$ of capital world endowment and exporter takes care of transport services. 


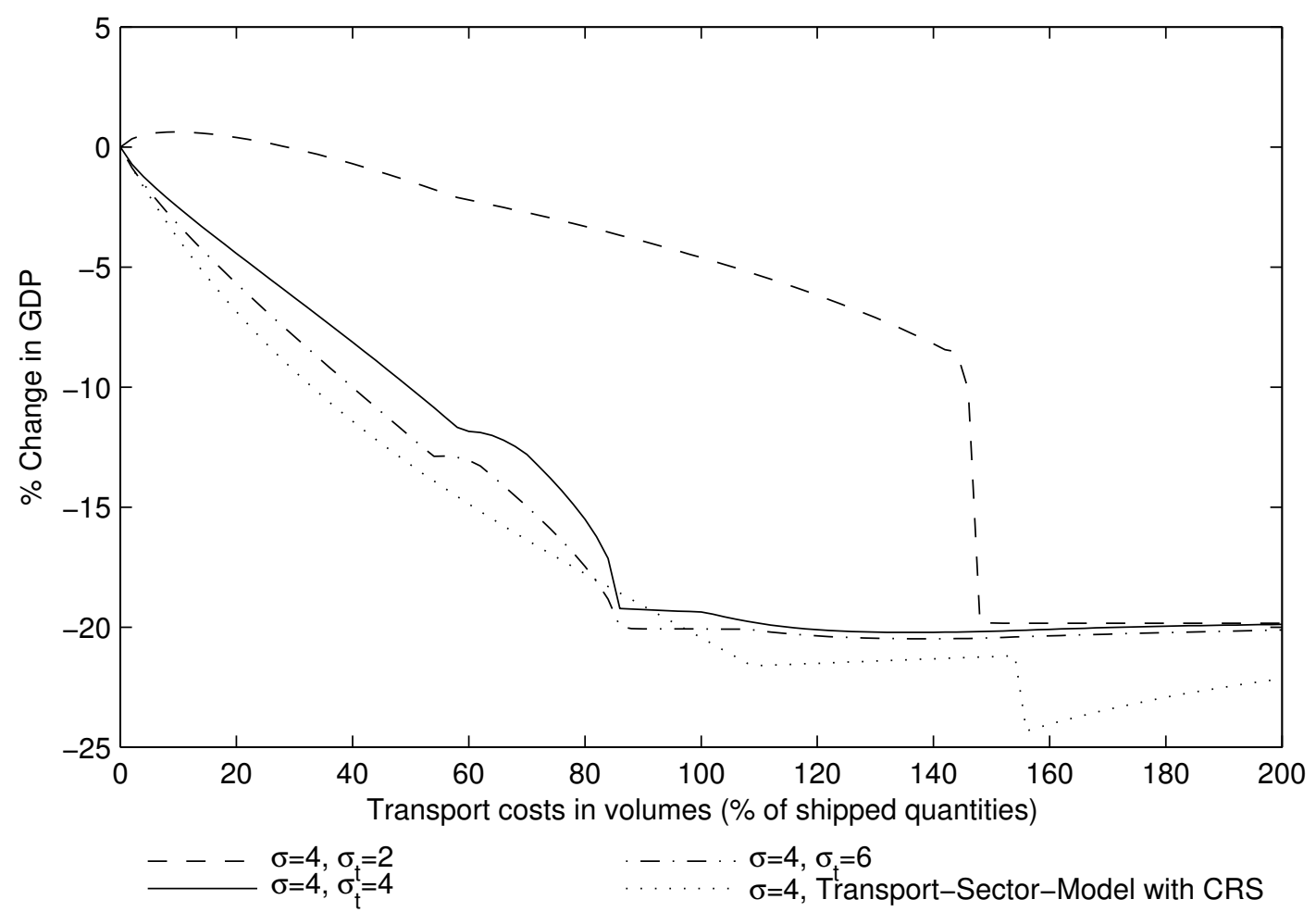

Figure 51: GDP changes in $\%$ if $\sigma_{t}$ changes, $i$ has $70 \%$ of capital world endowments and importer takes care of transport services.

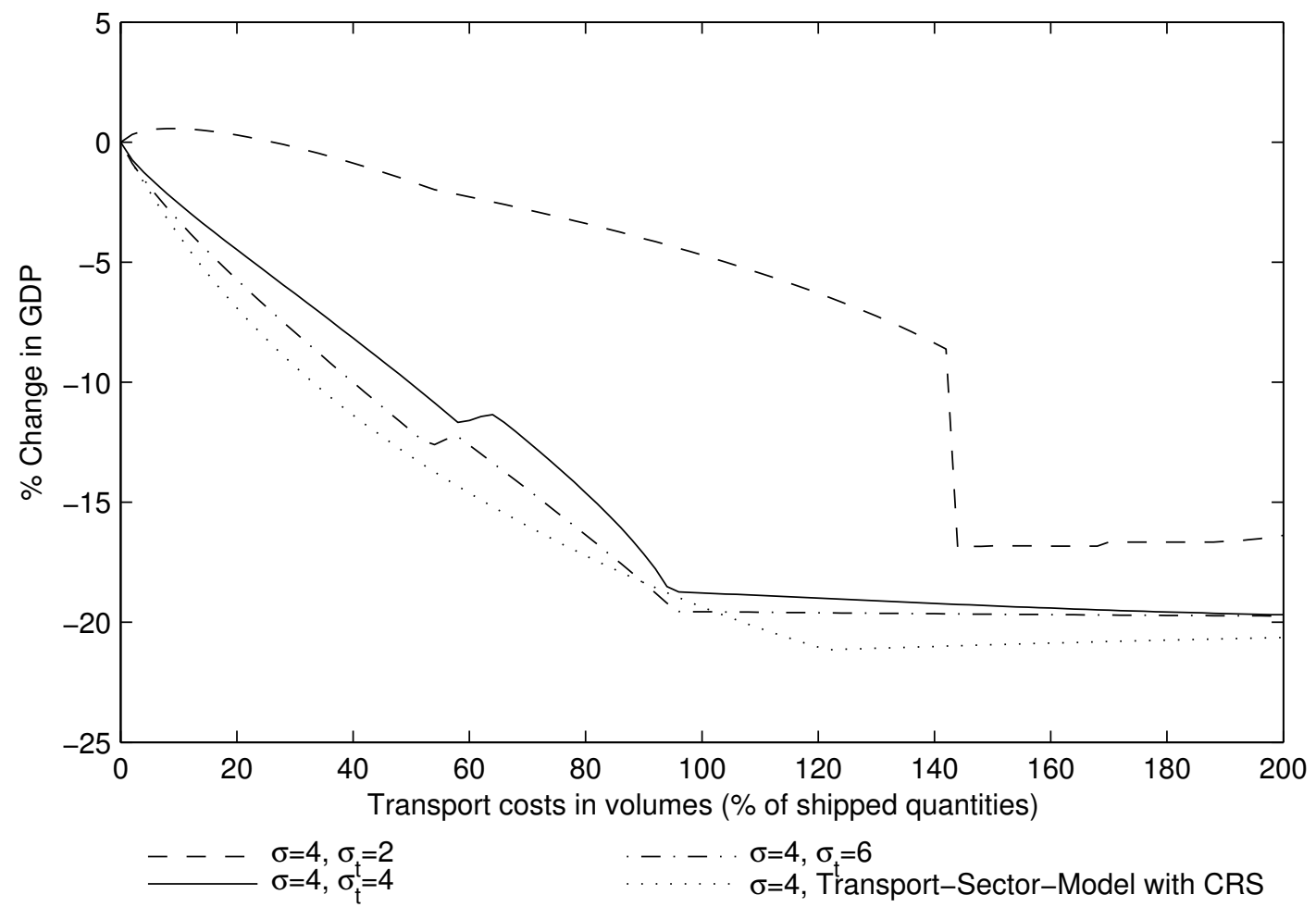

Figure 52: GDP changes in $\%$ if $\sigma_{t}$ changes, $i$ has $70 \%$ of capital world endowment and exporter takes care of transport services. 


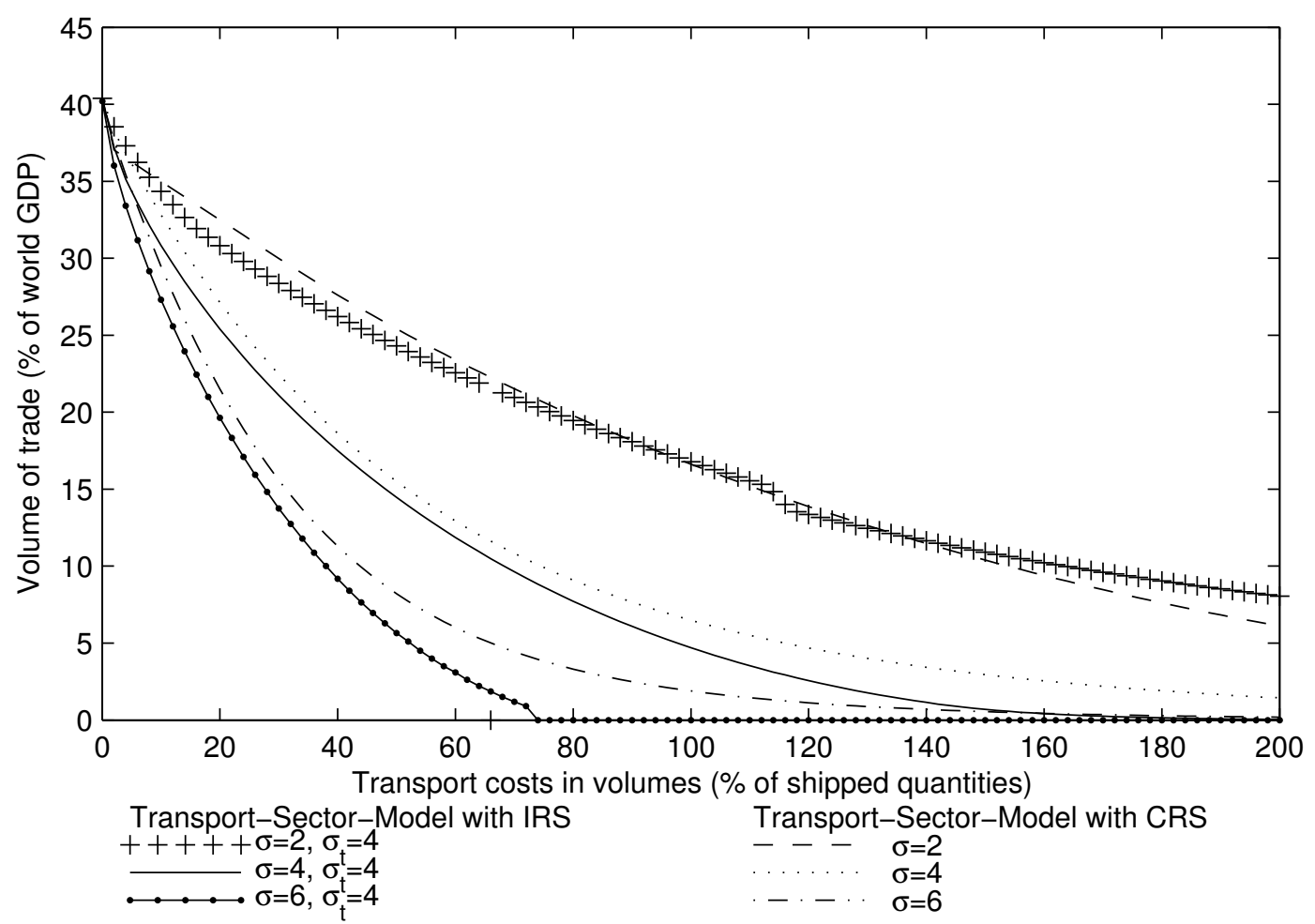

Figure 53: Volume of trade as \% of world GDP if $\sigma$ changes, $i$ has $70 \%$ of skilled labor world endowment and importer takes care of transport services.

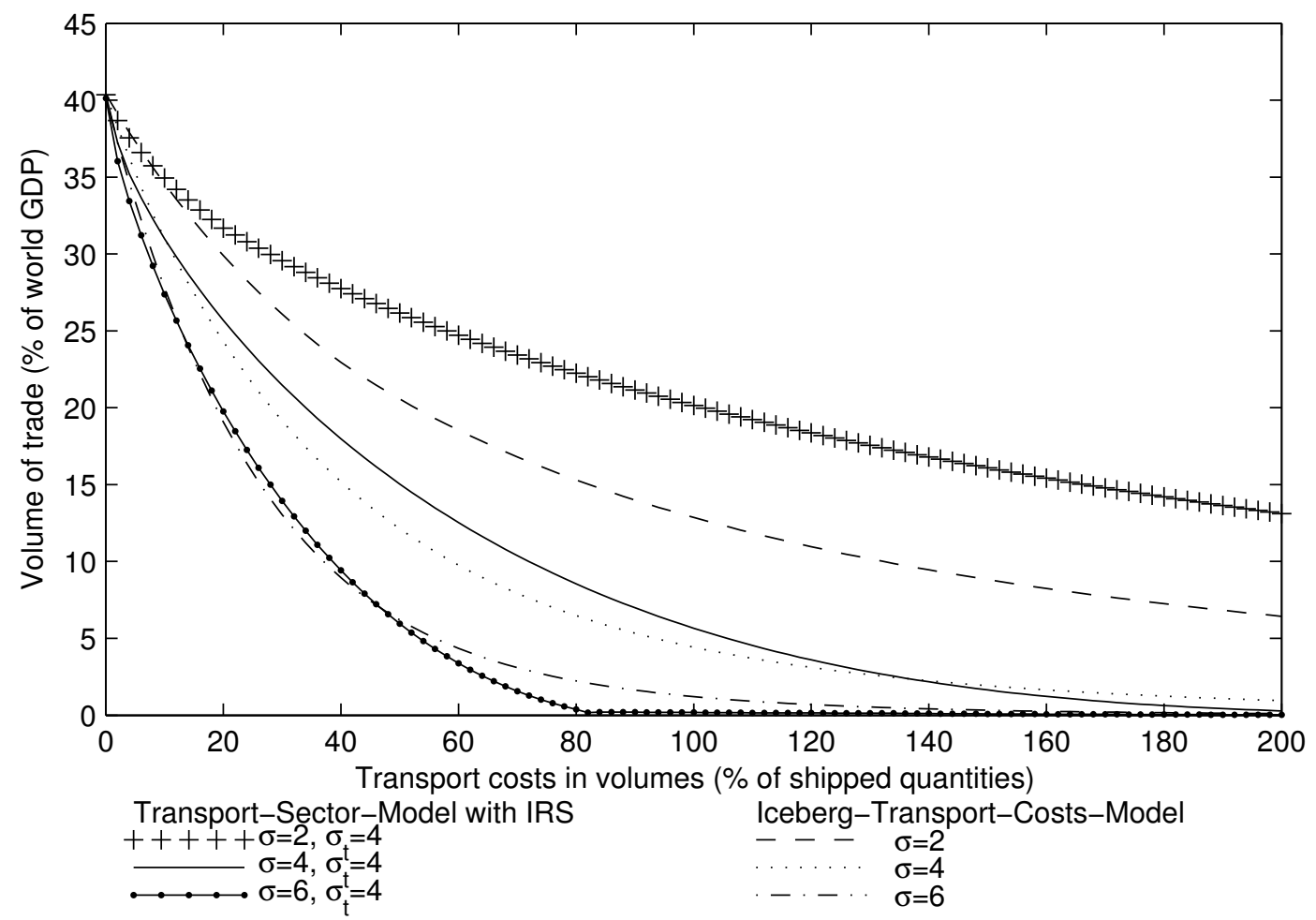

Figure 54: Volume of trade as \% of world GDP if $\sigma$ changes, $i$ has $70 \%$ of skilled labor world endowment, exporter takes care of transport services. 


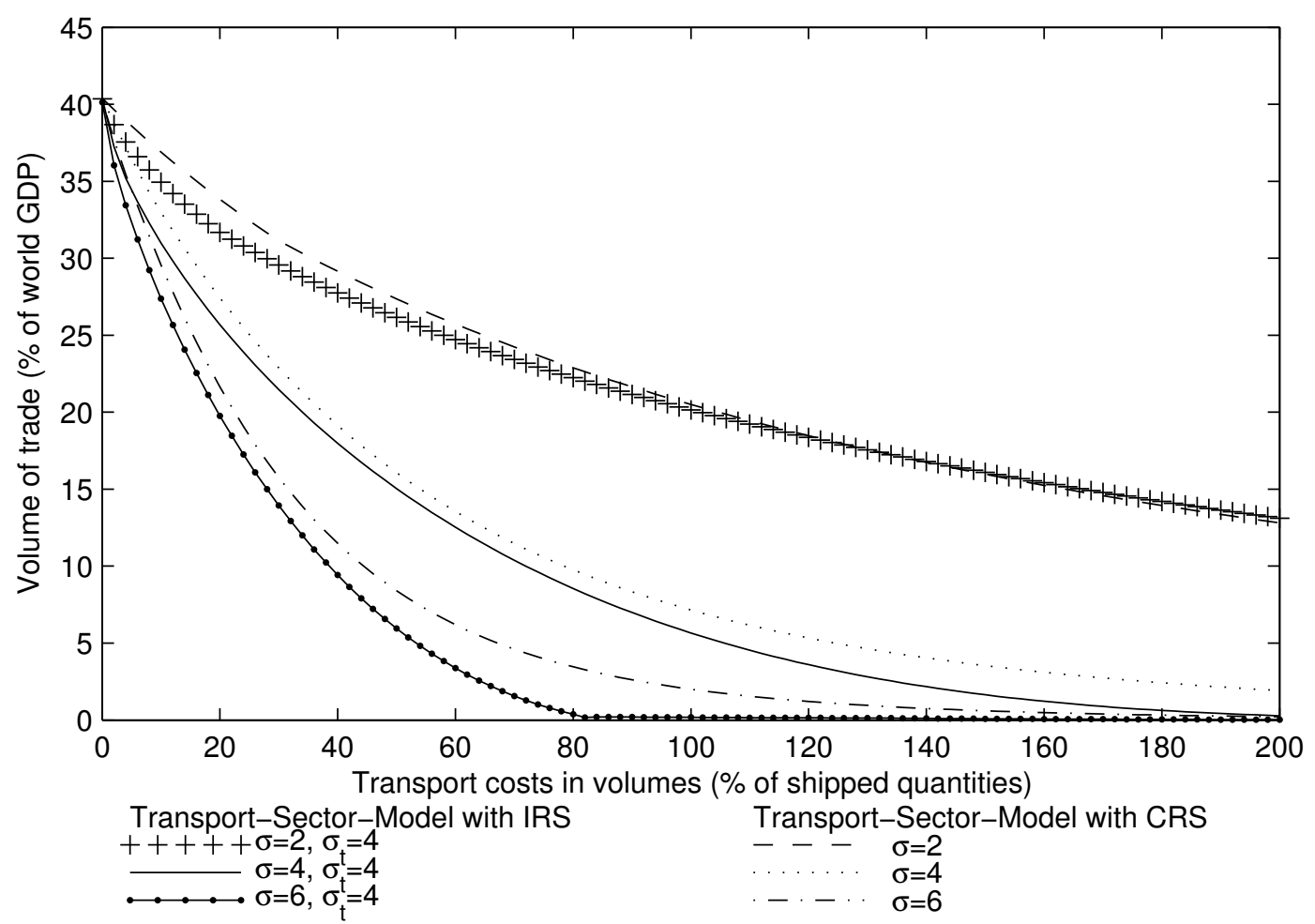

Figure 55: Volume of trade as \% of world GDP if $\sigma$ changes, $i$ has $70 \%$ of skilled labor world endowment and exporter takes care of transport services.

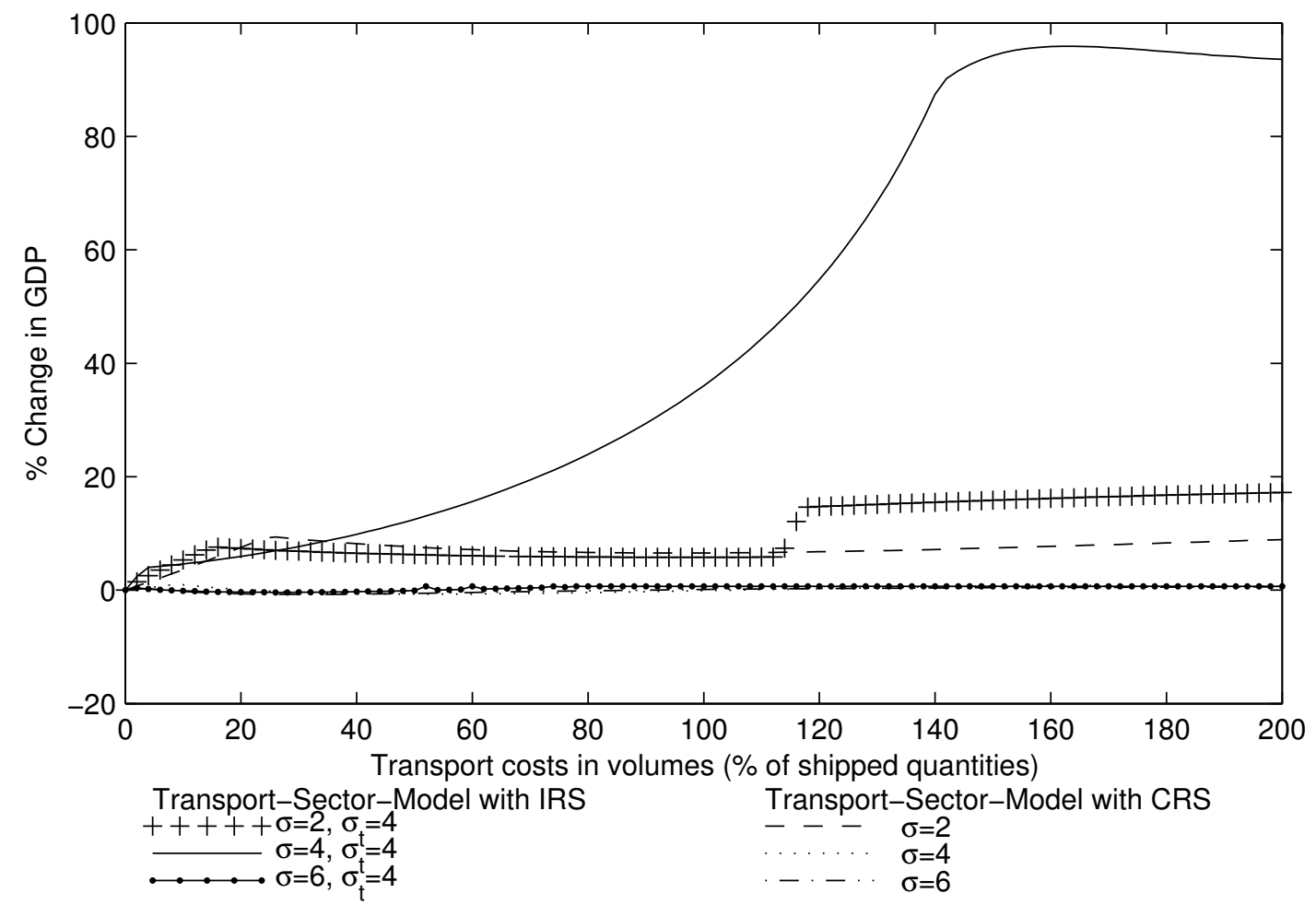

Figure 56: GDP changes in \% if $\sigma$ changes, $i$ has $30 \%$ of skilled labor world endowment and importer takes care of transport services. 


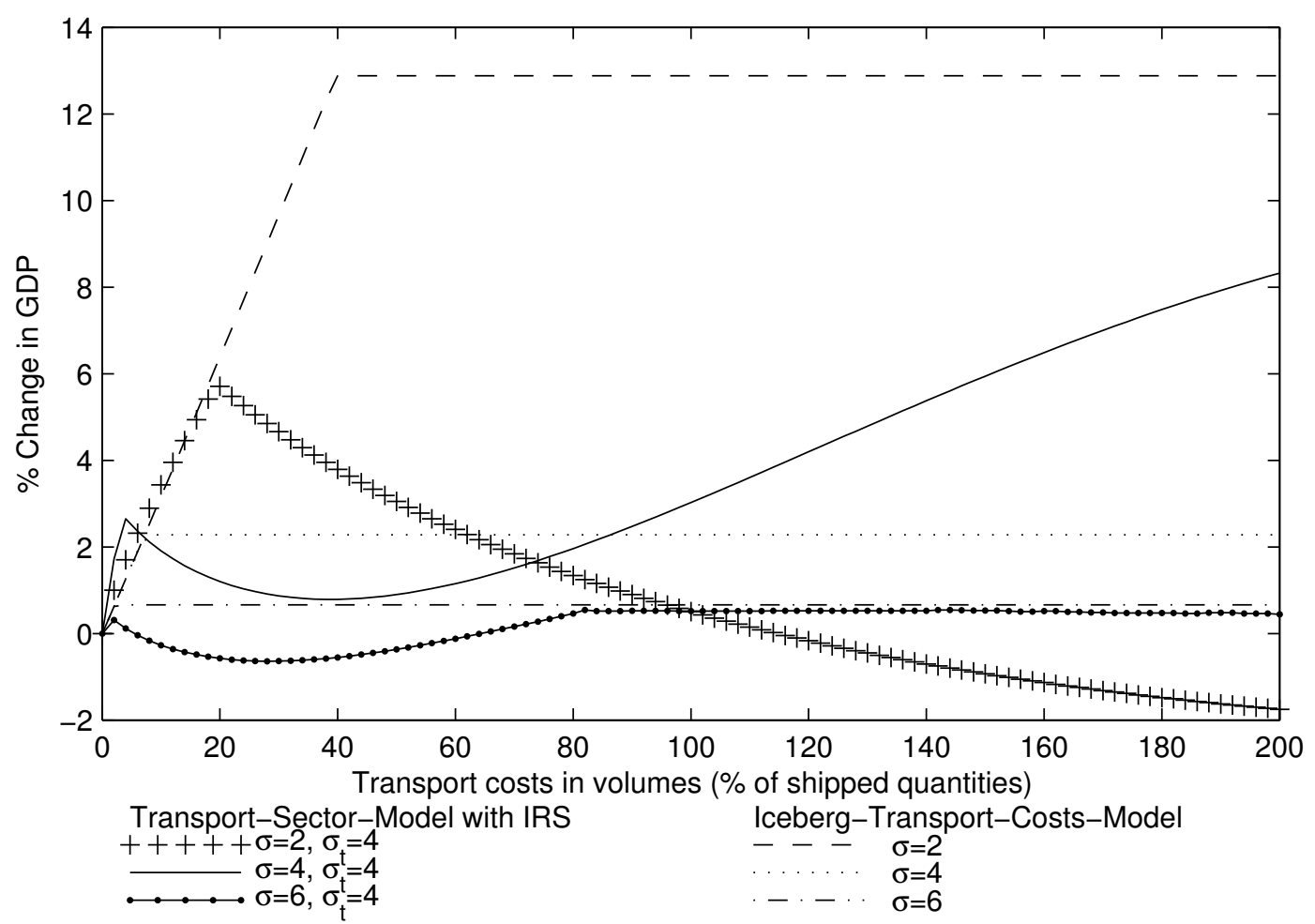

Figure 57: GDP changes in \% if $\sigma$ changes, $i$ has $30 \%$ of skilled labor world endowment and exporter takes care of transport services.

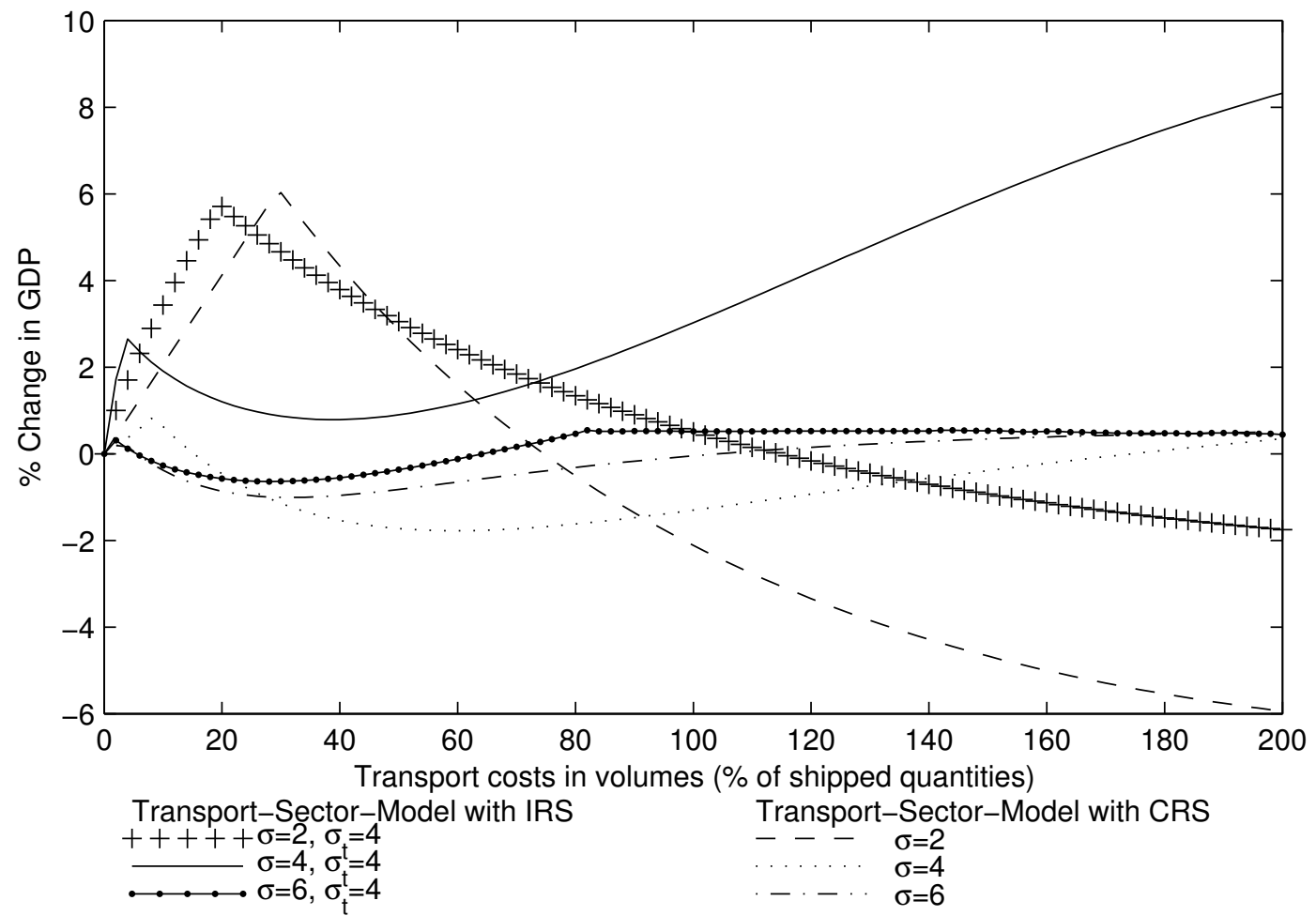

Figure 58: GDP changes in $\%$ if $\sigma$ changes, $i$ has $30 \%$ of skilled labor world endowment and exporter takes care of transport services. 


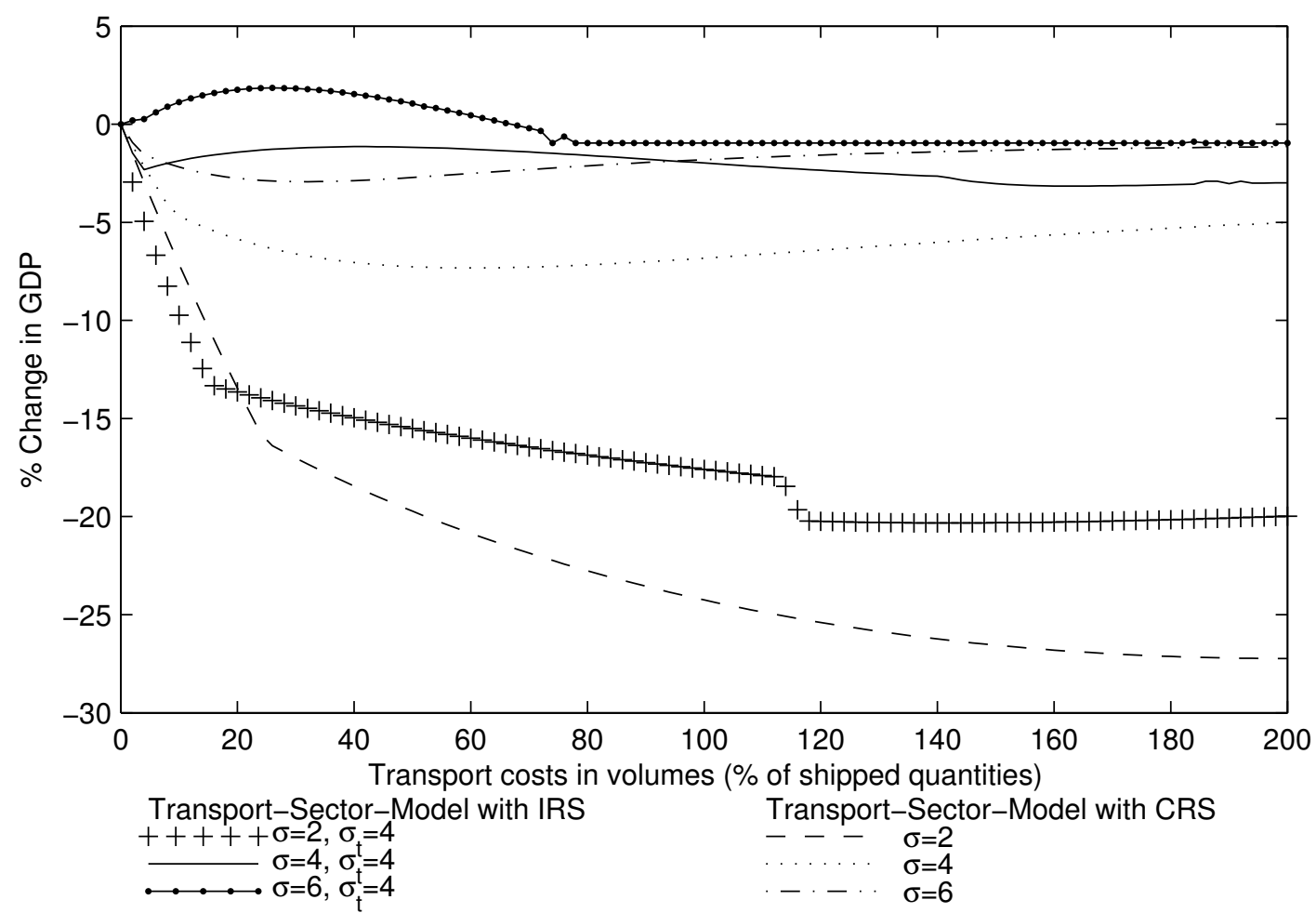

Figure 59: GDP changes in \% if $\sigma$ changes, $i$ has $70 \%$ of skilled labor world endowment and importer takes care of transport services.

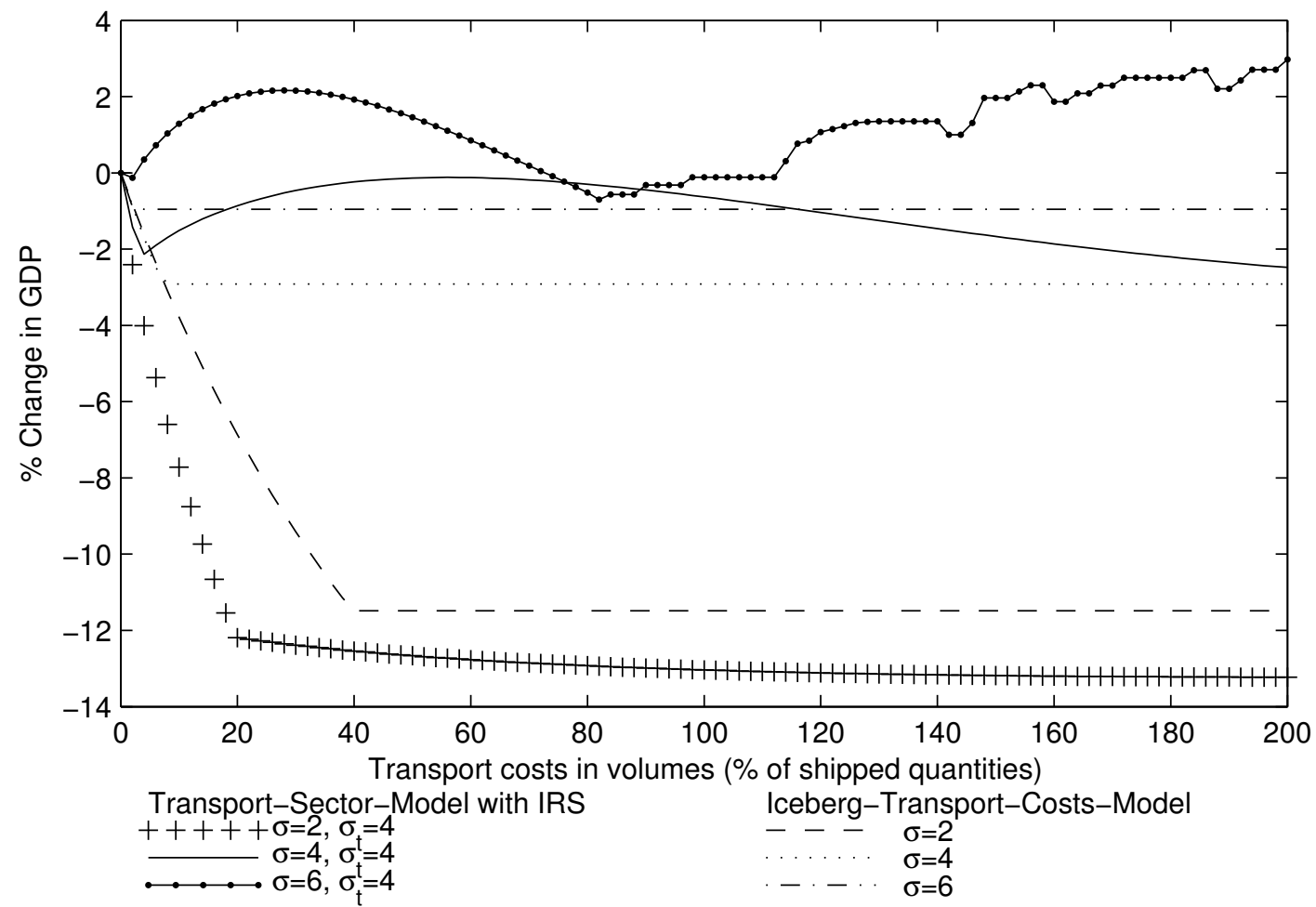

Figure 60: GDP changes in $\%$ if $\sigma$ changes, $i$ has $70 \%$ of skilled labor world endowment and exporter takes care of transport services. 


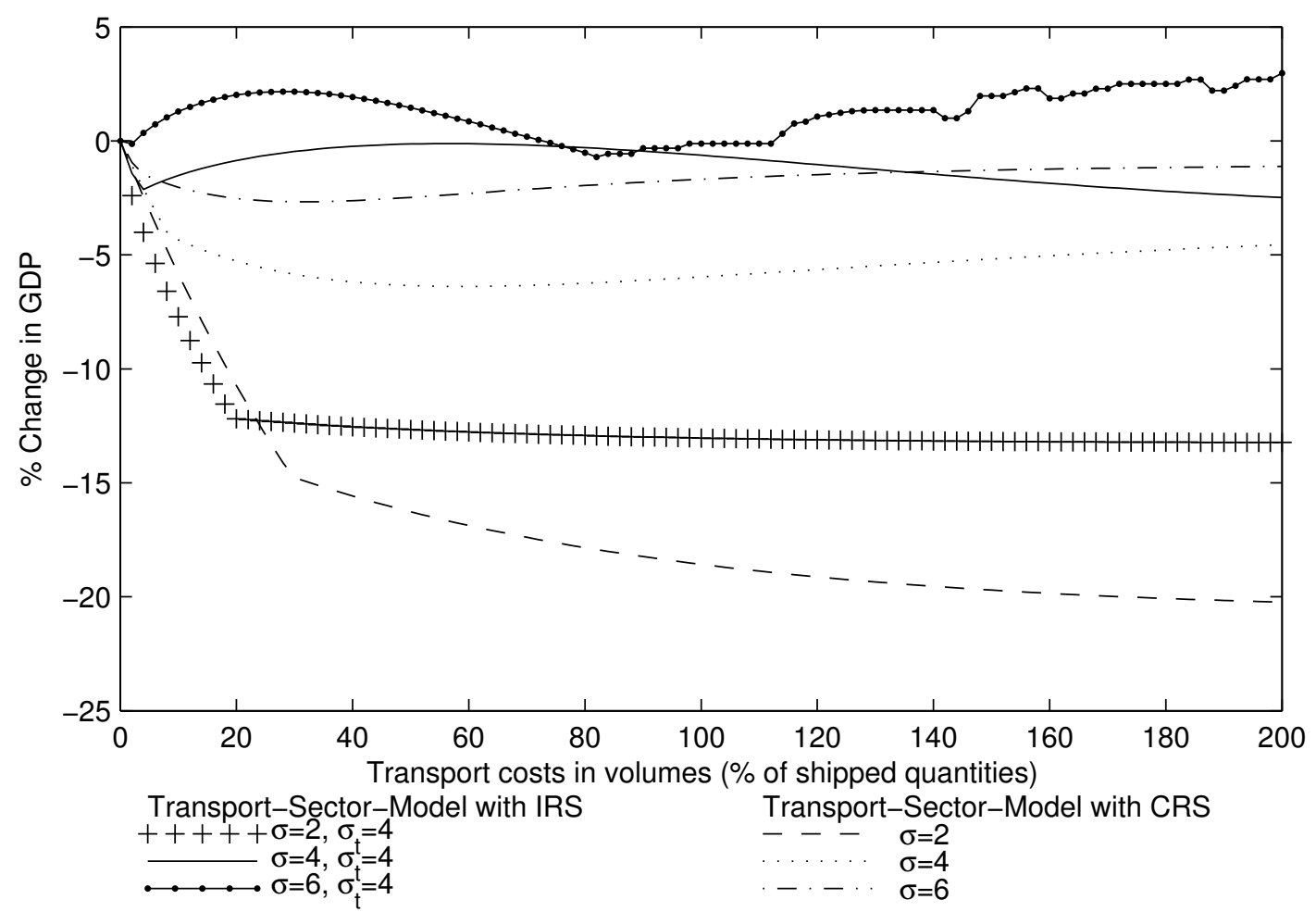

Figure 61: GDP changes in \% if $\sigma$ changes, $i$ has $70 \%$ of skilled labor world endowment and exporter takes care of transport services.

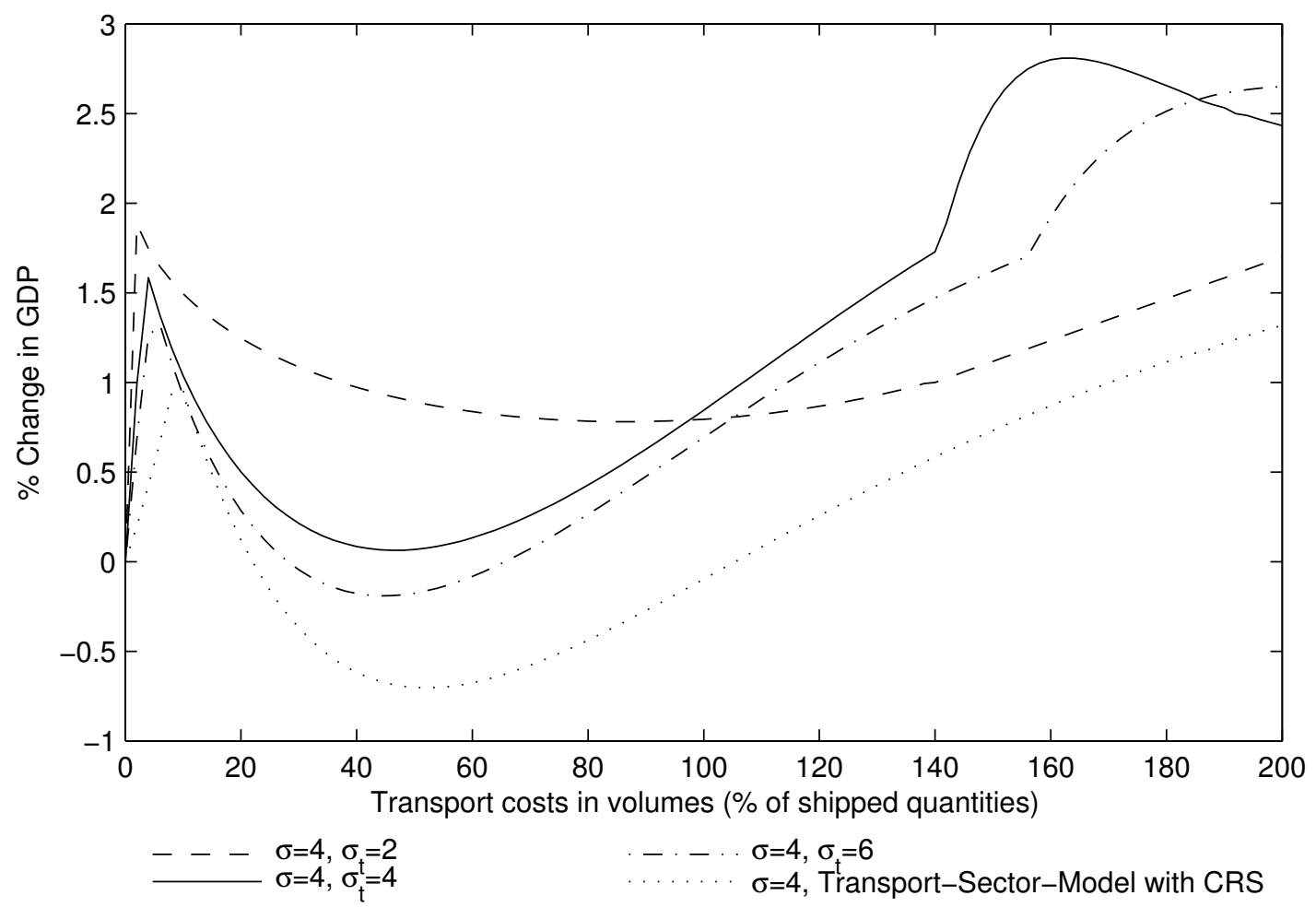

Figure 62: GDP changes in $\%$ if $\sigma_{t}$ changes, $i$ has $30 \%$ of skilled labor world endowment and importer takes care of transport services. 


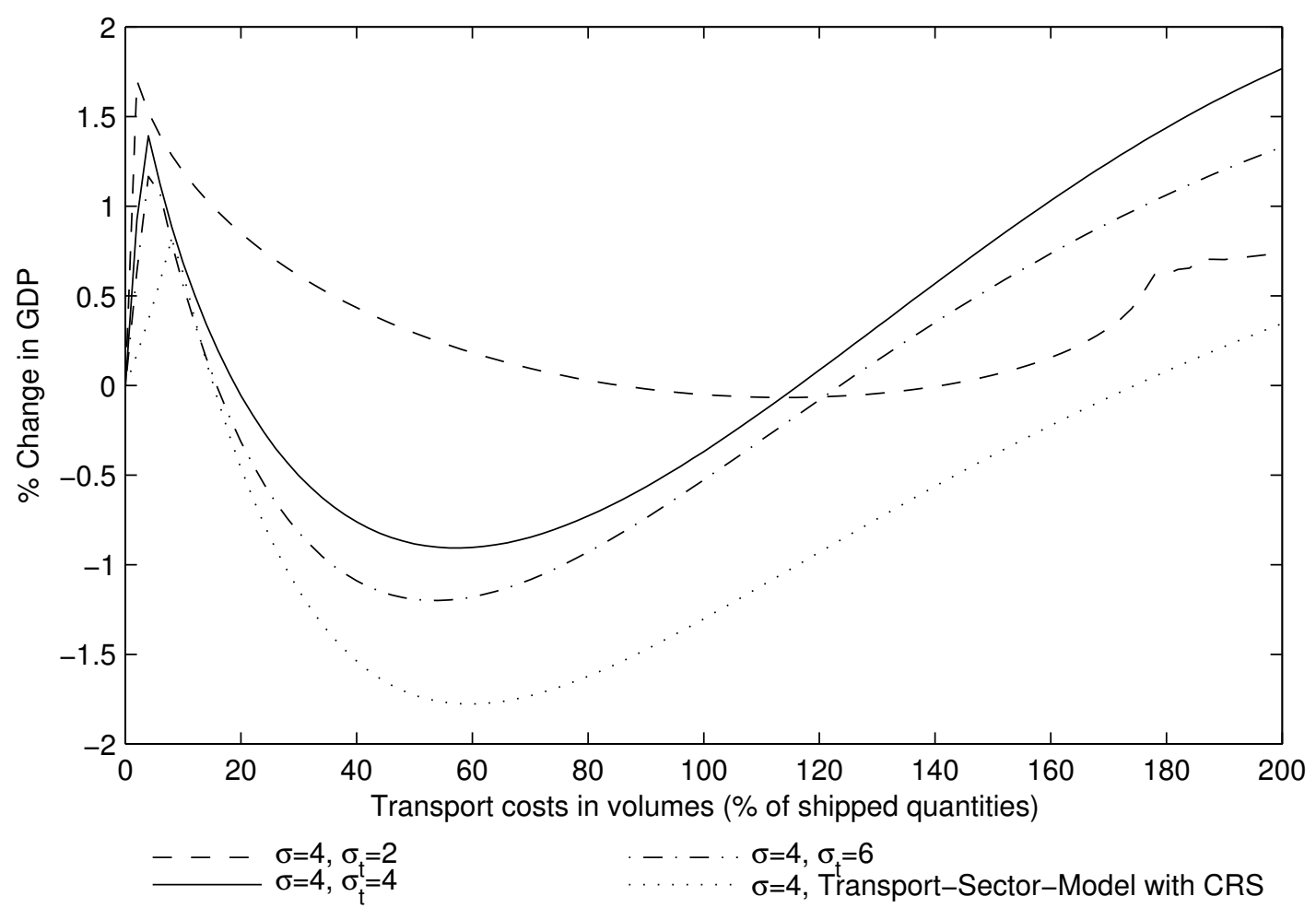

Figure 63: GDP changes in $\%$ if $\sigma_{t}$ changes, $i$ has $30 \%$ of skilled labor world endowment and exporter takes care of transport services.

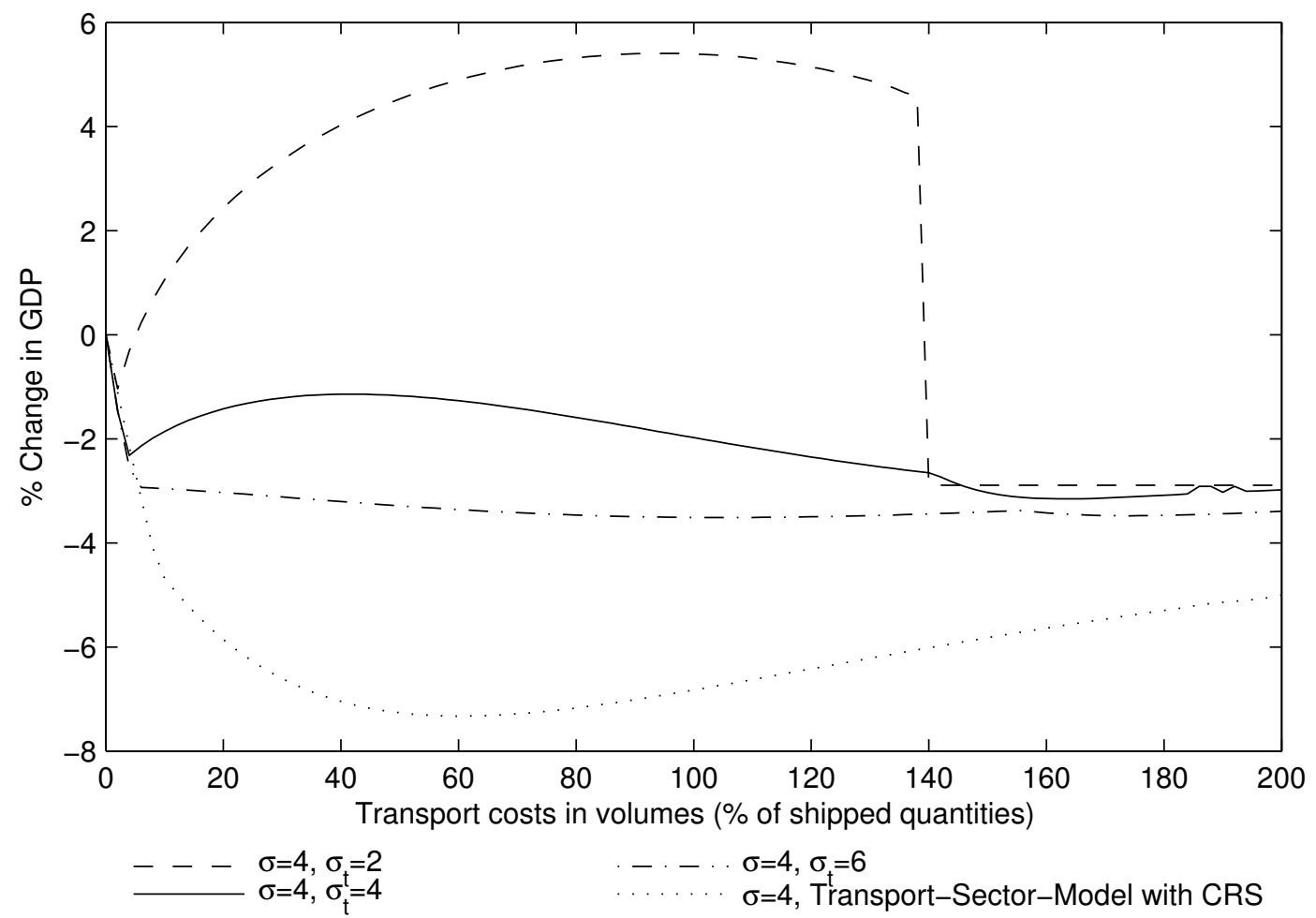

Figure 64: GDP changes in $\%$ if $\sigma_{t}$ changes, $i$ has $70 \%$ of skilled labor world endowment and importer takes care of transport services. 


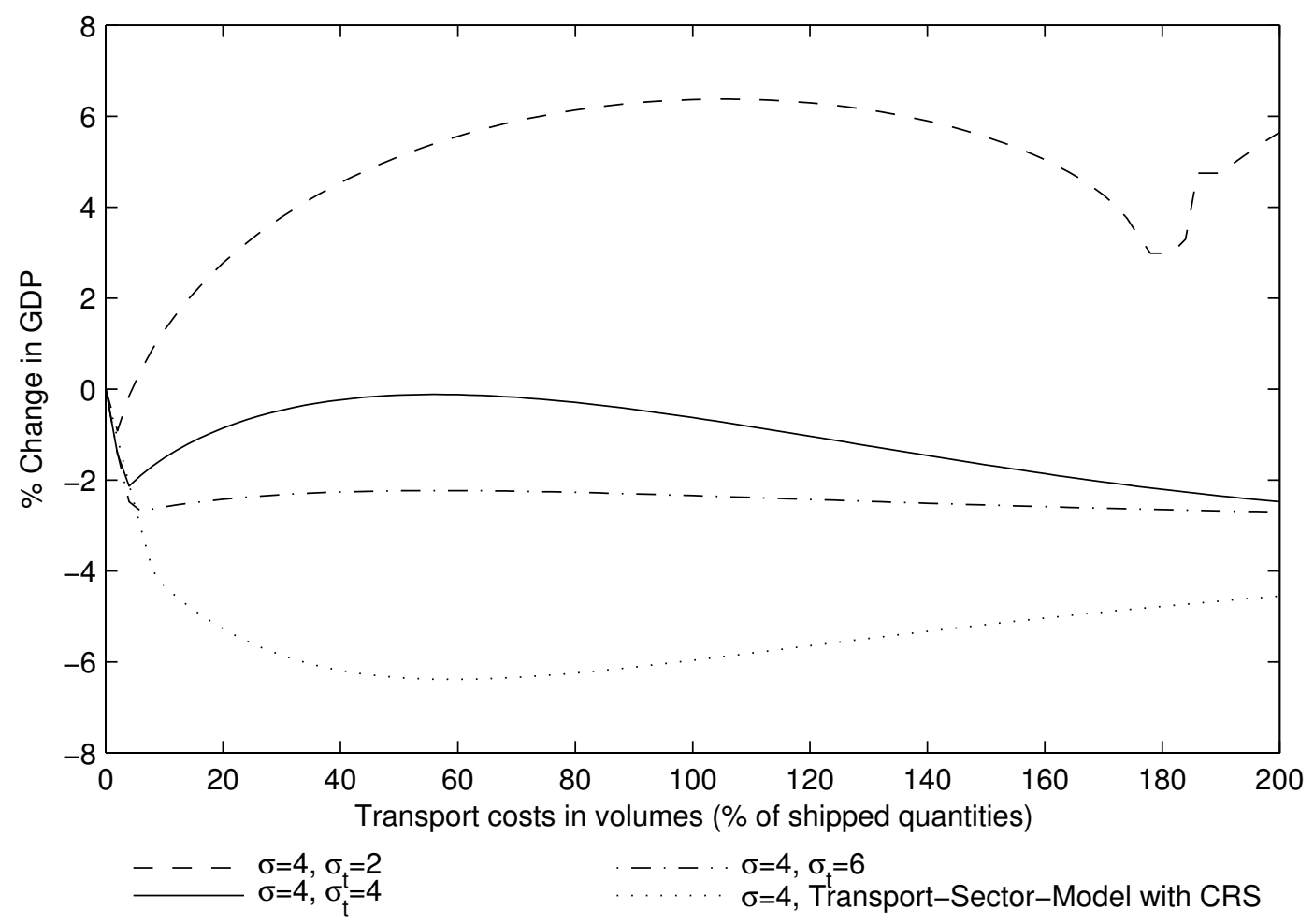

Figure 65: GDP changes in $\%$ if $\sigma_{t}$ changes, $i$ has $70 \%$ of skilled labor world endowment and exporter takes care of transport services. 